\title{
PULSE COLUMN DESIGN
}

By

Lawrence E. Burkhart

R.W. Fahien

November 1958

\author{
Ames Laboratory \\ Iowa State College \\ Ames, Iowa
}

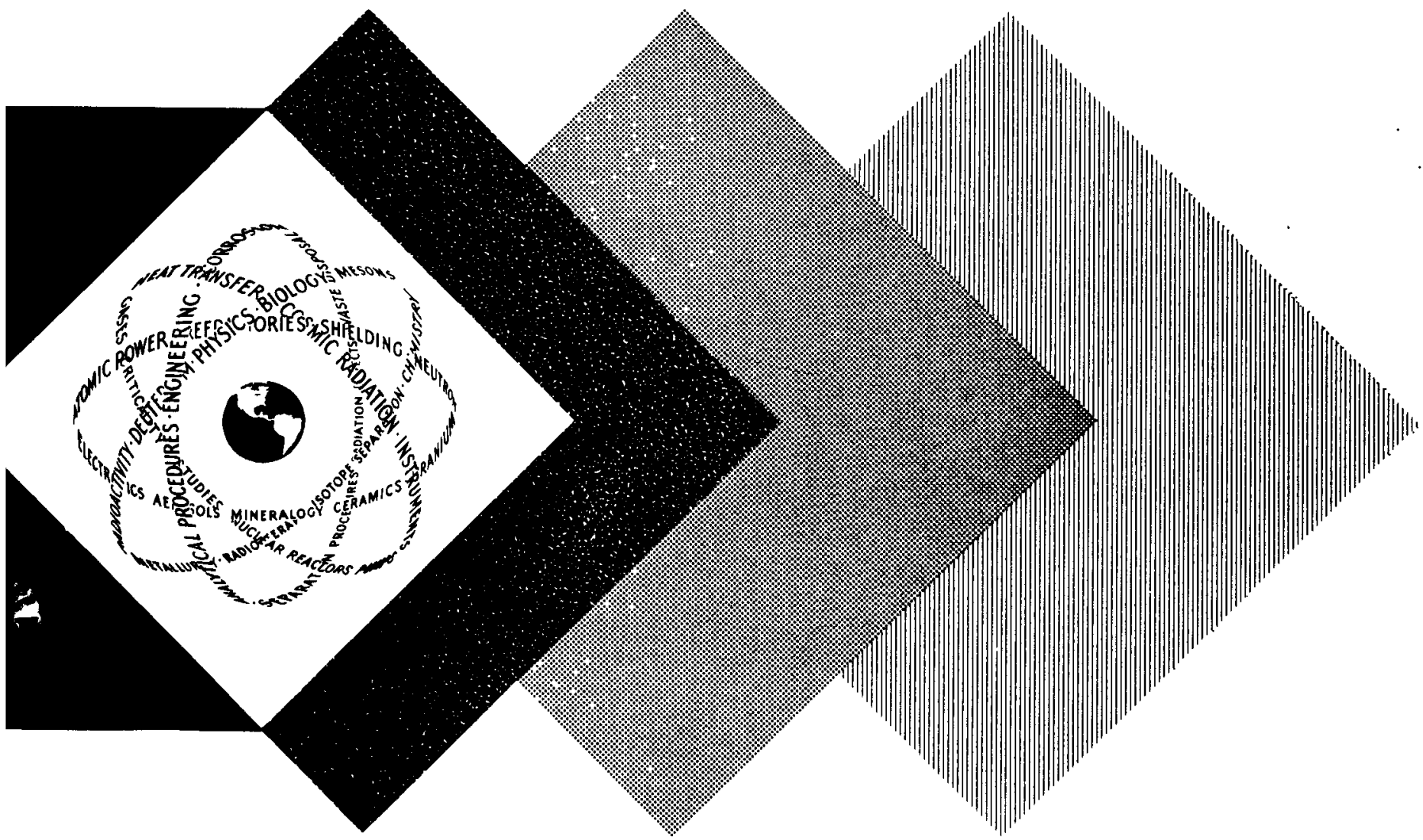




\section{DISCLAIMER}

Portions of this document may be illegible in electronic image products. Images are produced from the best available original document. 
F. H. Spedding, Director, Ames Laboratory.

Work performed under Contract No. W-7405-Eng-82.

\section{LEGAL NOTICE}

Th1s report was prepared as an account of Government sponsored work. Neither the United States, nor the Commission, nor any person acting on behalf of the Commission:

A. Makes any warranty or representation, expressed or implied, with respect to the accuracy, completeness, or usefuiness of the information contained in this report, or that the use of any information, apparatus, method, or process disclosed in this report may not infringe privately owned rights; or

B. Assumes any liabilities with respect to the use of, or for damages resulting from the use of any information, apparatus, method, or process disclosed in this report.

As used in the above, "person acting on behalf of the Commission" includes any employee or contractor of the Commission, or employee of such contractor, to the extent that such employee or contractor of the Commission, or employee of such contractor prepares, disseminates, or provides access to, any information pursuant to his employment or contract with the Commission, or his employment with such contractor.

This report has been reproduced directly from the best available copy .

Printed in USA. Price \$2.75. Available from the Office of Technical Services, Department of Commerce, Washington 25, D. C.

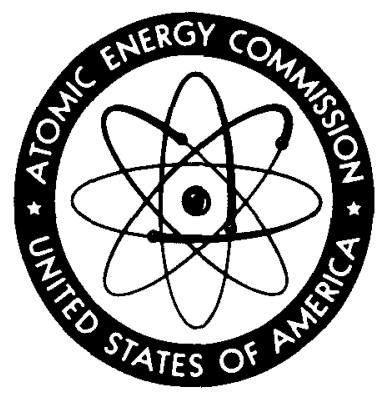




\section{ISC-1095}

$11 i$

TABLE OF CONTENTS

Page

ABSTRACT ........................... iv iv

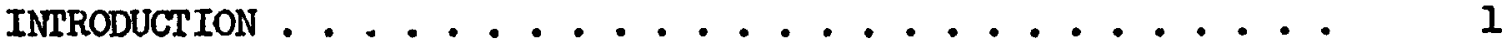

LTTERATURE REVIEN . . . . . . . . . . . . . . . 7

SCOPE OF THE INVESTIGATION . . . . . . . . . . . 12

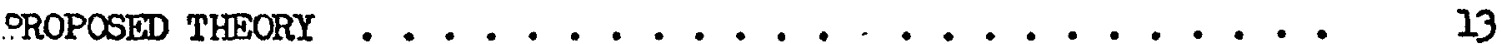

Mixer-Settler Region .............. 13

Basis of theory ................ 13

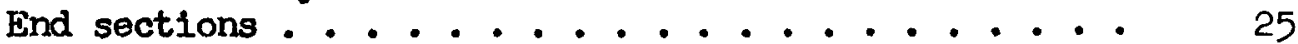

Recycle .................... 29

Stage efficiencies............. . . . 39

The Emulsion Region . . . . . . . . . . . . 42

EQUIPMENT AND EXPEERIMENTAL TECHNIQUES . . . . . . . . . . 52

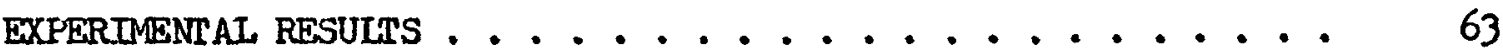

Hold-up Studies . . . . . . . . . . . . . 63

The isoamyl alcohol-water system . . . . . . . 63

The methyl isobutyl ketone-water system . . . . . 72

Discussion of Hold-up Data . . . . . . . . . . 78

Extraction Studies ................ 80

Discussion of Extraction Studies . . . . . . . . . 98

Sampling techniques .... . . . . . . 98

Stage efficiencies and recycle .......... 103

CONCLUSTONS AND RECOMMENDATIONS . . . . . . . . . . 206

NOMENCLATURE ........................................ 108

LITERATURE CITED . . . . . . . . . . . . . . . 110

APPENDIX . . . . . . . . . . . . . . . . . 112 


\section{PULSE COLUMN DESIGN*}

Lawrence E. Burkhart and R. W. Fahien

\section{ABSTRACT}

A theoretical analysis of the pulse column was made using a stagewise approach to the problem. The column was assumed to be divided into discrete stages, each stage having been defined as that part of the column between two adjacent perforated plates. The cyclic reversal of flow which is characteristic of the pulse column permitted more material balance equations to be written than for a simple countercurrent extractor.

The operation of the pulse column was described mathematically using material balance equations and, from the theory developed, a design method was derived which used two "stage" lines and two "operating" Iines, one set for the upstroke and one set for the downstroke of the pulse generator. The stages could be stepped off between aach of these sets of lines in much the same manner as is done on a McCabe-Thiele diagram. Assuming equilibrium contact, the effect of recycle in a pulse column was shown to cause a large decrease in the separation obtained as the pulse frequency was increased. To account for non-eçilibrium contact, two stage efficiencles were defined; one for the upstroke and one for the downstroke halfcycle.

Hold-up studies were made using two systems, isoamyl alcohol - water and methyl isobutyl ketone - water. Under proper operating conditions the hold-up, per cycle, of the dispersed phase for both systems was shown to be

* This report is based on a Ph. D. thesis by uawrence E. Burkhart submitted November 1958, to Iowa State College, Ames, Iowa. This work was done under contract with the U. S. Atomic Energy Commission. 
equal to the interstage flow, per cycle, of the dispersed phase. Also for both systems the stagewise hold-up per cycle first decreased then increased as the pulse frequency was increased. This hold-up behavior had been predicted qualitatively by the theory. With the water phase discontinuous, a sharp increase in the dispersed phase hold-up was observed at critical pulse frequencies for the isoamyl alcohol - water system. The critical frequency was a function of the superficial flow rate of the dispersed phase. This break in the hold-up curve was attributed to a hindered settling effect due primarily to the high viscosity of the continuous isoamyl alcohol phase. Hold-up behavior at high frequencies was quite different for the two systems.

Extraction runs were made using the system methyl isobutyl ketone acetic acid - water. It was shown both theoretically and experimentally that even though the stage efficiencies may increase, the over-all separation performed by the column may decrease with increased pulse frequency because of the effect of recycle. The stage efficiencies wele lower for that half-cycle in which the wetting fluid passed through the plates. The over-all operating line shifted closer to the equilibrium line as the pulse frequency was increased, and this was explained by the theory to be due to the unequal effect of recycle on the end-sections of the column as compared with the recycle effect in the stages.

On the basis of the theory presented for a pulse column operating in the emulsion region it was found to be theoretically possible for a column to be operating in a pinched-in region even though this is not apparent by an examination of the superficial flow rate ratio of the two streams being fed to the column. The change in the phase composition would change the actual interstage flow ratio between the stages and thus alter the slopes 
of the over-all stage line and the over-all operating line.

Sampling techniques were developed to take samples of the interstage flowstreams in a column operating in the mixer-settler region. Samples were taken by forcing hypodermic needles through rubber stoppers in the column and then inserting the tips of the needles through holes in the plates. Removal of the sample from the column during the desired part of the pulse cycle was controlled by microswitches located on the pulse generator. The microswitches operated specially constructed solenoid valves in the sampling lines. 


\section{INTRODUCTION}

The pulse column, as we know it now, developed from an extractor patented by Van Dijck (19) in 1935. Van Dijck's patent concerned a column in which perforated plates were oscillated up and down to disperse the two liquid phases. Also mentioned in this patent was the possibility of dispersing the phases by pulsing the liquid instead of moving the plates. This latter method of agitation is the basis of what has come to be called a "pulse column".

Serious interest in the pulse column probably started in about 1949 when C. Croot used it at Hanford for the processing of uranium (15). At that time it was used because it offered approximately a two-fold reduction in height from the heights of conventional packed columns to obtain a given uranium separation. This reduction in height was, and still is. very important when problems of shielding and criticality for reactor fuel processing equipment are considered.

A functional diagram of the pulse colurn is shown in Figure 1. Perforated plates are spaced at intervals up the column. Heavy liquid enters from the top of the column and light liquid enters from the bottom of the column. Ordinarily the size of the holes in the perforated plates is small enough that no countercurrent flow occurs through the plates due to gravity alone. The pulse generator at the bottom serves to disperse or mix the two liquid phases and also to pump the liquids through the column. In Flgure 1 the light phase is the dispersed or discontinuous phase and the heavy phase is the continuous phase. The light phase is present In the smaller quantity, as is customary for the discontinuous phase, and 


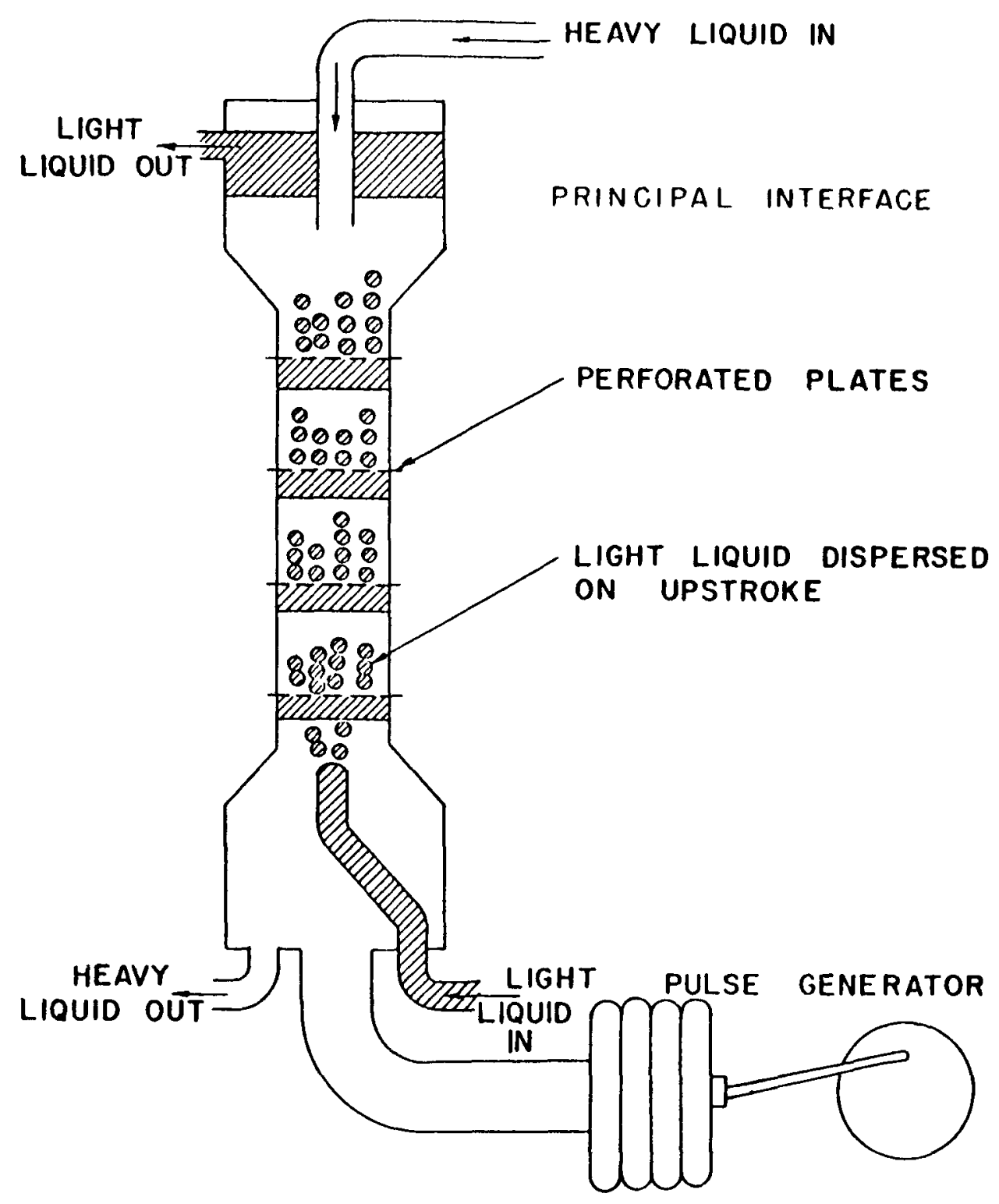

Figure 1. Diagrarn of pulse column. 
the principal interface is located in the top end-section of the column. If the heavy phase were the discontinuous phase then heavy phase would be present in the smaller quantity and the principal interface would be in the bottom end-section of the column.

Figure 2 shows the operating characteristics of a pulse column. The curve was presented by Sege and Woodfield (15) to illustrate the various types of dispersion in a pulse column as a function of the flow rates and the pulse frequency. The curve only shows general trends and has no numerical values along its axes.

Choose an arbitrary total flow rate and follow a horizontal line across the Figure. Region A is a flooding region in which the column will not operate because the amount of pulsation is too small to pump liquid through the column as fast as it is fed at each end. At a point on the line marked "Pulse Volume Velocity", the pulsation applied to the column is just enough to maintain a net flow equal to the superficial flow rates, or the rates at which the two liqulds are being fed to the column. This point is called the lower flooding limit or the point of incipient flooding due to insufficient pulsation.

When the pulse frequency is increased so that the column operates in area $B$, mixer-settler operation is obtained. The two phases settle out completely between pulses; thus there is an alternating sequence of mixing and settling in each portion of the column between two adjacent perforated plates. When a pulse column is operated in Region C, the two phases in the column give the appearance of a homogeneous "emulsion" at all times and so the area is called the "emulsion region". Increasing the pulse frequency still further causes the dispersion to become irregular and 


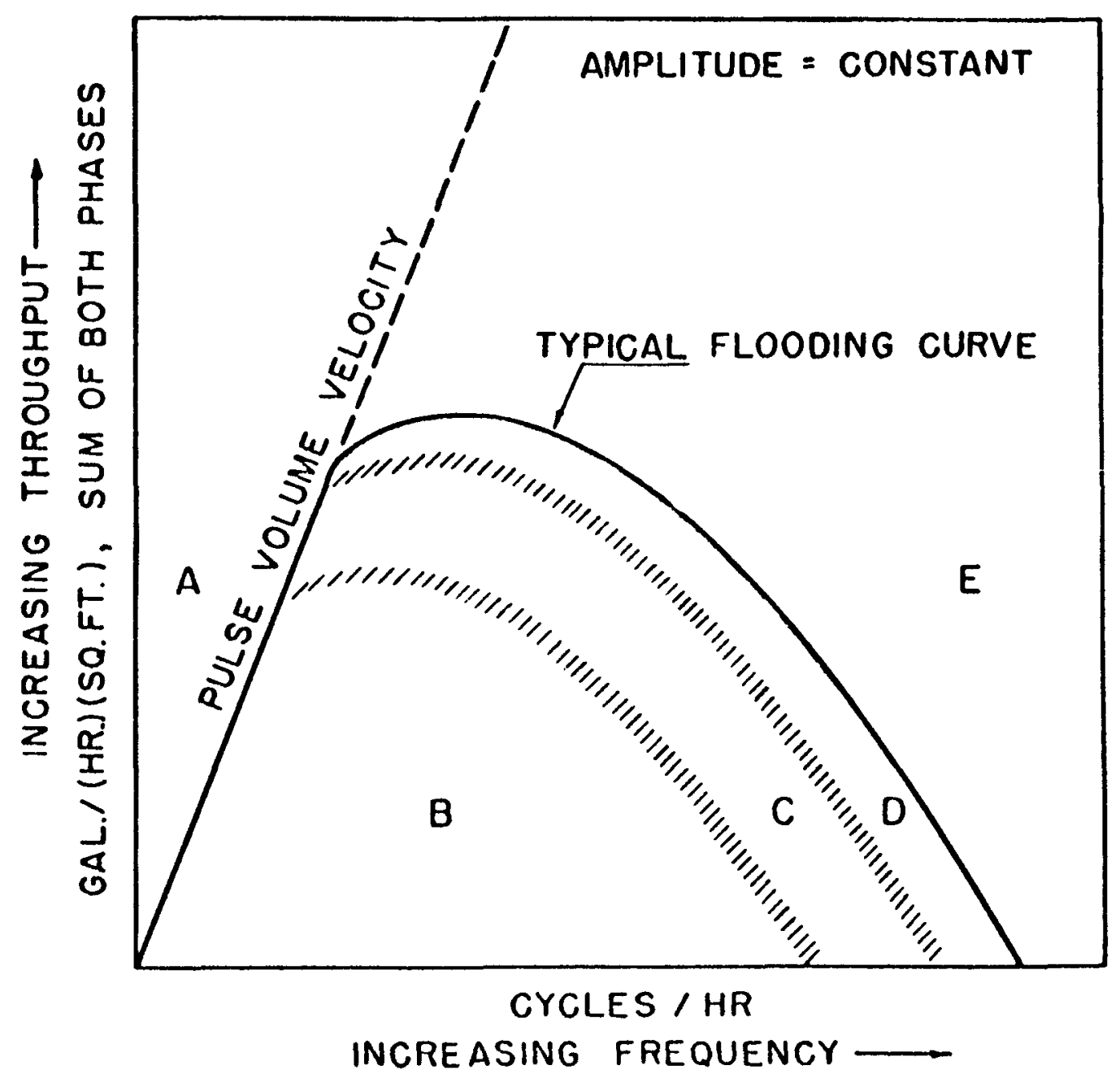

Figure 2. Operating characteristics of a pulse column. 
non-uniform. Large globules of liquid begin to appear and local flooding, or reversal of the dispersion, may occur. This unstable region is indicated by area $D$ in Figure 2. The transitions between regions $B$ and $C$, and regions C and D are not well defined.

The flooding curve which separates regions $D$ and $E$ represents the locus of points at which the net flow of liquids through the column is again just equal to the superficial flow rates. This time the trouble is not too little pulsation but too much pulsation. Hindered settling has reduced the net flow of liquid through the column. A point on this line is often referred to as the upper flooding point or the point of incipient flooding due to excessive pulsation.

The pulse column has two flooding points. Both points are sharply defined and the permissible operating range of the column is sandwiched between these two flooding points. The extraction efficiency varies throughout this range and the resulting degree of separation obtained depends on the net effect of two opposing phenomena. Ideally, increasing the pulsation applied to the extractor produces better dispersion of the phases and creates more interfacial area for mass transfer. Turbulence within the column is increased, tending to improve the rate of extraction.

On the other hand, back mixing, or recycle, is present throughout the operating range of the column, decreasing as the pulsation rate decreases, and reaching zero at the lower flooding limit. This recycle can be seen intuitively by noting that, at steady-state, the net flow of liquids through the extractor must be equal to the superficial flow rates. But the amount of liquid moved up and down the column by the pulse generator will vary greatly as the pulse amplitude or the pulse frequency is varied 
between the two flooding points. The problem has been described mathematically by Edwards and Beyer (6). 
LTTFRATURE REVIEW

Because of the high extraction efficiencies which have been obtained with pulse columns, they have been the subject of considerable research in recent years. Goundry and Romero (9), in a senior research project at Cornell used a $1 \frac{1}{2}-$ in. diameter column packed with $\frac{1}{4}$-in. Raschig rings to observe the effect of pulsing a packed colurn. Pulsing the column resulted in a three-fold decrease in the over-all H.T.U. Some time later, Wiegandt and Von Berg (20) published the results of further work on the same column and the same system, methyl isobutyl ketone-acetic acid-water, reporting a change of $7.8 \mathrm{in}$. to $1.6 \mathrm{in}$. for the H.E.T.S. between the non-pulsed column and the column pulsed at an amplitude of $\frac{1}{4}$ in. and a frequency of 74 cycles/ min. This was about a five-fold change.

Feick and Anderson (8) also worked with a pulsed, packed column. They measured over-all mass transfer coefficients. Simall amplitudes ( $1 / 16$ 1/4 in.) and high frequencies (200 - 1000 cycles/min.) were used. The increased values of the over-all mass transfer coefficient were, they reasoned, due either to an increase in interfacial area, to increased turbulence, or both as the pulsation applied to the column was increased. The initial part of the investigation was carried out using the system, toluenebenzoic acid-water, where the major resistance was in the water phase. Later acetic acid, whose controlling resistance is in the toluene phase, was used. The increase in the mass transfer coefficient, upon pulsing, was about the same in both systems and so Feick and Anderson concluded that the main effect on mass transfer contributed by the pulse was to increase the interfacial area between the two phases. 
About the same time, Griffith, Jasny, and Tupper (10) were separating cobalt from nickel with a pulse column at the M.I.T. Engineering Practice School at Oak Ridge. They were concerned with plate spacing and total flow rates. The plates were removed and the column operated as a spray column. The solvent to water ratio was 1.57 and the H.T.U. varied from $1.1 \mathrm{in.}$ to $24 \mathrm{in}$. between the pulse and the spray column at low total flow rates. At high total flow rates the change was from 34 in. to 57 in. A change from 2 in. to 1 in. in the plate spacing resulted in an increase in the efficiency of the pulse column. The pulse column flooded easier than the spray column, however, the difference being $955 \mathrm{gal} . / \mathrm{hr} . / \mathrm{sq} . \mathrm{ft}$. as compared with $1820 \mathrm{gal} . / \mathrm{hr} . / \mathrm{sq}$.ft. for a 2-in. diameter column. These authors first commented on the reasons, mentioned earlier, for the appearance of the two flooding points which are characteristic of the pulse column.

Belaga and Bigelow (2) also using the column at Oak RIdge, studied the effects of pulse amplitude and pulse frequency on extraction efficiency. The over-all H.T.U. was plotted against the amplitude-frequency product in an attempt to obtain a correlation. The authors indicated that this correlation was dependent on the system employed. Amplitude was varied from $1 / 8 \mathrm{in}$. to $2 \mathrm{in}$. and frequency was varied from 20 to 80 cycles per minute. The H.T.U. change was from 2.63 to 6.25 in. for the system, methyl isobutyl ketone-acetic acid-water.

At Iowa State College, Cohen and Beyer (5) Investigated flow rates and amplitude-frequency effects. Mass transfer data were correlated by a plot of H.T.U. against the amplitude-frequency product. The recycle, or back-mixing, which occurs in a pulse column was discussed qualitatively. 
Later, Edwards and Beyer (6) put the phenomenon of recycle on a mathematical basis in an equation designed primarily to predict the lower flooding point of the pulse column for any liquid system.

In 1954, Sege and Woodfield (15) published a compilation of work done at Hanford where the pulse column was first introduced for production work. Most of the pulse column variables were discussed and the general trends of their effects indicated. The discussion was illustrated with data on the solvent extraction of uranyl nitrate with tributyl phosphate. A relation $a f^{n}$, where $a$ is the amplitude, $f$ is the frequency and $n$ is an exponent dependent upon the system was suggested as a better correlating factor than the simple amplitude-frequency product.

The work described so far has dealt mainly with over-all trends in pulse column operation. Probably the most significant study which has yet been reported is the work of $\mathrm{Li}$ and Newton (12). The work was published in 1957 although it was submitted by $L_{i}$ as a doctoral dissertation at Georgia Tech in 1951. Ii used the system toluene-benzoic acid-water in a 2-in. pulse column. The approach used was the classical attack on liquid-liquid extraction based on Colburn's H.T.U. method of correlation (17), a procedure which has been used by several other authors $(1,14,18)$ to correlate their data on liquid-liquid extraction in perforated plate columns.

Considering the pulse column essentially as a perforated plate column with a superimposed pulse, Ii used a Reynolds" number based on the plate perforations, taking the arithmetic average of the velocity through the plates and the physical properties of a two-phase mixture of toluene and water. The data were correlated with the equation: 


$$
\frac{\mathrm{K}_{\mathrm{W}} \mathrm{aH}}{(\mathrm{Re})^{\mathrm{d}}}=\phi_{\mathrm{T}}\left(\mathrm{V}_{\mathrm{T}}\right)^{\mathrm{n}}\left(\mathrm{V}_{\mathrm{W}}\right)^{\mathrm{m}}
$$

With the toluene phase dispersed, the over-all mass transfer coefficient, $K_{W^{a}}$, was found to increase with increasing Reynolds' number and to exhibit a sharp break at a critical Reynolds' number $(R e)_{c} \approx 1200$. The slope of the curve was 0.175 below $(R e)_{c}$ and 1.07 above $\left(R_{e}\right)_{c}$, showing a much faster increase of $\mathrm{K}_{\mathrm{W}^{a}}$ with Re above the critical point. Pressure drop across the column also increased sharply at the critical Reynolds' number of 1200.

Rans were made at constant values of the Reynolds number to determine the effect of flow rates. With either phase dispersed, the over-all mass transfer coefficient was affected mainly by the flow rate of the dispersed phase and only slightly by the flow rate of the continuous phase.

The hold-up increased with increasing flow rate of the discontimuous phase and was independent of the flow rate of the continuous phase. With constant flow rates, hold-up increased exponentially with an increase in the Reynolds number.

At the British Atomic Energy Research Establishment in Harwell, England, the pulse column has been under study for several years as part of a larger program of research in liquid-liquid extraction. A . comprehensive paper on the pulse column work at Harwell was published by Thornton (16) in 1958. A method of design, based on model tests, was presented which was reported to permit the various design parameters to be evaluated to within approximately $\pm 15 \%$ in the range over which the 
11

tests were made.

In the absence of interfacial effects due to solute transfer, the droplet size range was found to be small for any given set of operating conditions. A statistical mean droplet size and its associated characteristic mean velocity was used in the design equation for flooding and for H.T.U. The effect of solute transfer on interfacial effects was added as an "enhancement factor".

A program to determine individual film H.T.U.'s and to study flooding in a pulse column is under way at North Carolina State College (13). 
SCOPE OF THE INVESTICATION

In order to evaluate the use of a pulse column in a process a certain amount of design data is necessary. This was what appeared to be lacking in the pulse column literature. Consequently the project was planned with the object of obtaining information which could be used for design. An orderly approach to how the pulse column operates was the first objective. To achieve this end the operation of the pulse column was described in terms of equations. The simplest possible cases were considered first and additional refinements were added as the theory was developed.

Among column-type extractors the cyclic reversal of flow characteristic of the pulse column is unique. This feature of the pulse column increases the number of material balance equations which can be written, and mach of the theory developed so far is an extensive use of the material balance. The pulse column cannot be truly represented as either a differential or a stagewise type of extractor. Nor is it truly countercurrent or cocurrent, since the presence of recycled liquid imposes a cocurrent stream upon the intended countercurrent flow. It will be shown later that this cocurrent stream does in fact become larger than the countercurrent stream under conditions of high pulsation.

Most previous investigators have used a differential approach to the pulse column, employing the H.T.U. However, in the present work a stagewise approach was employed. 
PROPOSED THEORY

Mixer-Settler Region

\section{Basis of theory}

Assume that a pulse column is divided into discrete stages, a stage being defined as that part of the column between two adjacent perforated plates. Consider that only equilibrium contacts are obtained and that the column is operating at the point of incipient flooding due to insufficient pulsation. At this point of incipient flooding, mixer-settler type operation occurs. The two phases settle out completely and there is no recycle, or back-mixing between stages.

The following assumptions hold for this analysis:

(I) equilibrium contact

(2) mixer-settler type operation

(3) zero recyclo

(4) no volume changes

(5) straight equilibrium line

(6) constant and equal hold-up in all stages

(7) an element of fluid passes through only one stage per half-cycle of the pulse generator.

The following nomenclature will be used:

$$
\begin{aligned}
& E=\text { organic phase hold-up per stage (liters) } \\
& R=\text { aqueous phase hold-up per stage (liters) } \\
& G=\text { organic phase interstage flow rate (liters/cycle) } \\
& L=\text { aqueous phase interstage flow rate (liters/cycle) } \\
& \mathrm{y}=\text { concentration of solute in organic phase (grams/liter) }
\end{aligned}
$$




$$
\begin{aligned}
& x=\text { concentration of solute in aqueous phase (grams/liter) } \\
& m=\text { distribution coefficient. }
\end{aligned}
$$

Primed quantities (') refer to conditions at the end of an upstroke but before the beginning of a downstroke of the pulse generator. Concentrations which are not primed refer to conditions at the end of a down stroke but before the beginning of an upstroke.

A hypothetical extraction problem will serve as a numerical illustration of the design of a pulse column, subject to the assumptions listed above. The end sections of the column have not been considered. Aqueous phase containing $100 \mathrm{gm}$./ liter of solute is to be reduced to a concentration of $34 \mathrm{gm}$./ Iiter by solvent extraction in a 3-in. dia. pulse column. The entering solvent contains 0.5 grams of solute per Iiter. The column has a 3-in. plate spacing and is to be operated at the lower flooding point, with a $\frac{1}{2}$-in. pulse amplitude. The flow rates to the column will be 0.8 liter/min. for each phase. Assume that the organic to aqueous phase hold-up ratio is $1 / 3$ for each stage. The equation of the equilibrium line for the system is $y=0.75 x$. How many stages are necessary to perform the separation?

A diagram of the extractor is shown in Figure 3. By an over-all material balance, $y_{N}$ is found to be $66.5 \mathrm{gm}$./liter. The total volume of each stage is 0.348 liter. Since the organic to aqueous phase holdup ratio is $1 / 3$, the volume of organic phase, $E$, in each stage is 0.176 liter and the volume of aqueous phase, $R$, in each stage is 0.232 liter. An equation developed by Edwards and Beyer (6) may be used to determine the pulse frequency at the lower flooding limit. 
$X_{F}^{\prime}=100 \mathrm{gm} /$ liter $\quad y_{N}=66.5 \mathrm{gm} /$ lifer
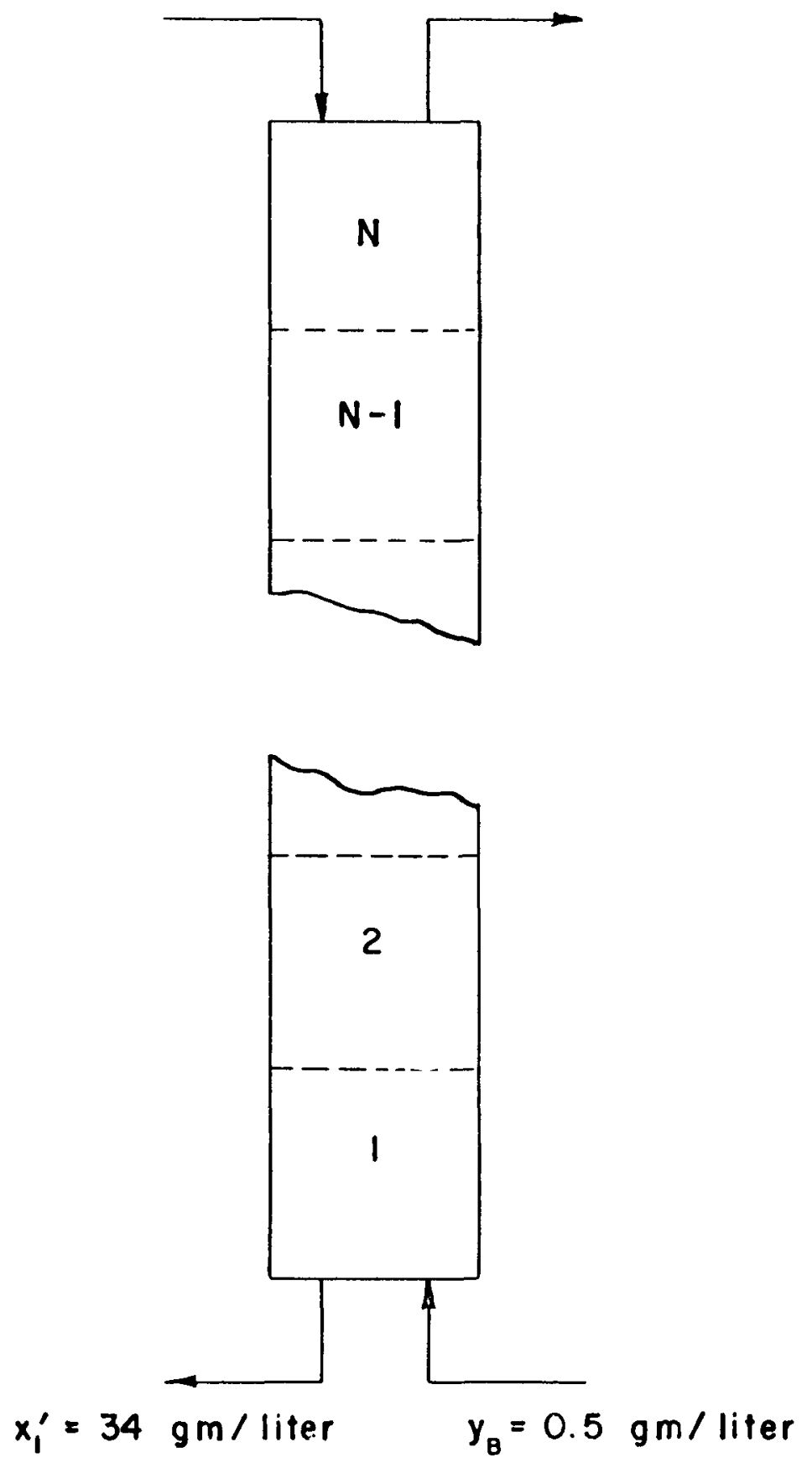

Figure 3. Flow diagram of extractor. 


$$
\operatorname{aAf} \cosh \left(\frac{G_{s}}{\text { aAf }}\right)=\frac{G_{s}}{2}+I_{s}
$$

where,

$$
\begin{aligned}
& a=\text { pulse amplitude }(\mathrm{cm} .) \\
& f=\text { pulse frequency (cycles/min.) } \\
& A=\text { cross-sectional area of column }\left(\mathrm{cm}_{\cdot}^{2}\right) \\
& G_{s}=\text { superficial flow rate of organic phase }\left(\mathrm{cm}^{3} / \mathrm{min} .\right) \\
& L_{s}=\text { superficial flow rate of aqueous phase }\left(\mathrm{cm}^{3} / \mathrm{min} .\right)
\end{aligned}
$$

This equation assumes that the raffinate leaves the column only during an upstroke of the pulse generator. By trial and error calculations the pulse frequency is found to be 20.2 cycles/min. The interstage flow rates for each phase are,

$$
\frac{0.8}{20.2}=0.0396 \text { Iiters }
$$

Begin at the bottom of the column. On the upstroke of the pulse generator, organic phase flows into the bottom of stage one. Consider that the upstroke takes place in two steps as show in Figure $4 a$. First, $G$ liters of organic phase of concentration $y_{B} m i x$ with $R$ liters of aqueous phase of concentration $x_{1}$, according to the equation:

$$
G y_{B}+R x_{1}=G \bar{y}_{1}^{\prime}+R x_{1}^{\prime} \text {. }
$$

The concentration $\bar{y}_{1}^{\prime}$ is a transient concentration within the column at the end of the first step of this two-step process. Since equilibrium contact is assumed, the point $\left(\bar{y}_{1}^{\prime}, x_{1}^{\prime}\right)$ lies on the equilibrium line. Second, the $G$ liters of organic phase of concentration $\bar{y}_{I}^{\prime}$ mix with the 


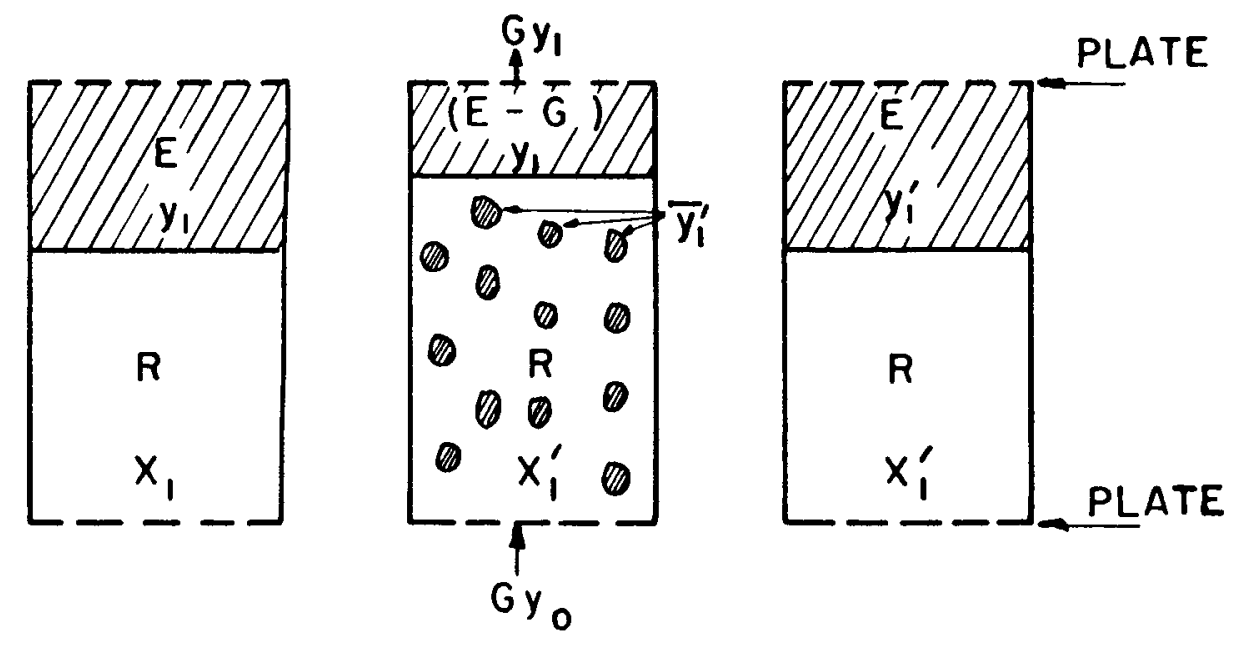

Figure 4a. Stage 1 during an upstroke of the pulse generator. 


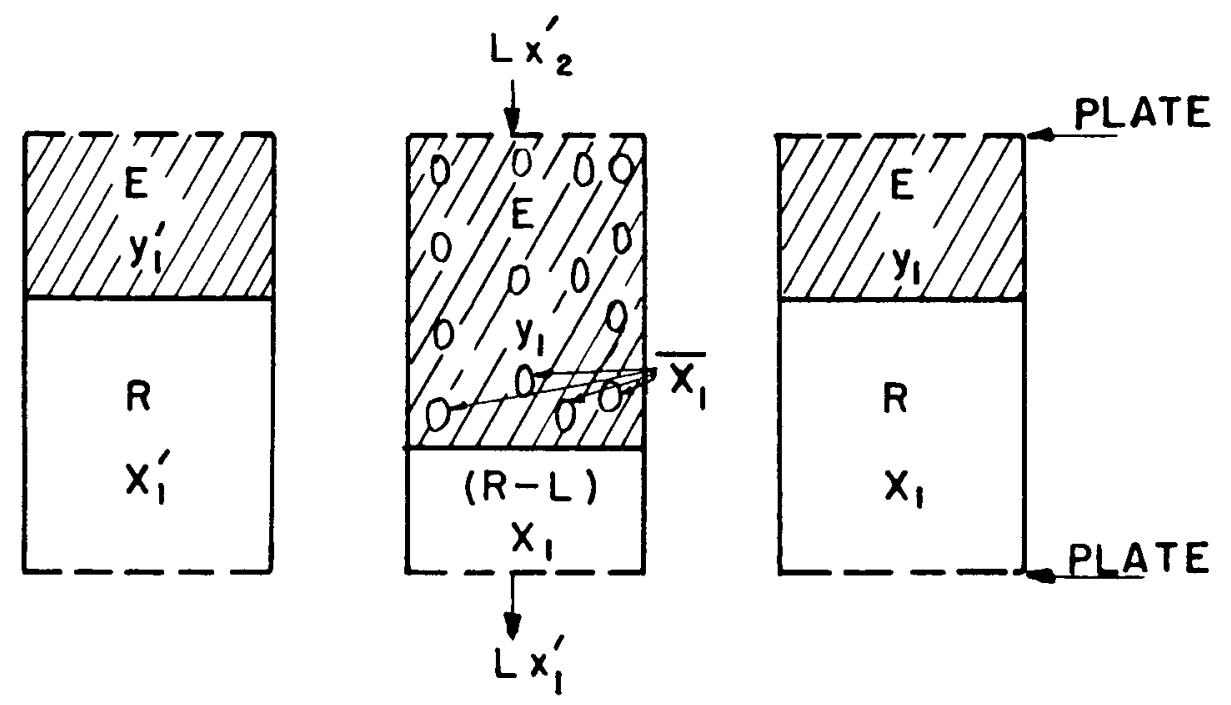

Figure 4b. Stage 1 during a downstroke of the pulse generator. 
(E-G) liters of organic phase of concentration $y_{1}$ remaining at the top of stage one to give E liters of organic phase of concentration $y_{1}^{\prime}$ or:

$$
G \bar{y}_{1}^{\prime}+(E-G) y_{1}=E y_{1}^{\prime}
$$

The downstroke may also be assumed to occur in two steps as shown in Figure 4b. The equations are:

$$
\begin{aligned}
& L x_{2}^{\prime}+E y_{1}^{\prime}=I \bar{x}_{1}+E y_{1} \\
& L \bar{x}_{1}+(R-L) x_{1}^{\prime}=R x_{1} .
\end{aligned}
$$

Equation I may be rearranged to give:

$$
\bar{y}_{I}^{\prime}=\frac{-R}{G} x_{I}^{\prime}+\left[\frac{R}{G} x_{1}+y_{B}\right]
$$

which is the equation of a straight line through the points $\left(y_{B}, x_{1}\right)$ and $\left(\bar{y}_{1}^{\prime}, x_{1}^{\prime}\right)$. The slope is $\frac{-R}{G}=-5.86$. This line, drawn through the point $\left(\bar{y}_{1}^{\prime}, x_{1}^{\prime}\right)$ on Flgure 5 intersects the line $y=y_{B}$ at the point $\left(y_{B}, x_{1}\right)$. From Figure 5, $x_{1}=38.4 \mathrm{gm}$./ liter. Since $x_{1}^{\prime}$ and $x_{1}$ are known, $\bar{x}_{I}$ can be calculated from Equation 4:

$$
\bar{x}_{1}=\frac{R}{L} x_{1}+\left(I-\frac{R}{L}\right) x_{1}^{\prime}=59.8 \text { gm./Liter } .
$$

The value of $y_{1}$ may be read from Figure 5 since $\left(y_{1}, \bar{x}_{1}\right)$ lies on the equilibrium line. Hence $y_{1}=44.8 \mathrm{gm} . /$ Iiter. With $y_{I}$ and $\bar{y}_{I}^{\prime}$ knowm, $y_{1}^{\prime}$ can be determined from Equation 2:

$$
\mathrm{y}_{1}^{\prime}=\frac{\mathrm{G}}{\mathrm{E}} \overline{\mathrm{y}}_{1}^{\prime}+\left(1-\frac{\mathrm{G}}{\mathrm{E}}\right) \mathrm{y}_{1}=38.2 \text { gm./liter } .
$$

Equation 3 may be rearranged to give: 


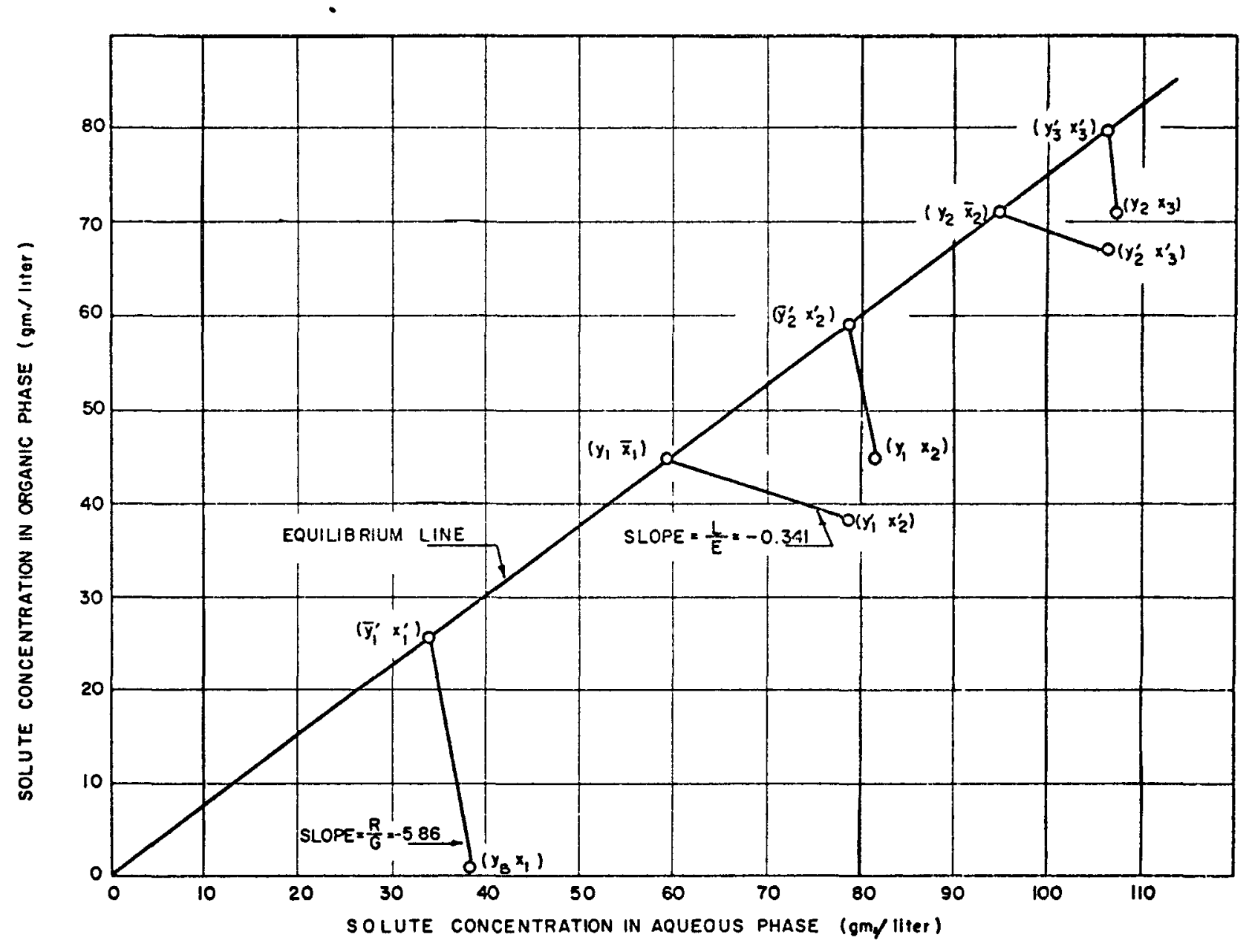

Figure 5. Solution to problem by stage-to-stage calculations. 


$$
y_{1}=-\frac{L}{E} x_{1}+\left[\frac{L}{E} x_{2}^{\prime}+y_{1}^{\prime}\right]
$$

which is the equation of a straight line through the points $\left(y_{1}, \bar{x}_{1}\right)$ and $\left(y_{1}^{\prime}, x_{2}^{\prime}\right)$. The slope is $-\frac{I}{E}=-0.341$. The intersection of this line with the line $y=y_{1}^{\prime}$ determines the point $\left(y_{1}^{\prime}, x_{2}^{\prime}\right)$ and hence the value of $x_{2}^{\prime}$ can be read from Figure 3 as $x_{2}^{\prime}=79$ gm./1iter.

The procedure can now be repeated starting with the point $\left(\bar{y}_{2}^{\prime}, x_{2}^{\prime}\right)$ on the equilibrium line. This point is analogous to the point $\left(\bar{y}_{1}^{\prime}, x_{1}^{\prime}\right)$ of the preceding calculation. The calculations are contimed until the desired separation has been reached. In this case, comparing Figures 1 and 3 it is seen that:

$$
\begin{aligned}
& \mathrm{y}_{2}=\mathrm{y}_{\mathrm{N}}=71.8 \mathrm{gm} \cdot / \text { Iiter } \\
& \mathrm{x}_{3}^{\prime}=\mathrm{x}_{\mathrm{F}}^{\prime}=106.2 \mathrm{gm} \cdot / \text { Iiter } .
\end{aligned}
$$

Slightly less than two stages are needed.

Notice, as shown in Figure 6, that by drawing a straight line through each of the following series of points,

$$
\begin{aligned}
& \text { (1) } x_{n}, y_{n} \\
& \text { (2) } x_{n}^{\prime}, y_{n}^{\prime} \\
& \text { (3) } x_{n+1}, y_{n} \\
& \text { (4) } x_{n+1}^{\prime}, y_{n}^{\prime}
\end{aligned}
$$

It is possible to step off the stages in much the same manner as is done on a McCabe-Thiele diagram. However, there are two sets of lines; one set is for the upstroke of the pulse generator and one set is for the downstroke of the pulse generator. The upper line in each set is not an 


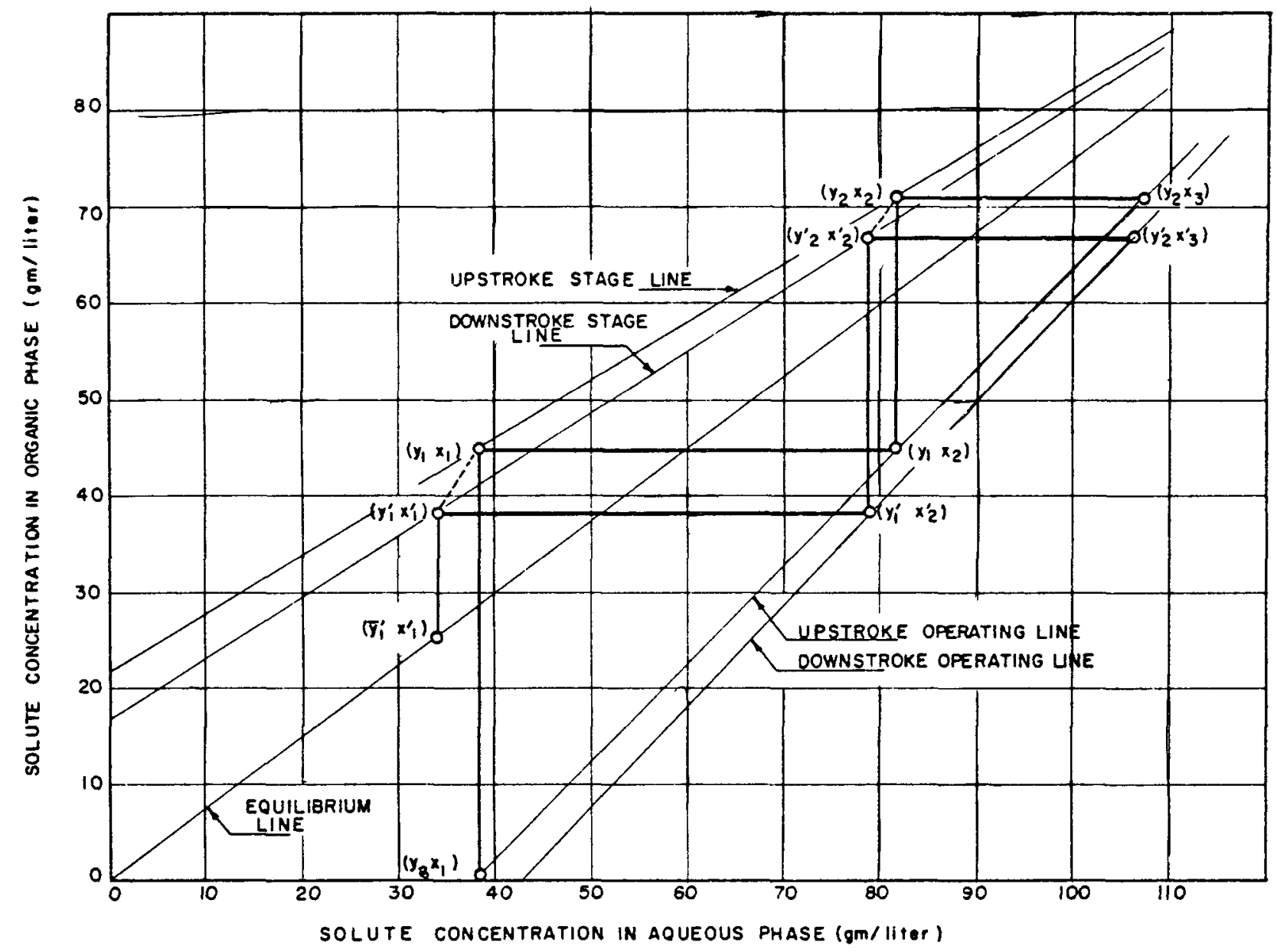

Figure 6. Solution to problem by using stage lines and operating lines. 
equilibrium Iine as in a McCabe-Thiele diagram, nor is the bottom line a McCabe-Thtele operating 11ne. For conventence, the lower line in each set will be called an "operating line" since it serves the same purpose on the diagram as a conventional operating line. On the other hand, the upper lines cannot very well be called equilibrium lines. These upper Iines will be called "stage lines" since they represent the locus of points corresponding to stage concentrations of aqueous and organic phases at the end of each half-cycle of the pulse generator.

The diagram in Figure 6 shows clearly the stagewise nature of pulse column operation. The dotted linss show the change in concentration in each stage when the column is operating at steady-state. The concentration values oscillate back and forth between the points at each end of these lines.

The problem may also be solved by use of an "over-all stage line" and an "over-all operating line". The first is a relation between $y_{n}$ and $x_{n}^{\prime}$. The second is a relation between $y_{n}$ and $x_{n+l}^{\prime}$. The necessary equations are derived from Equations 1 through 4, the two equilibrium relations, and a material balance over one end of the column. A material balance over the bottom of the column, including stage $n$ as show in Figure 7 is:

$$
y_{n}=\frac{I}{G} x_{n+I}^{\prime}+\left[y_{B}-\frac{L}{G} x_{1}^{\prime}\right] \text {. }
$$

The resulting equations are:

$$
\begin{array}{ll}
y_{n}=\frac{m^{2} G}{L} x_{n}^{\prime}-\frac{m G}{L}\left[y_{B}-\frac{L}{G} x_{I}^{\prime}\right] & \text { over-all stage line. } \\
y_{n}=\frac{L}{G} x_{n+1}^{\prime}+\left[y_{B}-\frac{L}{G} x_{I}^{\prime}\right] & \text { over-all operating line. }
\end{array}
$$




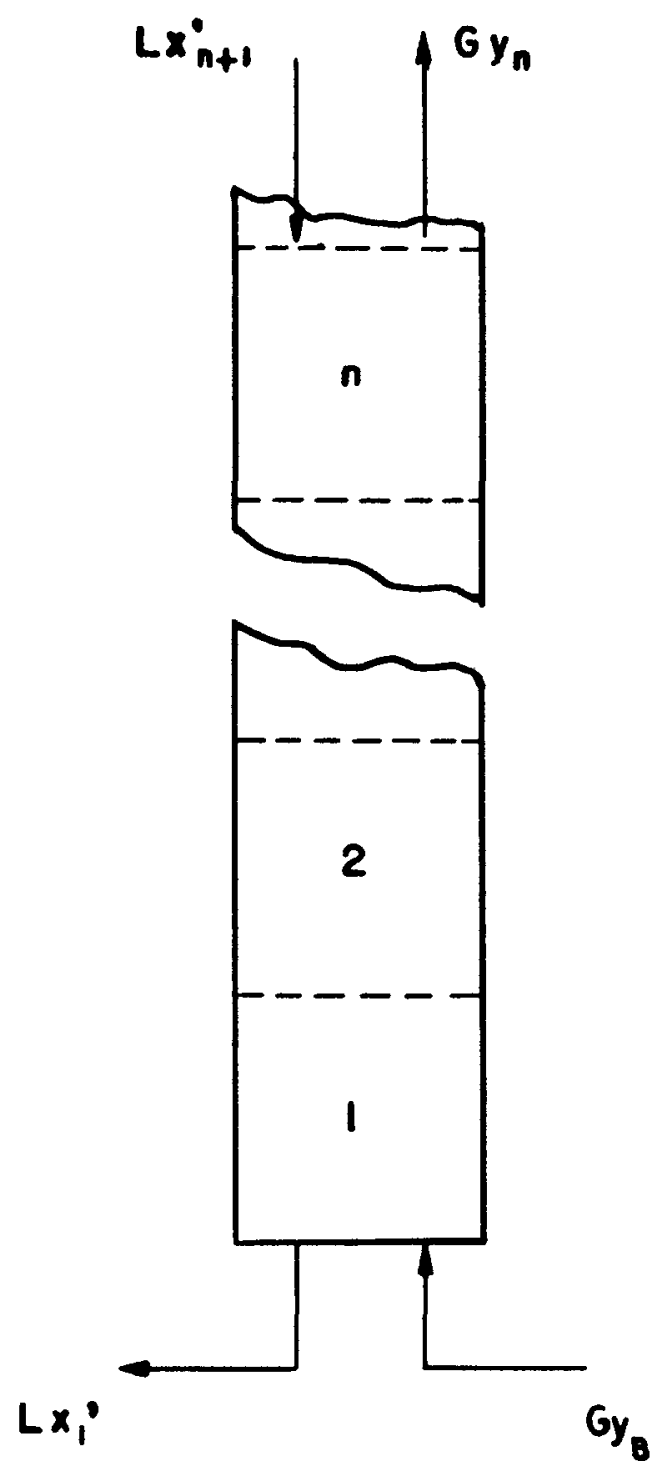

Figure 7. Diagram of bottom portion of a pulse column. 


\section{End sections}

A diagram of the top end-section is shown in Figure 82. Aqueous feed enters the top end section continuously. Notice that only that portion of the end section where the two phases may come into contact is of any importance from the standpoint of extraction. Consider a downstroke of the pulse generator, shown in Figure 8a. I/2 liters of aqueous phase of concentration $x_{A}$ enter and I liters of aqueous phase of concentration $x_{F}$ leave the section. The following equations may be written:

$$
R_{T} x_{F}^{\prime}+\frac{L}{2} x_{A}^{\prime}-L x_{F}^{\prime}=\left(R_{T}-\frac{L}{2}\right) x_{F}
$$

or:

$$
\left(R_{T}-L\right) x_{F}^{\prime}+\frac{L}{2} x_{A}^{\prime}=\left(R_{T}-\frac{L}{2}\right) x_{F}
$$

Next consider an upstroke of the pulse generator, as shown in Figure 8b. G liters of organic phase of concentration $y_{N}$ enter the top end section. Since aqueous phase enters the top end section contimuously, $\frac{L}{2}$ liters of aqueous phase of concentration $x_{A}^{\prime}$ also enter on the upstroke. G liters of organic phase of concentration $y_{A}$ leave during this period. Thus, at the end of the upstroke, the top end section contains $\mathrm{R}_{\mathrm{T}}$ liters of aqueous phase. Assuming that the two phases reach equilibrium on the upstroke, then:

$$
\left(\mathrm{R}_{\mathrm{T}}-\frac{\mathrm{L}}{2}\right) \mathrm{x}_{\mathrm{F}}^{\prime}+\frac{\mathrm{L}}{2} x_{\mathrm{A}}^{\prime}+\operatorname{cog}_{\mathrm{N}}=\mathrm{R}_{\mathrm{T}} x_{\mathrm{F}}^{\prime}+G_{\mathrm{A}} .
$$

Values of $x_{A}^{\prime}, y_{A}, R_{T}, G$ and $L$ will probably be known for most problems. So $y_{N}$ and $x_{F}$ must be determined from the above equations. The point $\left(x_{F}^{\prime}, y_{A}\right)$ lies on the equilibrium line so the value of $x_{F}^{\prime}$ can 


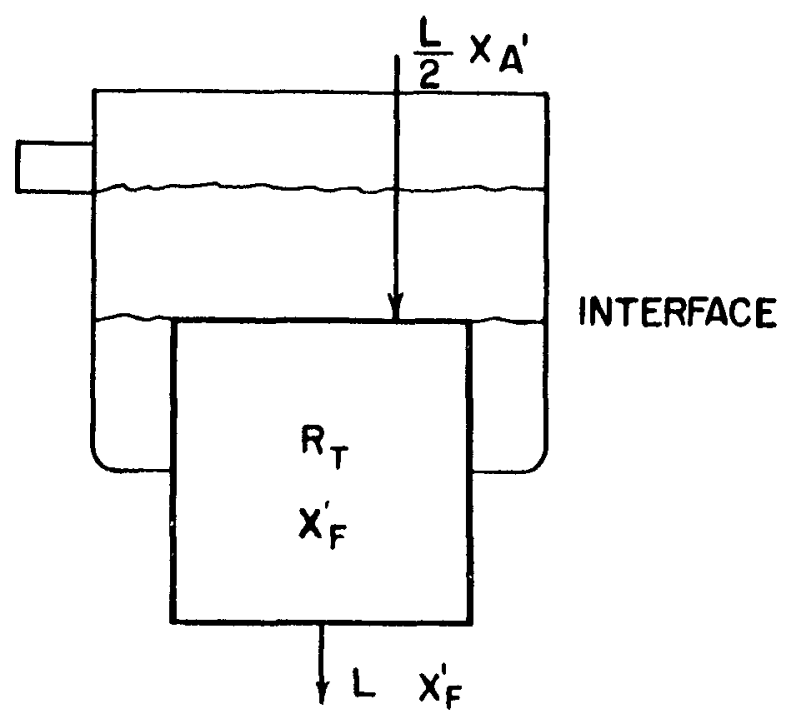

Figure 8a. Top end-section; downstroke.

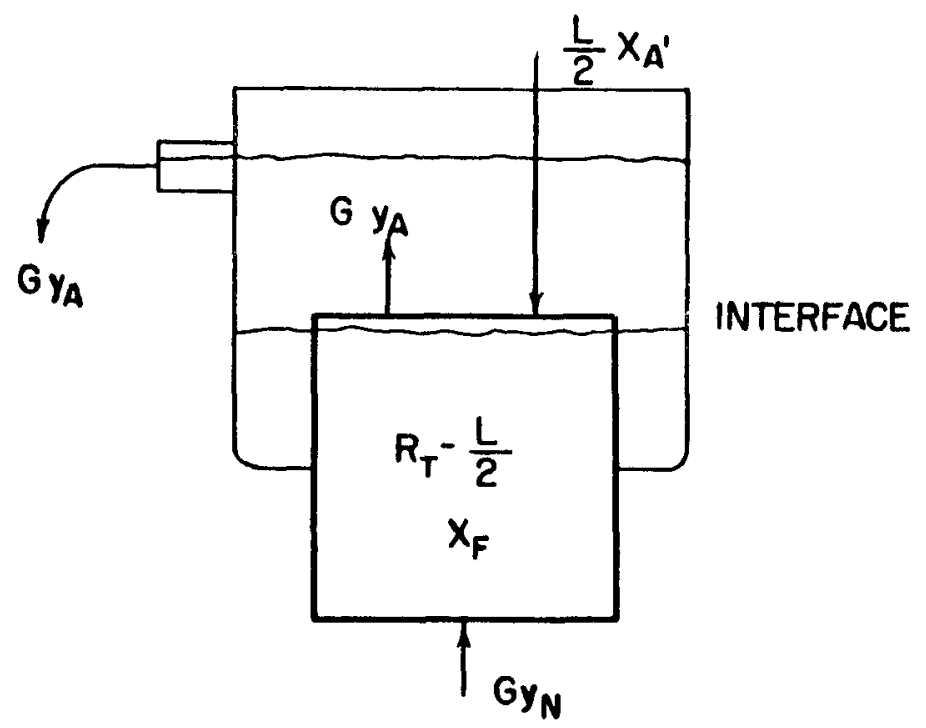

Figure 8b. Top end-section; upstroke. 
be found since $\mathrm{J}_{\mathrm{A}}$ is known. Then:

$$
x_{F}=\left[\frac{2\left(R_{T}-L\right)}{2 R_{T}-L}\right] x_{F}^{\prime}+\left[\frac{L}{2 R_{T}-I}\right] x_{A}^{\prime}
$$

and:

$$
y_{N}=\frac{R_{T}}{G}\left(x_{F}^{\prime}-x_{F}\right)+\frac{L}{2 G}\left(x_{F}-x_{A}^{\prime}\right)
$$

Figure 9a shows the bottom end-section of a pulse column during an upstroke of the pulse generator. G/2 liters of organic phase of concentration $y_{B} m i x$ with $R_{B}$ liters of aqueous phase of concentration $x_{B}$ according to the equations

$$
\begin{aligned}
& \frac{G}{2} y_{S}+R_{B} x_{B}=\frac{G}{2} \bar{y}_{B}^{\prime}+R_{B} x_{B}^{\prime} \\
& \frac{G}{2} \bar{y}_{B}^{\prime}+\left(E_{B}-G\right) y_{B}=\left(E-\frac{G}{2}\right) y_{B}^{\prime} .
\end{aligned}
$$

Similarly, the following equations may be written for the botton endsection during a downstroke of the pulse generator:

$$
\begin{aligned}
& L x_{1}^{\prime}+\left(E_{B}-\frac{G}{2}\right) y_{B}^{\prime}+\frac{G}{2} y_{S}=L \bar{x}_{B}+E_{B} y_{B} \\
& L \bar{x}_{B}+\left(R_{B}-L\right) x_{B}^{\prime}=R_{B} x_{B}=
\end{aligned}
$$

Values for $y_{B}$ and $x_{1}^{\prime}$ must be determined from these equations. The point $\left(\bar{y}_{B}^{\prime}, x_{B}^{\prime}\right)$ lies on the equilibrium line. A line through this point and the point $\left(y_{S}, x_{B}\right)$ has a slope equal to $-\left(2 R_{B}\right) / G$. Thus the value of $x_{B}$ may be found since ys will probably be known from the conditions of the problem. Then:

$$
\bar{x}_{B}=\frac{R_{B}}{I} x_{B}+\left(1-\frac{R_{B}}{I}\right) x_{B}^{\prime}
$$




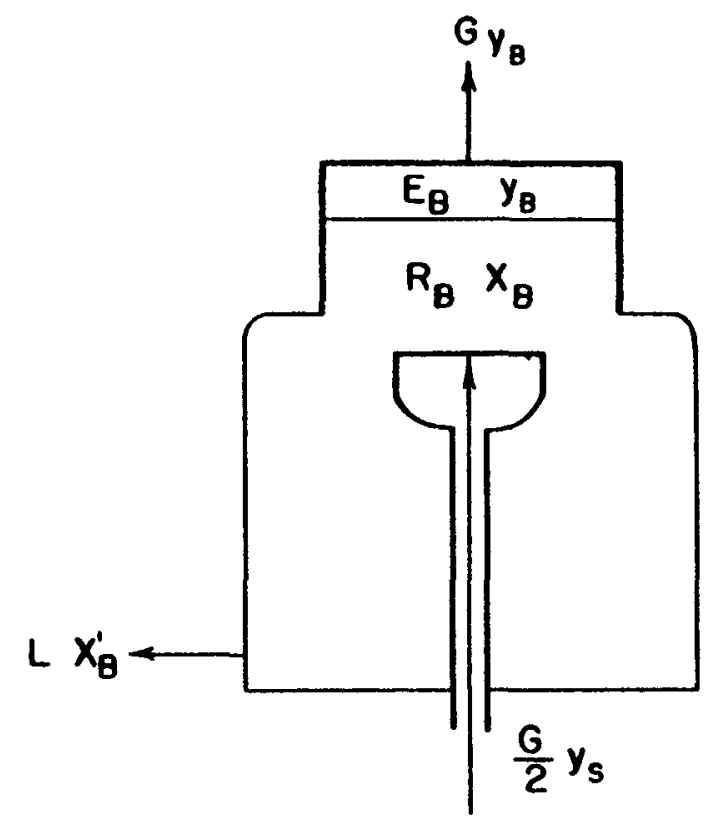

Figure 9a. Bottom end-section; upstroke.

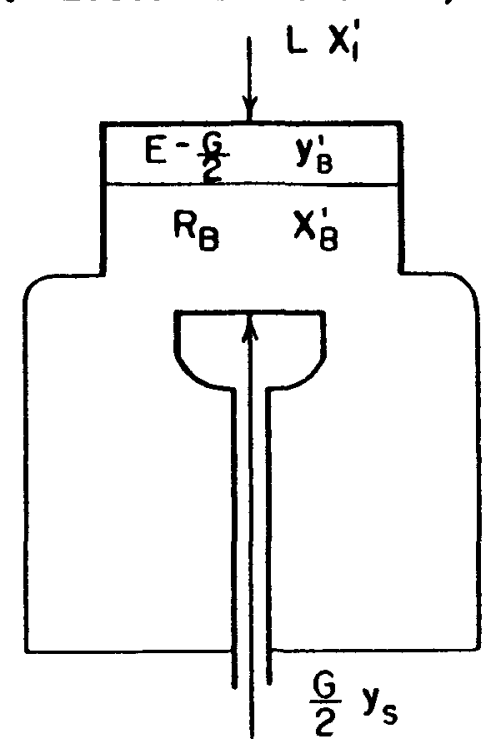

Figure 9b. Bottom end-section; downstroke. 
The point $\left(\bar{x}_{B}, y_{B}\right)$ lies on the equilibrium line, so $y_{B}$ can be determined. Next:

$$
x_{1}^{\prime}=\bar{x}_{B}+\frac{G}{2 I}\left(y_{B}^{\prime}-y_{B}\right)+\frac{E_{B}}{L}\left(y_{B}-y_{B}^{\prime}\right) .
$$

To illustrate a complete column design using this analysis, consider the following problem.

A 3-in. diameter pulse column has ten stages, each 3-in. high. Organic solvent is avallable which has a concentration of one gram of solute per liter. The flow rates to the column are to be $1.085 \mathrm{liters} / \mathrm{min}$. for the organic phase and 0.800 liters/min. for the aqueous phase. When the column operates at the lower flooding point with a $\frac{1}{2}$-in. pulse amplitude, the pulse frequency is $22.3 \mathrm{cycles} / \mathrm{min}$. The organic phase hold-up in each stage may be taken as 0.0486 liters/stage. The equilibrium curve for the system is $y=0.75 x$. What must be the concentration of aqueous feed if the raffinate from the column is to have a solute concentration not greater than $5 \mathrm{gm} . / \mathrm{liter}$ ?

The solution of this problem is show in Figure 10. The concentration of aqueous feed, $x_{A}^{\prime}$, must be $98 \mathrm{gm} . /$ iter. The organic extract leaves the column at a concentration of $70 \mathrm{gm} . /$ liter.

\section{$\underline{\text { Recycle }}$}

When a pulse column is operated above the lower flooding point, the recycle rate is no longer zero. In effect, the presence of recycled liquid means that some of the fluid which leaves a stage on one halfcycle of the pulse generator returns to the stage on the following halfcycle. However, this fluid suffers a decrease in solute concentration 


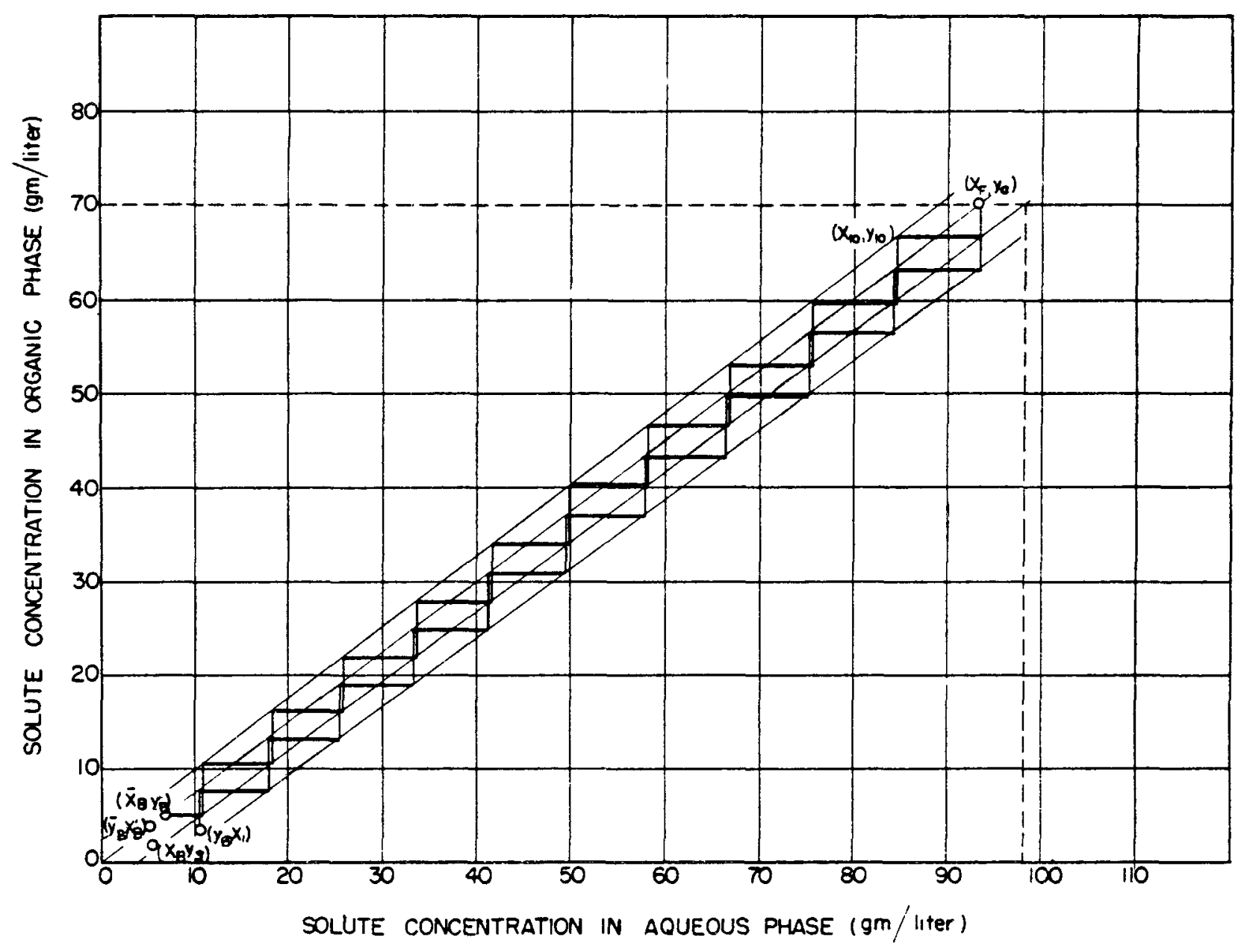

Figure 10. Solution to pulse column destgn problem; operation at the lower flooding limit. 
during the time it is gone from the stage. When it returns as recycle, this fluid causes a decrease in the over-all concentration gradient available for mass transfer. Hence the effect of recycle in a pulse column is opposite to that of reflux in a distillation column. The potential importance of recycle with increasing pulsation can be seen from the curves in Figure 11 where recjcle rate as a function of pulse frequency is shown for a particular case.

Any analysis of pulse column operation above the lower flooding limit must include the effect of recycle. By using an approach similar to that employed for describing operation at the lower flooding limit, a mechanism can be proposed to explain extraction in the mixer-settler region. However, this method requires a knowledge of the hold-up in each stage. The following relations hold for any liquid system so long as the column follows true mixer-settler operation. The assumptions previously listed still apply.

The phase composition of the recycled liquid must be known in order to predict the steady-state hold-up. The equation of Edwards and Beyer (6) permits calculation of the amount of liquid recycled on each half-cycle of the pulse generator. However, this equation cannot be used to determine if the recycled liquid is aqueous phase, organic phase, or a mixture of both aqueous and organic phases. For mixersettler operation, with the principal interface at the top of the column (organic phase dispersed), the recycled liquid will consist entirely of aqueous phase. This can be seen by observing the column in mixer-settler operation. Figure 12 shows the theoretical approach to steady-state, under these conditions, of a 3-in. diameter pulse column with a 3-in. 


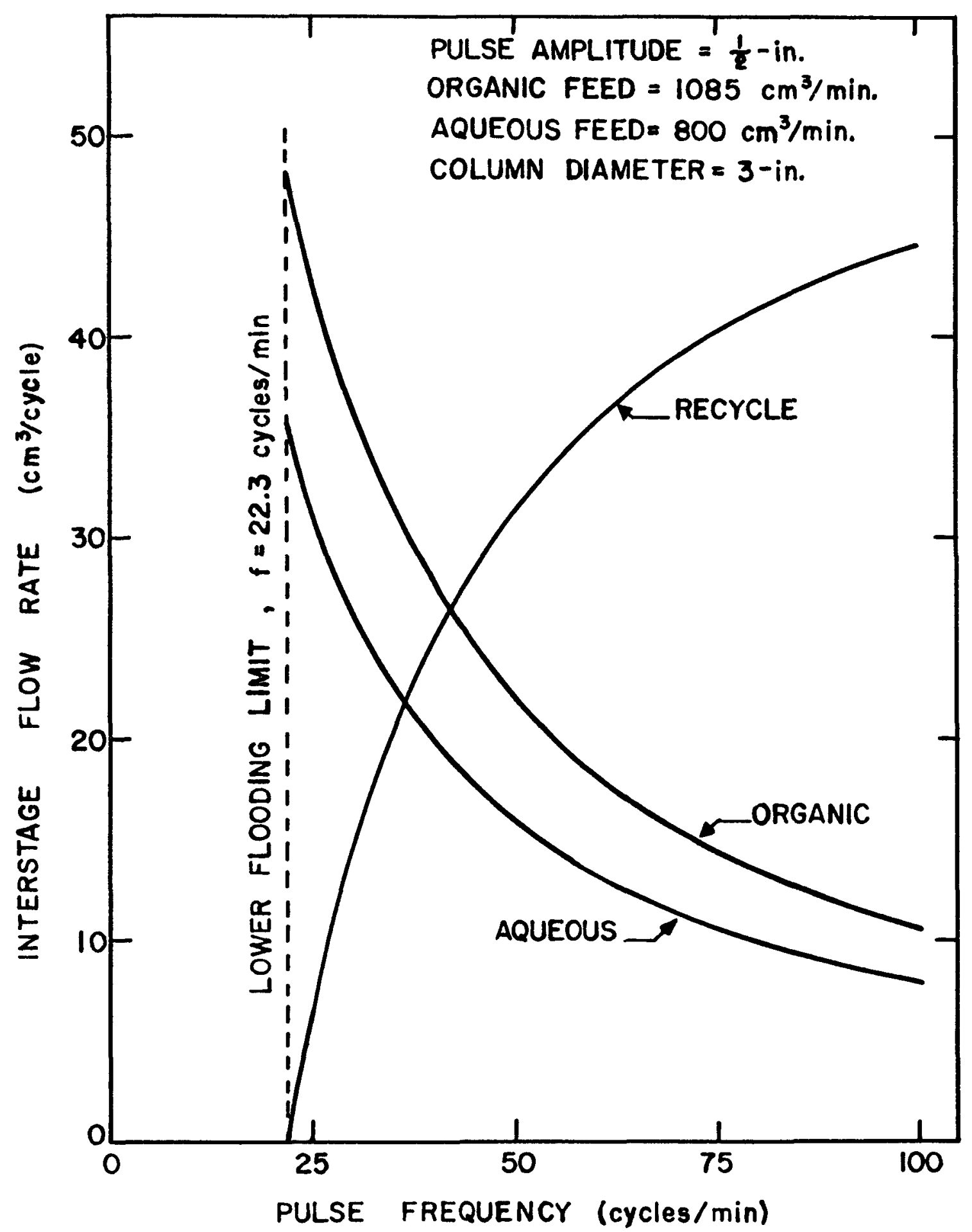

Figure 11. Interstage flow rates as a function of pulse frequency. 


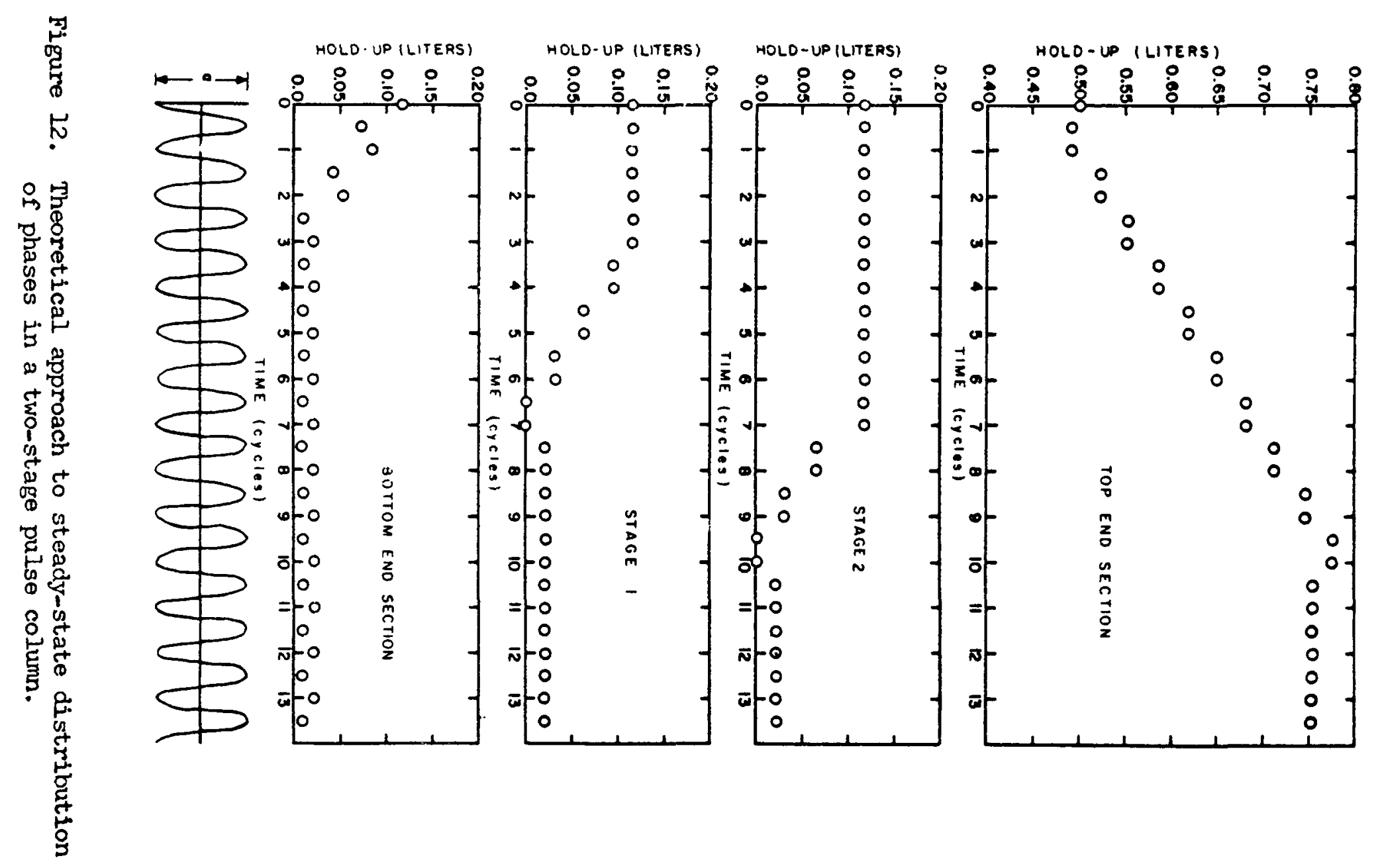


plate spacing if it were pre-loaded with one-third organic phase and two-thirds aqueous phase in each stage and allowed to run until the holdup reaches a constant value over each cycle. The hold-up of the dispersed phase in the two stages and in each end-section is plotted against the time in cycles. The distribution of the two phases is shown schematically in Figure 13. The hold-up of organic phase becomes equal to the organic phase interstage flow per cycle.

The volumes of the two phases in the top end-section in Figure 13 will depend on the height of the principal interface. According to the theory, then, if the position of the jack-leg which balances the pressure drop across the column is changed, the corresponding adjustment of the aqueous-to-organtc phase ratio must appear only in the top end-section after the column reaches steady-state again. The aqueous-to-organic phase ratio elsewhere in the column will only be temporarily affected by varying the position of the jack-leg.

Refer to Figure 13. If the same assumptions are made as in the previous analysis, then the following equations may be written:

(A) Top end-section

$$
\begin{aligned}
& \frac{L}{2} x_{A}^{\prime}+R_{T} x_{T}^{\prime}-\left(V_{R}+L\right) x_{T}^{\prime}=\left(R_{T}-V_{R^{-}}-\frac{L}{2}\right) x_{T} \quad \text { downstroke } \\
& C y_{N}+V_{R} x_{N}^{\prime}+\left(R_{T}-V_{R}-\frac{L}{2}\right) x_{T}+\frac{L}{2} x_{A}^{\prime}=R_{T} x_{T}^{\prime}+C_{y_{A}} \quad \text { upstroke }
\end{aligned}
$$

(B) Bottom end-section

$$
\begin{aligned}
& \left(V_{R}+L\right) x_{I}^{\prime}+\frac{G}{2} y_{B}^{\prime}+\frac{G}{2} y_{S}=\left(V_{R}+L\right) \bar{x}_{B}+V_{B} \\
& \left(V_{R}+L\right) \bar{x}_{B}+\left(R-V_{R}-L\right) x_{B}^{\prime}=R_{B} x_{B}
\end{aligned}
$$




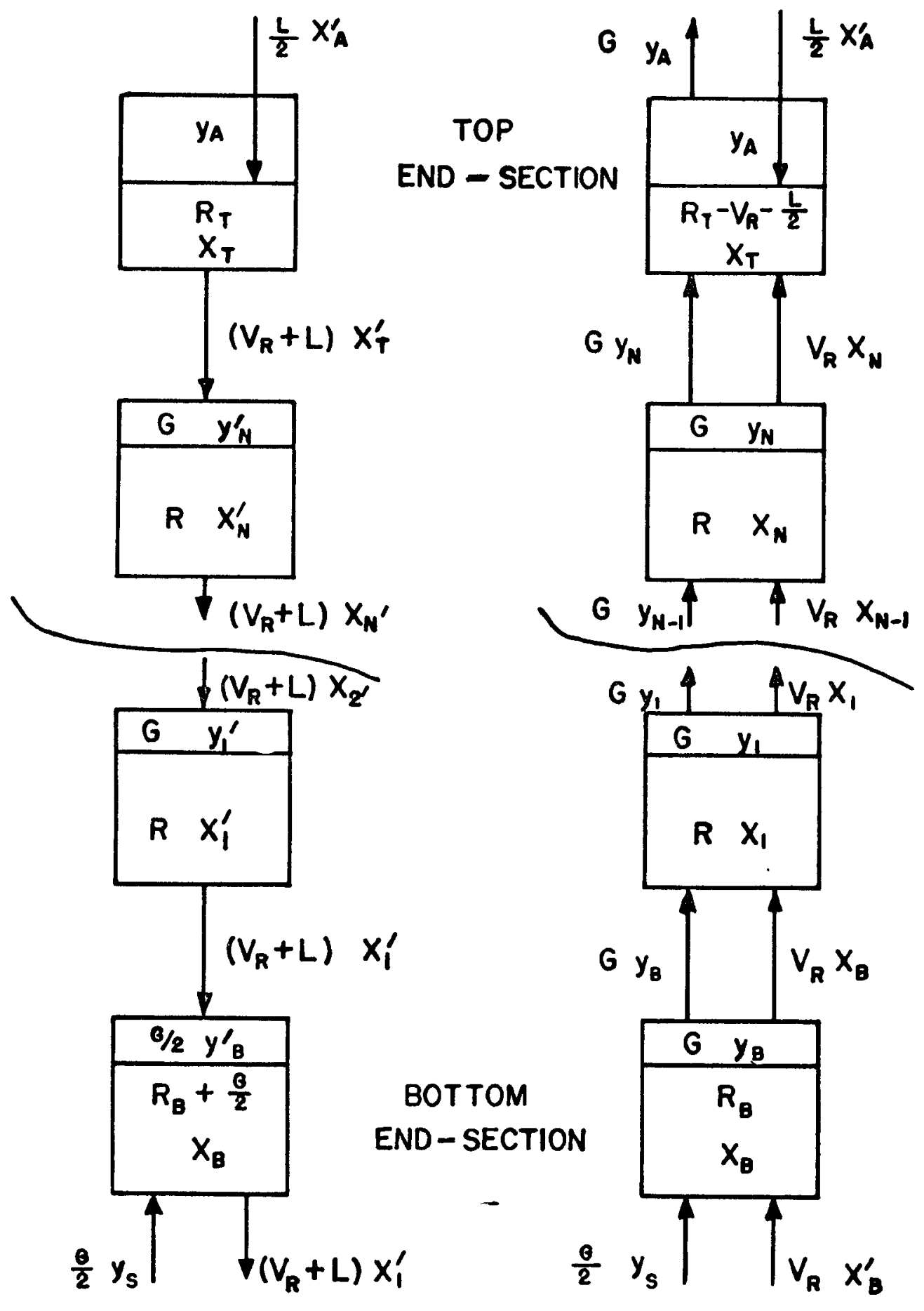

Figure 13. Distribution of phases in a pulse column operating with recycle in the mixer-settler region. 
$\frac{G}{2} y_{S}+\left(R_{B}-V_{R}\right) x_{B}+\left(V_{R}+\frac{G}{2}\right) x_{B}^{\prime}=\frac{G}{2} y_{B}^{\prime}+\left(R_{B}+\frac{G}{2}\right) x_{B}^{\prime} \quad$ upstroke

(c) Stages

$$
\begin{aligned}
& x_{n+1}=\bar{x}_{n+}\left(\frac{G}{V_{R}+L}\right)^{\left(y_{n}-y_{n}^{\prime}\right)} \\
& x_{n}=\left(\frac{R}{R-V_{R}}\right) x_{n}^{\prime}+\left(\frac{G}{R-V_{R}}\right)\left(y_{n}^{\prime}-y_{n-1}\right)-\left(\frac{V_{R}}{R-V_{R}}\right) x_{n-1} \\
& \bar{x}_{n}=\left(\frac{R}{V_{R}+L}\right) x_{n}-\left(\frac{R-V_{R-I}}{V_{R}+I}\right) x_{n}^{\prime} \\
& y_{n}=m \bar{x}_{n} \\
& \bar{y}_{n}^{\prime}=m x_{n}^{\prime} .
\end{aligned}
$$

Consider the example problem show in Figure 10 except that in this case the pulse frequency is increased to $50 \mathrm{cpm}$. Assume that, at this frequency, the column still operates in the mixer-settler region. Since equilibrium contact is assumed in both cases, the degree of separation obtained at the higher frequency should be less because of the effect of recycle. Figure 14 shows the solution of this problem. The separation obtained is drastically reduced. The required concentration of the aqueous feed stream is now $26.3 \mathrm{gm}$./ liter as compared with $98 \mathrm{gm} . /$ Itter for the same column operating at a pulse frequency of $22.3 \mathrm{cpm}$. which is the lower flooding point where recycle rate is zero. This change in $x_{A}^{\prime}$ as the pulse frequency is increased above the lower flooding limit is shown in Figure 15.

Thus far equilibrium contact has been assumed. The actual efficiency of the column has yet to be evaluated. However, by making the equilibrium 


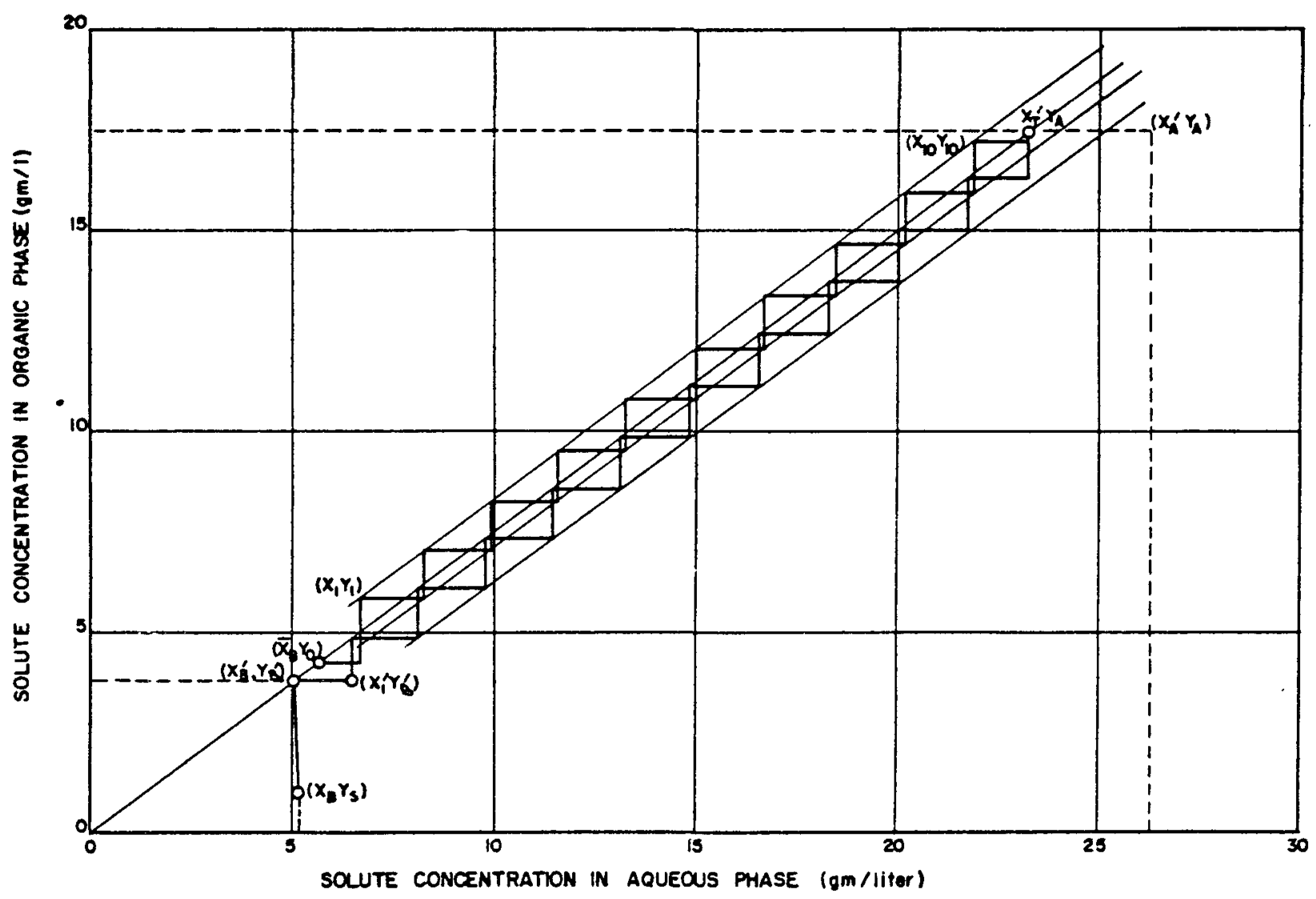

Figure 14. Solution to pulse column design problem in which the effect of recycle is considered. 


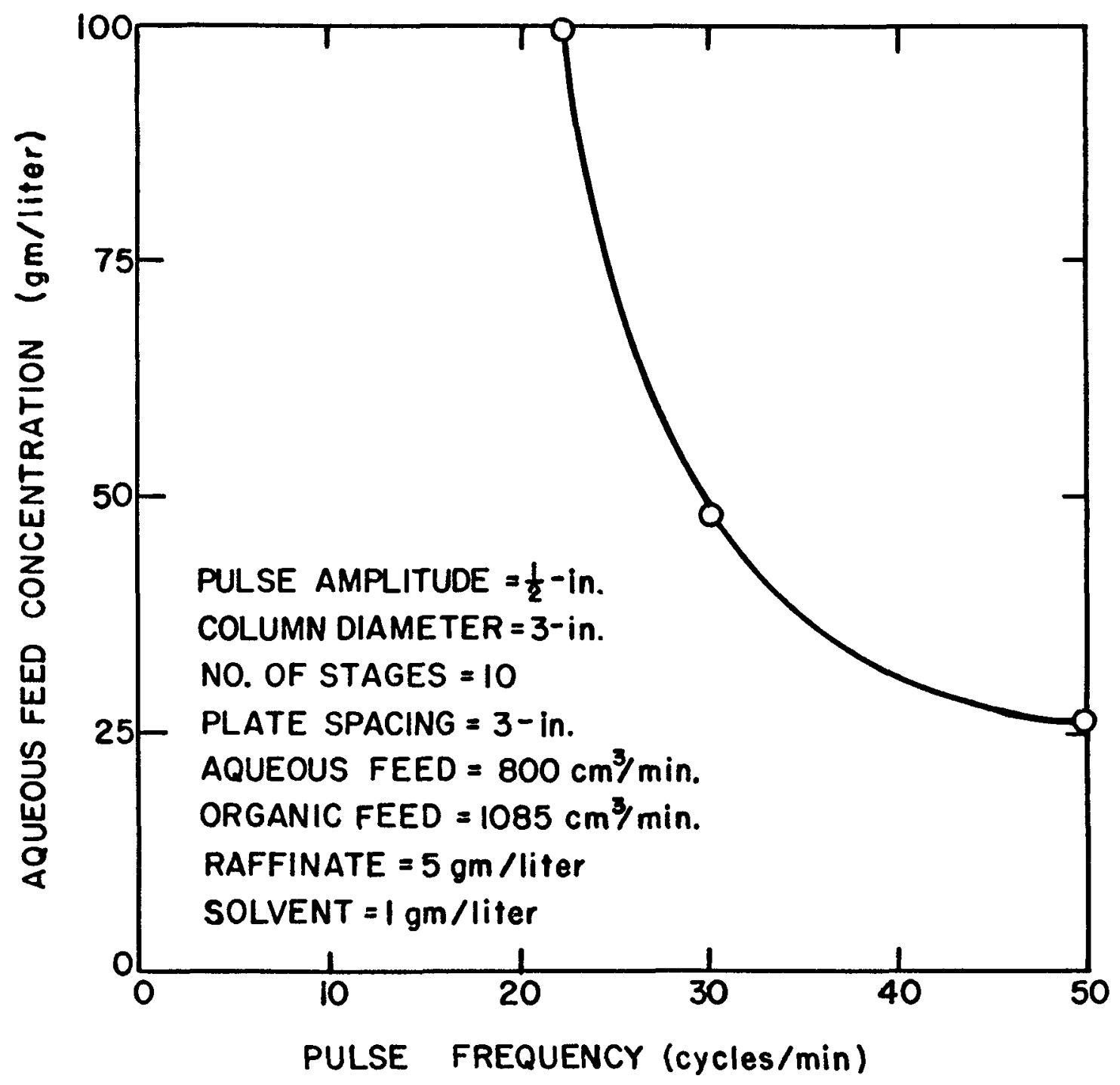

Figure 15. Change in required feed concentration as a function of the puise frequency. 
contact assumption in all cases it is possible to investigate, from theoretical relationships, the effects of recycle alone on the operation of the pulse column. In addition, the theoretical model having 100 per cent efficiency provides a standard with which to compare experimental data. Other applications exist for the model. Relative effects of flow rates, plate spacing, and other variables can be studied.

\section{Stage efficiencies}

For an actual column operating in the mixer-settler region, equilibrium contact would not be expected. Hence, from a design standpoint, it is necessary to introduce the concept of stage efficiency. Figure 16 shows a typical stage $n$ for a pulse column operating in the mixer-settler region. The following material balance equations can be written around this stage:

Upstroke:

$$
\begin{aligned}
& \left(G+O_{R_{u}}\right) y_{n-1}+\left(R-A_{R_{u}}\right) x_{n}+A_{R_{u}} x_{n-1}=\left(G+O_{R_{u}}\right) \bar{y}_{n}^{\prime}+R x_{n}^{\prime} \\
& \left(G+O_{R_{u}}\right) \bar{y}_{n}^{\prime}+\left(E-G-O_{R_{u}}\right) y_{n}=E y_{n}^{\prime}
\end{aligned}
$$

Downstroke:

$$
\begin{aligned}
& \left(L+A_{R_{d}}\right) x_{n+1}^{\prime}+\left(E-O_{R_{d}}\right) y_{n}^{\prime}+O_{R_{d}} y_{n+1}^{\prime}=\left(L+A_{R_{d}}\right) \bar{x}_{n}+E y_{n} \\
& \left(I+A_{R_{d}}\right) \bar{x}_{n}+\left(R-L-A_{R_{d}}\right) x_{n}^{\prime}=R x_{n},
\end{aligned}
$$

For the case of equilibrium contact, these equations become:

Upstroke:

$$
\left(G+O_{R_{u}}\right) y_{n-1}+\left(R-A_{R_{u}}\right) x_{n}+A_{R_{u}} x_{n-1}=\left[m\left(G+O_{R}\right)+R\right] x_{n}^{\prime} \text {. }
$$


40

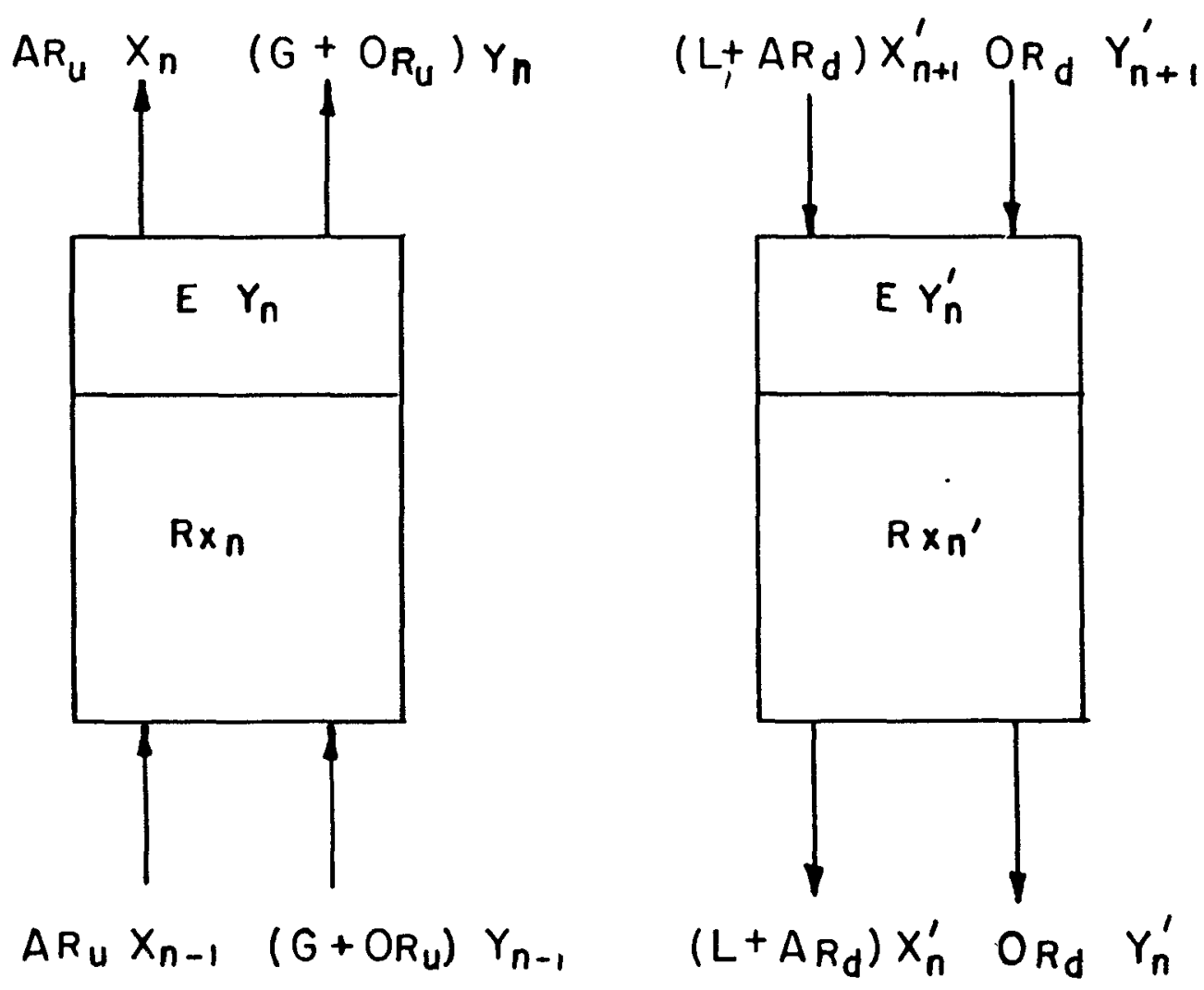

Figure 16. Diagram of a typical stage in a pulse column. 


$$
\left(G+O_{R_{u}}\right) m x_{n}^{\prime}+\left(E-G-O_{R_{u}}\right) y_{n}=E y_{n}^{\prime},
$$

$$
\begin{aligned}
& \text { Downstroke: } \\
& \left(\mathrm{L}+\mathrm{A}_{\mathrm{R}_{\mathrm{d}}}\right) \mathrm{x}_{n+1}^{\prime}+\left(\mathrm{E}-\mathrm{O}_{\mathrm{R}_{d}}\right) \mathrm{y}_{n}^{\prime}+\mathrm{O}_{\mathrm{R}_{d}} \mathrm{y}_{n+1}^{\prime}=\left[\frac{\mathrm{L}+\Lambda_{R_{d}}}{\mathrm{~m}}+\mathrm{E}\right] \mathrm{y}_{n}^{*} .
\end{aligned}
$$

Now, for the case of non-equilibrium contact, stage efficiencies can be used. For a pulse column, two stage efficiencies may be defined, one for the upstroke and one for the downstroke. There is no reason to suppose that the two should be equal. The upstroke stage efficiency will be defined as:

$$
\varepsilon_{u_{n}}=\frac{\bar{y}_{n}^{\prime}-y_{n-1}}{\bar{y}_{n}^{*}-y_{n-1}}
$$

where, $\vec{y}_{n}^{\prime}=m x_{n}^{\prime}$

so: $\bar{y}_{n}^{\prime}=m \varepsilon_{u} x_{n}^{\prime}+\left(1-\varepsilon_{u}\right) y_{n-1}$.

Substituting for $\bar{y}_{n}^{\prime}$ in equations 28 and 29 gives,

$$
\begin{aligned}
& \mathcal{E}_{u_{n}}\left(G+O_{R_{u}}\right) y_{n-1}+\left(R-A_{R_{u}}\right) x_{n}+A_{R_{u}} x_{n-1}=\left[m \varepsilon_{u_{n}}\left(G+O_{R_{u}}\right)+R\right] x_{n}^{\prime} \\
& \left(G+O_{R_{u}}\right)\left[m \varepsilon_{u_{n}} x_{n}+\left(1-\varepsilon_{u_{n}}\right) y_{n-1}\right]+\left(E-G-O_{R_{u}}\right) y_{n}=E y_{n}^{\prime} .
\end{aligned}
$$

Similarly, the domstroke stage efficiency will be defined as:

$$
\varepsilon_{d_{n}}=\frac{x_{n+1}^{\prime}-\bar{x}_{n}}{x_{n+1}^{\prime} \bar{x}_{n}^{*}}
$$

where $\mathrm{y}_{\mathrm{n}}=\mathrm{m} \overline{\mathrm{x}}_{\mathrm{n}}{ }^{*}$

so: $x_{n}=\left(\frac{\varepsilon_{d_{n}}}{m}\right) y_{n}+\left(1-\varepsilon_{d_{n}}\right) x_{n+1}^{\prime}$, 
Substituting for $\bar{x}_{n}$ in Equations 34 and 35 gives,

$$
\begin{gathered}
\mathcal{E}_{d_{n}}\left(L+A_{R_{d}}\right) x_{n+1}^{\prime}+\left(E-o_{R_{d}}\right) y_{n}^{\prime}+o_{R_{d}} y_{n+1}^{\prime}=\left[\left(\frac{\mathcal{E}_{n}}{m}\right)\left(L+A_{R_{d}}\right)+E\right] y_{n} \\
\left(L+A_{R_{d}}\right)\left[\left(\frac{\varepsilon_{d_{n}}}{m}\right) y_{n}+\left(1-\varepsilon_{d_{n}}\right) x_{n+I}^{\prime}\right]+\left(R-L-A_{R_{d}}\right) x_{n}^{\prime}=R x_{n} .
\end{gathered}
$$

Certain terms in Equations 26, 27, 28 and 30 will drop out, depending on which phase is discontinuous. If the light phase is discontinuous there will be no $0_{R_{d}}$ terms. If the heavy phase is discontimuous there will be no $A_{R_{u}}$ terms.

\section{The Emulsion Region}

The analysis of the pulse column which has been postulated for operation in the mixer-settler region was based on the assumption that each half-cycle of operation could be divided into two steps. First the dispersing of two unlike phases with the resulting interphase mass transfer and second, the mixing of two like phases of different concentrations. This assurmption seemed plausible because of the separation of phases which occurs at the end of each half-cycle of the pulse generator.

When a pulse colurn operates in the emulsion region, this separation of phases between pulses does not occur and therefore the concept of a two-step process does not appear to fit the physical situation. For this reason a different mechanism must be postulated for emulsion operation. In the emulsion region each half-cycle can be assumed to occur in a single step and equations to describe the operation of the column can be derived from material balances taken from the flow diagram 
shown in Figure 17.

In the emulsion region, the recycled liquid may consist of a mixture of aqueous and organic phases. The total amount of liquid recycled on each half-cycle is $v_{R}$ liters, of which $A_{R}$ liters is aqueous phase and $O_{R}$ Itters is organic phase. Hence $A_{R}+O_{R}=V_{R}$. By a material balance over stage n:

Upstroke:

$$
A_{R} x_{n-1}+\left(R-A_{R}\right) x_{n}+\left(G+O_{R}\right) y_{n-1}+\left(E-G-O_{R}\right) y_{n}=E y_{n}^{\prime}+B x_{n}^{\prime}
$$

Downstroke:

$$
\left(L+A_{R}\right) x_{n+1}^{\prime}+O_{R} y_{n+1}^{\prime}+\left(E-O_{R}\right) y_{n}^{\prime}+\left(R-L-A_{R}\right) x_{n}^{\prime}=E y_{n}+P O x_{n} \quad
$$

By a material balance over the bottom of the column from the contacting portion of the lower end section through stage $n$ :

$$
\left(L+A_{R}\right) x_{n+1}^{\prime}+O_{R} y_{n+1}^{\prime}+G_{S}=I x_{B}^{\prime}+A_{R} x_{n}+\left(G+O_{R}\right) y_{n} .
$$

Similarly, material balances may be written around the top and bottom end-sections. By combining the material balance equations with the equilibrium relations $y=m x$ and $y^{\prime}=m x^{\prime}$ (assuming equilibrium contact) the following two equations can be derived:

$$
\begin{aligned}
& y_{n}=\frac{L+A_{R}+m O_{R}}{R+m E}\left(\frac{m}{\alpha}\right) x_{n+1}^{\prime}+\left(\frac{G y_{s}-I x_{B}^{\prime}}{R+m E}\right)\left(\frac{m}{\alpha}\right) \\
& y_{n}=\left(\frac{m}{I-\alpha}\right) x_{n}^{\prime}-\left(\frac{m \alpha}{I-\alpha}\right) x_{B}
\end{aligned}
$$

where, $\quad \alpha=\frac{m\left(G+O_{R}\right)+A_{R}}{R+m E}$ 

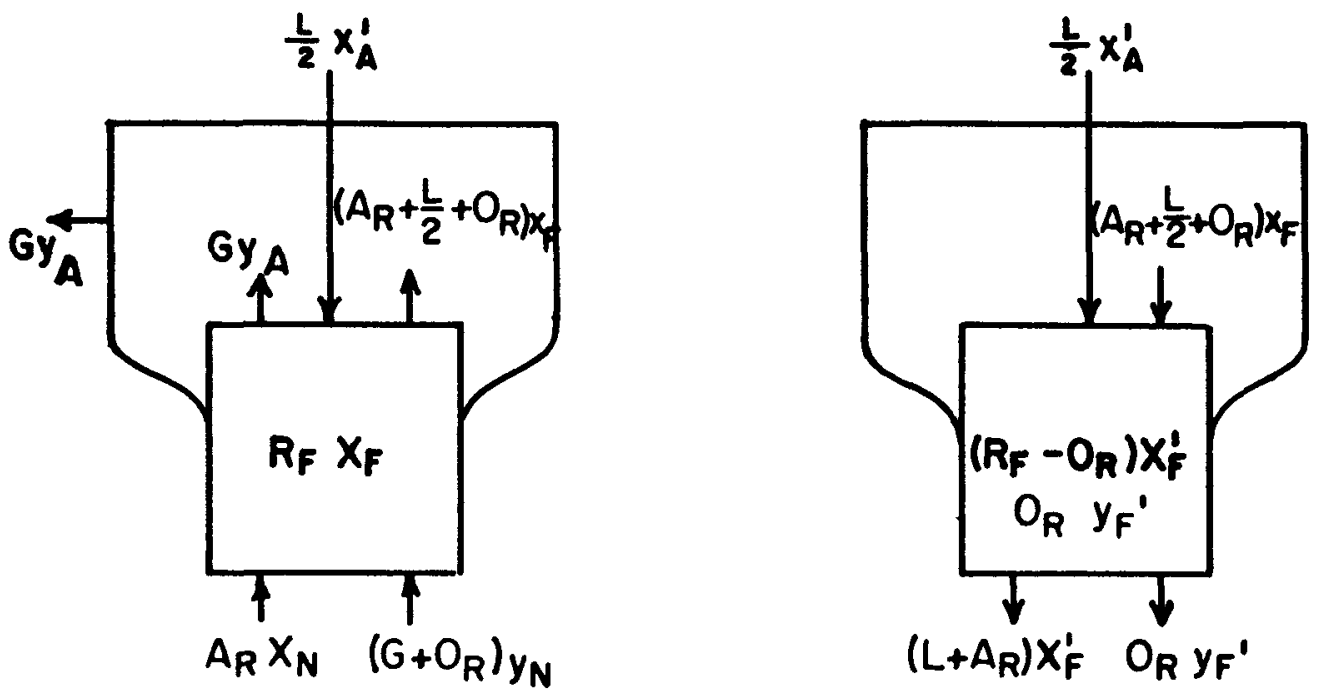

$$
\left(L+A_{R}\right) X_{F}^{\prime} \quad O_{R} y_{F}^{\prime}
$$
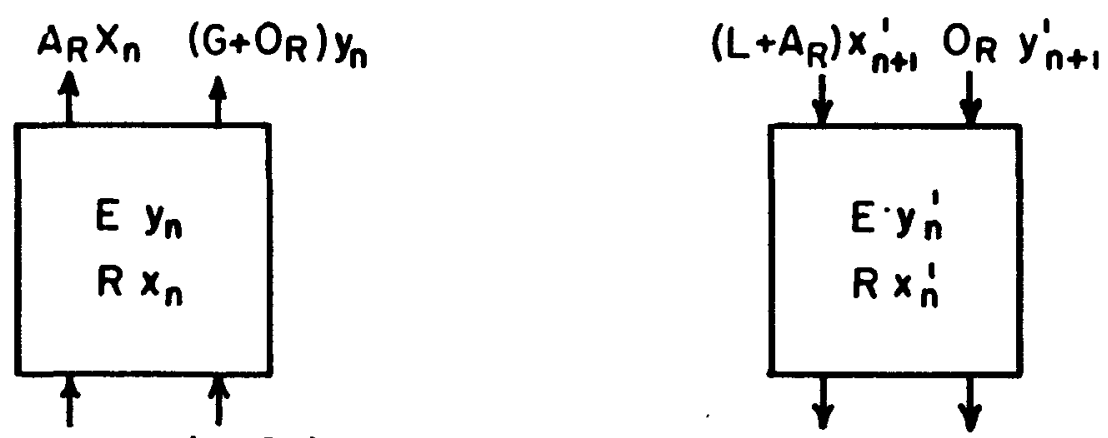

$A_{R} x_{n-1}\left(G+O_{R}\right) y_{n-1}$

$\left(L+A_{R}\right) x_{n}^{\prime} \quad O_{R} y_{n}^{\prime}$
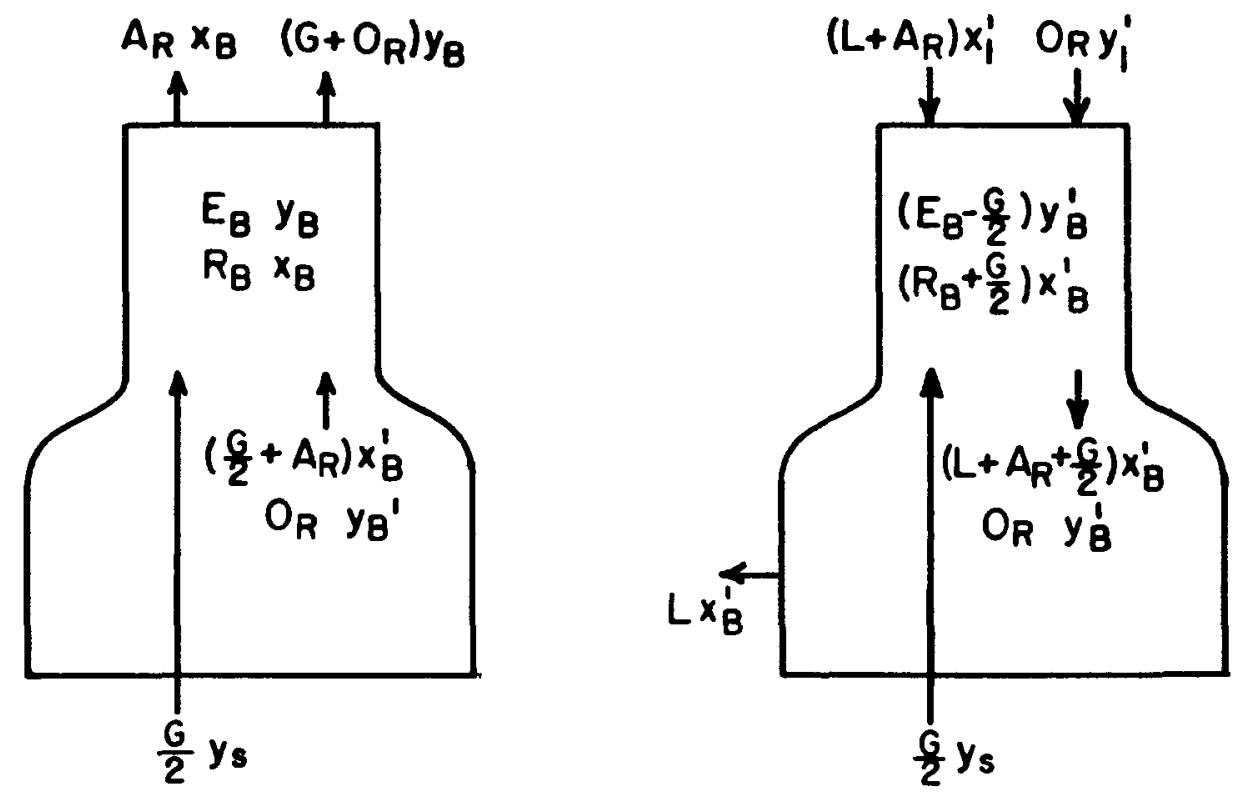

Figure 17. Distribution of phases in a pulse column operating in the emulsion region. 


$$
x_{B}=\left[\frac{R_{B}-A_{R}+m\left(E_{B}-\frac{G}{2}-O_{R}\right)}{R_{B}-A_{R}+m\left(E_{B}-G-O_{R}\right)}\right] x_{B}^{\prime}-\left[\frac{G / 2 y_{s}}{R_{B}-A_{R}+m\left(E_{B}-G-O_{R}\right)}\right] \text {, }
$$

At the top of the column:

$$
x_{F}^{\prime}=\frac{G y_{S}-L x_{B}^{\prime}}{m G}+\left[\frac{L}{m G}-\frac{L}{2\left(R_{F}-V_{R}-L\right)}\right] x_{A}^{\prime} .
$$

These equations may be used for stage-to-stage calculations starting from the bottom of the column. If these two equations are combined to form a finite difference equation, the solution of the equation with the boundary condition $x_{n}^{\prime}=x_{F}^{\prime}$ when $n=N+1$ yields a relation which can be used to determine the number of theoretical stages necessary to perform a given separation:

$$
x_{F}^{\prime}=x_{1}^{\prime} a^{-N}+K\left(1-a^{-N}\right)
$$

where,

$$
\begin{aligned}
a & =\left(\frac{\alpha}{1-\alpha}\right)\left(\frac{R+m E}{I+A_{R}+m o_{R}}\right) \\
\therefore \quad x & =\frac{\alpha^{2} x_{B}(R+m E)+(I-\alpha)\left(C_{y}-L x_{B}^{\prime}\right)}{\alpha(R+m E)-(I-\alpha)\left(I+A_{R}+m O_{R}\right)}
\end{aligned}
$$

The values of $x_{1}^{\prime}$ and $x_{A}^{\prime}$ must be determined from material balances over the end sections of the column.

Although equilibrium contact has been assumed in this analysis, the equation can be used to show the effect of the phase composition of the recycled liquid on the operation of the pulse column. Consider the following problem. 
A 3-In. dia. pulse column has 5 stages, each 3-in. high. Boric acid is to be extracted from water by using pure isoanyl alcohol (saturated with water) as solvent. The flow rate of the feed is to be 0.500 liter/min. and the flow rate of the solvent is to be 1.500 liters $/ \mathrm{min}$. The equation of the equilibrium line is $\mathrm{y}=0.291 \mathrm{x}$ in terms of millimols/ liter. Pulse amplitude will be $I$ in. and pulse frequency wlll be $50 \mathrm{cpm}$. Assume that the organic phase hold-up is 0.100 liter/stage for all stages. What must be the concentration of the aqueous feed if the raffinate from the column is to contain not more than 25 milimols of boric acid per liter and if:

(1) recycle is all aqueous phase

(2) recycle is $75 \%$ aqueous and $25 \%$ organic

(3) recycle is $50 \%$ aqueous and $50 \%$ organic

(4) recycle is $25 \%$ aqueous and $75 \%$ organic

(5) recycle is all organic phase?

The solution to the problem is shown in Figure 18, where the necessary feed concentration is given as a function of the per cent of organic phase in the recycled liquid. The presence of recycle causes a decrease In the separation which would be possible if no recycle existed. However, this recycling of liquid cannot be avoided in the pulse column unless it is operated at the lower flooding point.

If the two phases in each stage separated completely between pulses then, assuming the principal interface to be at the top of the column, all of the recycle would consist of aqueous phase. In the emulsion region, the organic phase does not rise to the top of the stage at the end of an upstroke, nor does all the aqueous phase settle to the bottom of the stage 


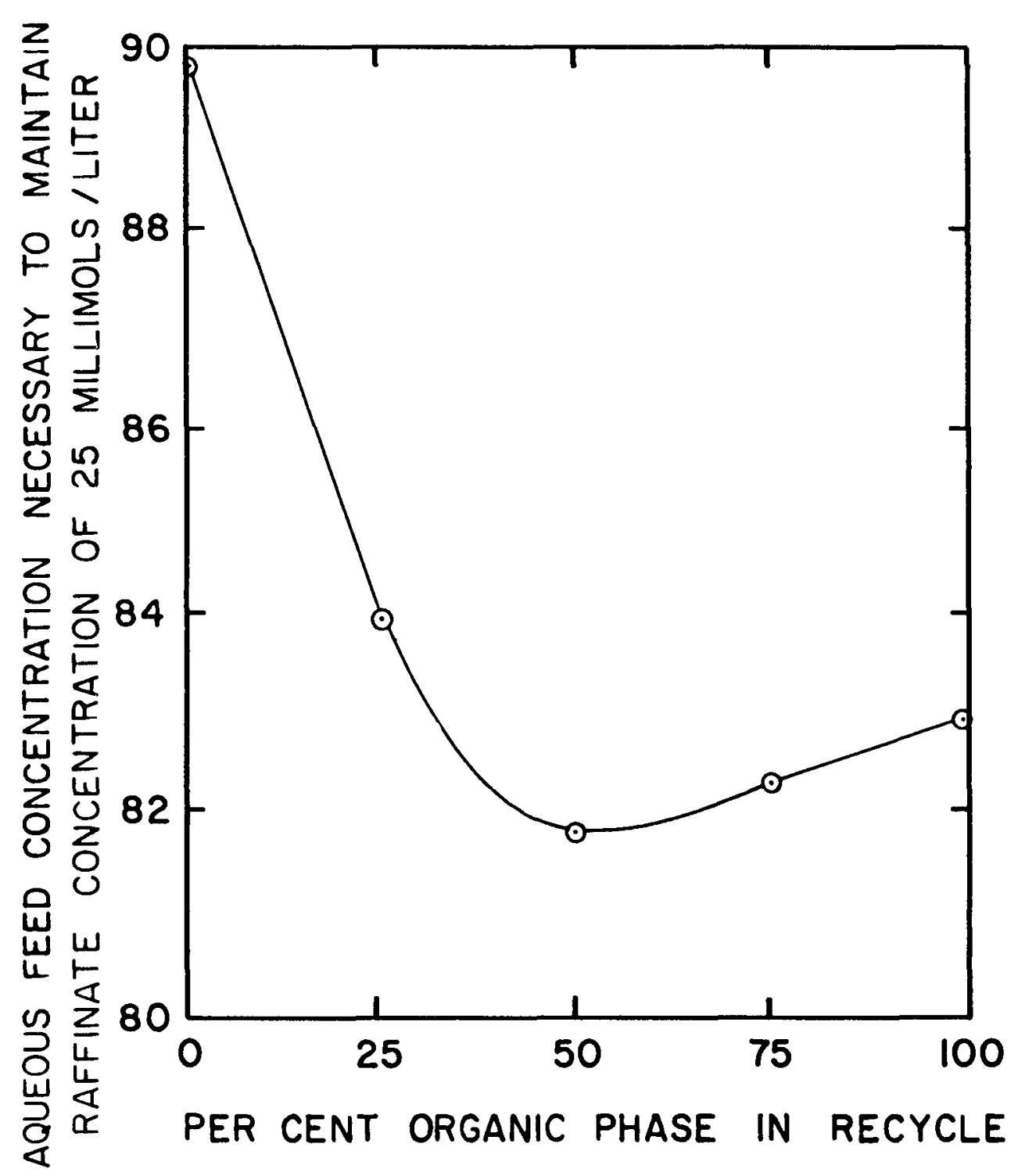

Figure 18. Change in required feed concentration as a function of the per cent organic phase in the recycle. 
at the end of a downstroke. Hence, in the emulsion region the recycle consists of a mixture of both phases. The amount of each phase in the recycle will be a function of the physical properties which affect the degree of dispersion.

From the results shown in Figure 18, organic phase recycle appears to be more harmful than aqueous phase recycle. The variation in aqueous phase concentration through the column for each case is shown in Figure 19. Graphical solutions for parts $I$ and 5 are shown in Figures 20 and 21. Although the equilibrium line obtained from shake-up data for the system is used in deriving the equations which have been developed, its role in the graphical solution of the problem is completely different from the role which the equilibrium line plays in the graphical solution of a problem involving either a simple cocurrent or countercurrent extractor.

If the problems shown in Figures 20 and 21 had been solved for the number of theoretical stages using only the end compositions and the method which applies to a countercurrent extractor, then the stages would have been stepped off between the over-all operating line and the equilibrium line. This latter method of calculation would have given considerably different answers.

The graphical solutions given in Figures 20 and 21 show that it is theoretically possible for a pulse column to be operating in a pinched-in region even though this is not indicated by the ratio of the superficial flow rates to the column. The phase composition of the recycled liquid in the column alters the actual flow rate ratio which exists within the column and hence a change in this ratio would cause a change in the slope of the over-all operating line. 


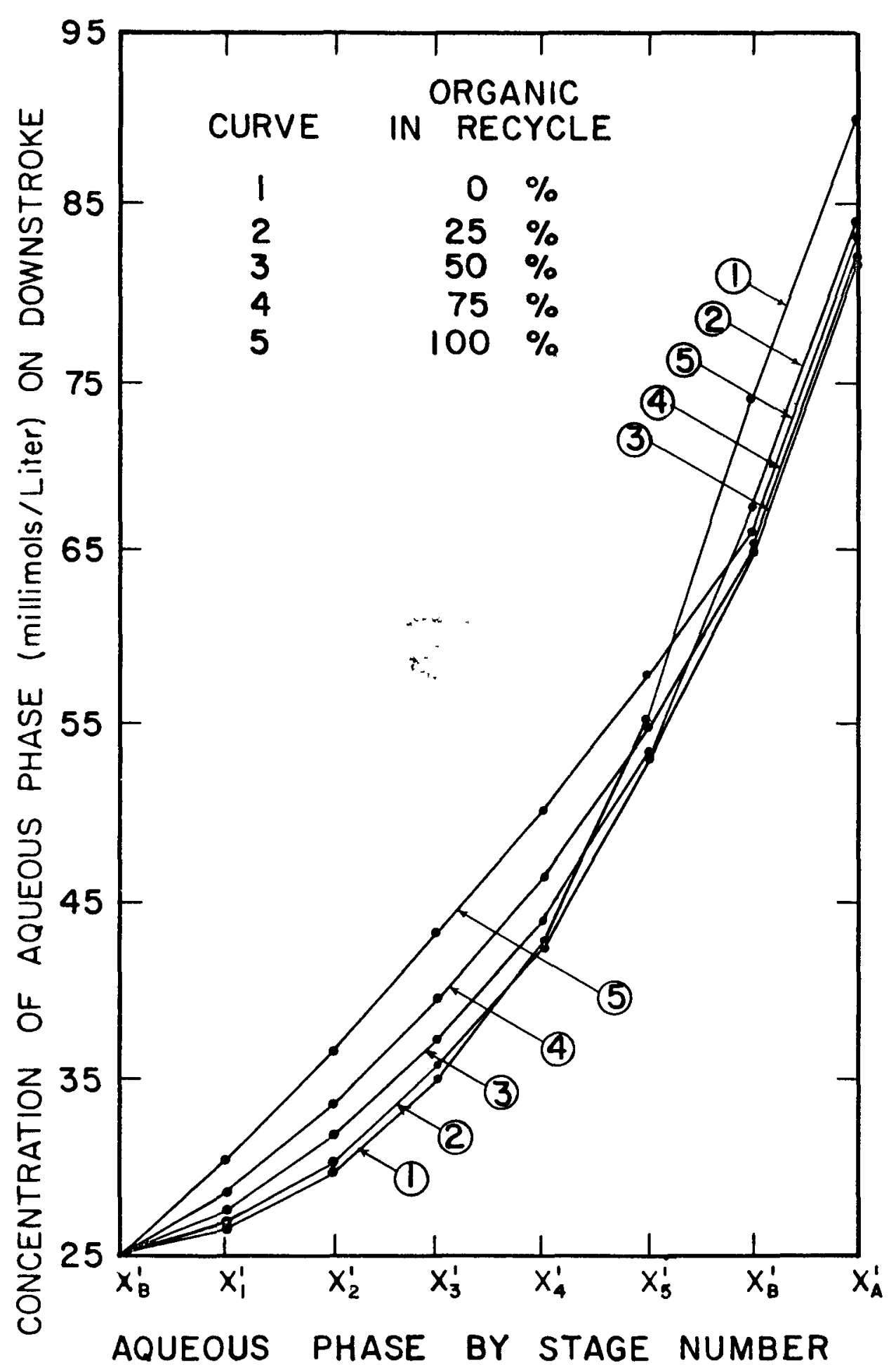

Figure 19. Change in aqueous phase concentration through the column with a change in per cent organic phase in the recycle. 


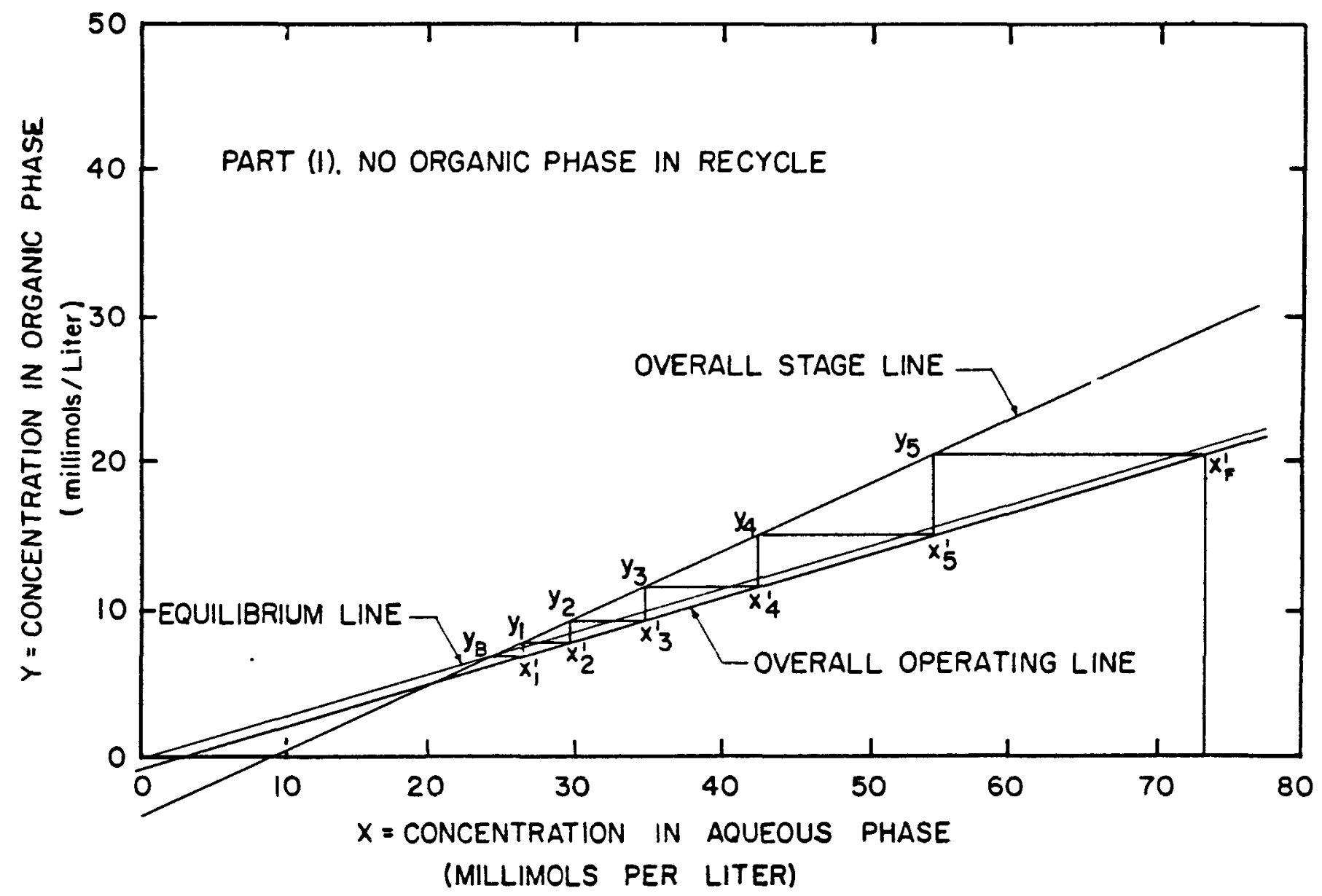

Figure 20. Graphical solution to problem of pulse column operating in the emulsion region; recycle is all aqueous phase. 


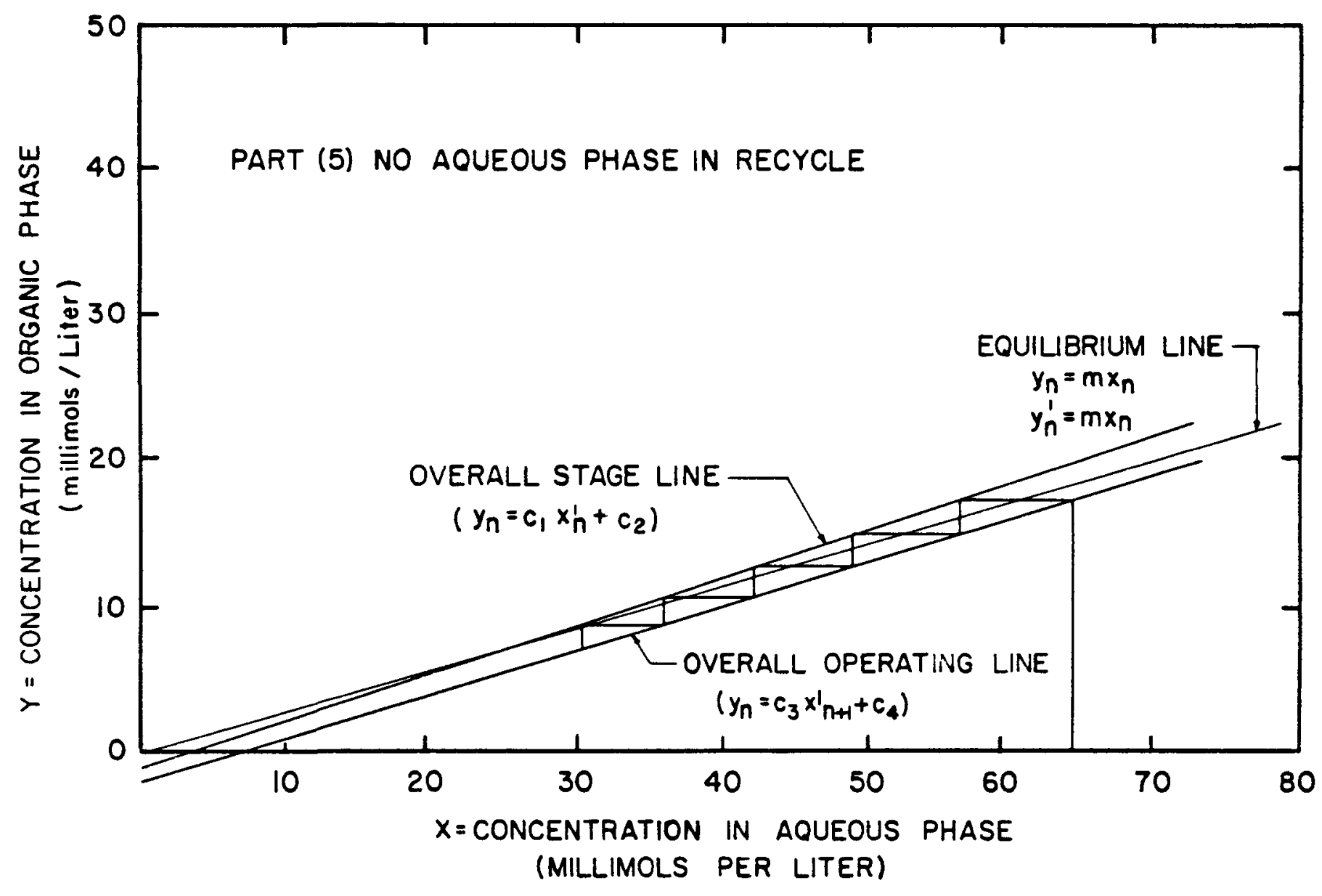

Figure 21. Craphical solution to problem of pulse column operating in the emulsion region; recycle is all organic phase. 
Before proceeding further with the theory it is necessary to describe the equipment which has been designed and the measuring and sampling techniques which were developed to carry out the experimental phase of the program. An over-all flow diagram of the equipment is shown in Figure 22. A photograph of the equipment is shown in Figure 23. The specifications of the pulse column are:

diameter - 3 inches

plate spacing - 3 inches

plate materials - alumimum and type 304 stainless steel

hole diameters $-0.0625 \mathrm{in}$. and $0.040 \mathrm{in}$.

number of stages - variable, up to 14

frequency $\dot{\text { range }}-13$ to 120 cycles per minute

amplitude range - 0 to 4 inches/cycle .

The column was constmucted of short glass sections. The perforated plates were sandwiched between polyethylene gaskets and the entire assembly was held together in compression by four tie rods extending the length of the column.

Aqueous and organic phases were fed to the column by Eastern Model D-II centrifugal purmps and metered by rotameters. The principal interface was controlled by a valve in the aqueous effluent line unless the pulse generator caused excessive pulsation of the raffinate stream. In the latter case the raffinate was drawn from the column by a centrifugal pump and metered by a rotameter in the raffinate line. The pulse generator consisted of a 6-in. dia. stainless steel bellows driven by a variable speed drive through the gear box from a Lapp Pulsafeeder. The pulse was 


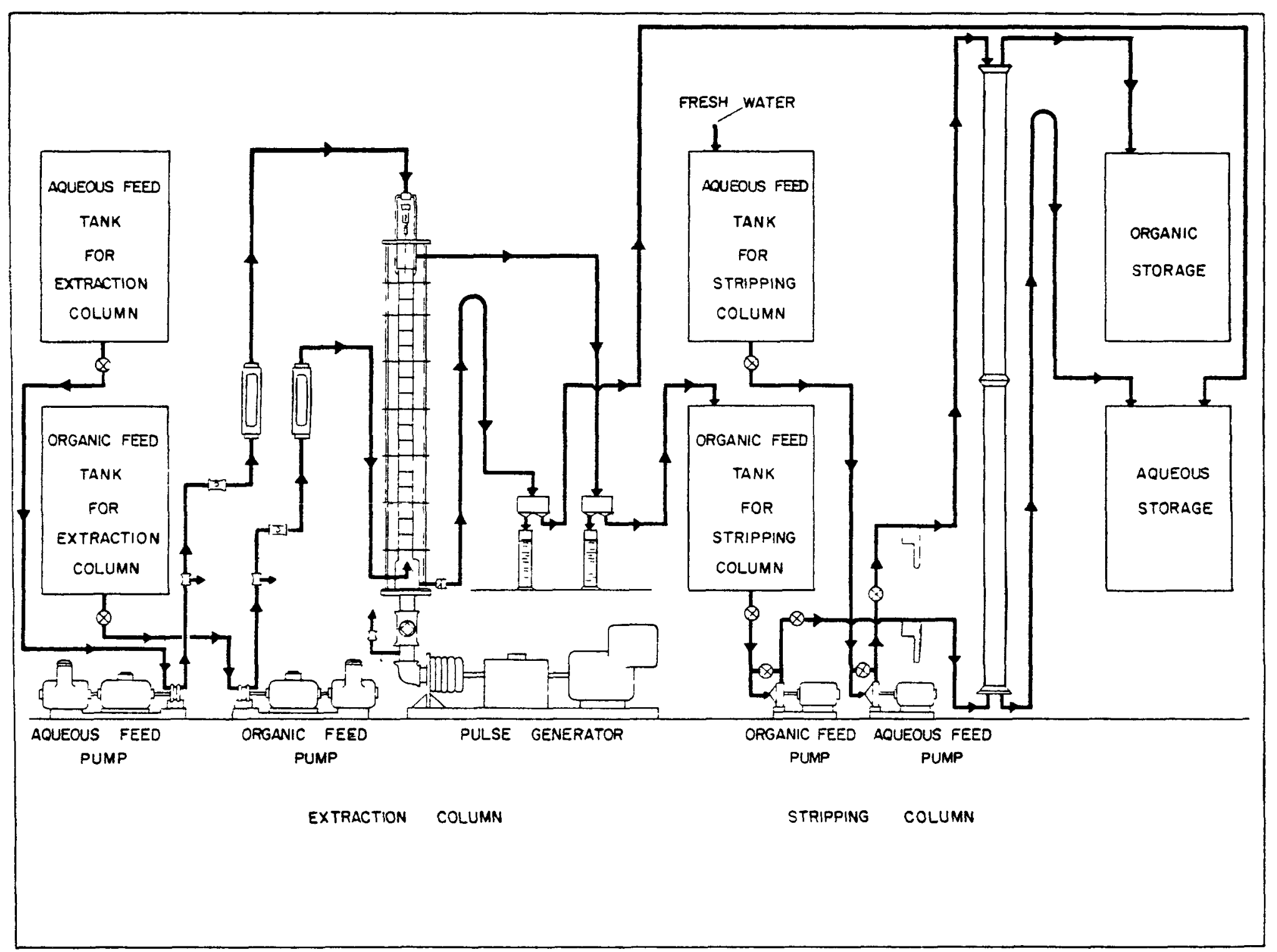

Figure 22. Flow diagram of the pulse column and associated equipment. 


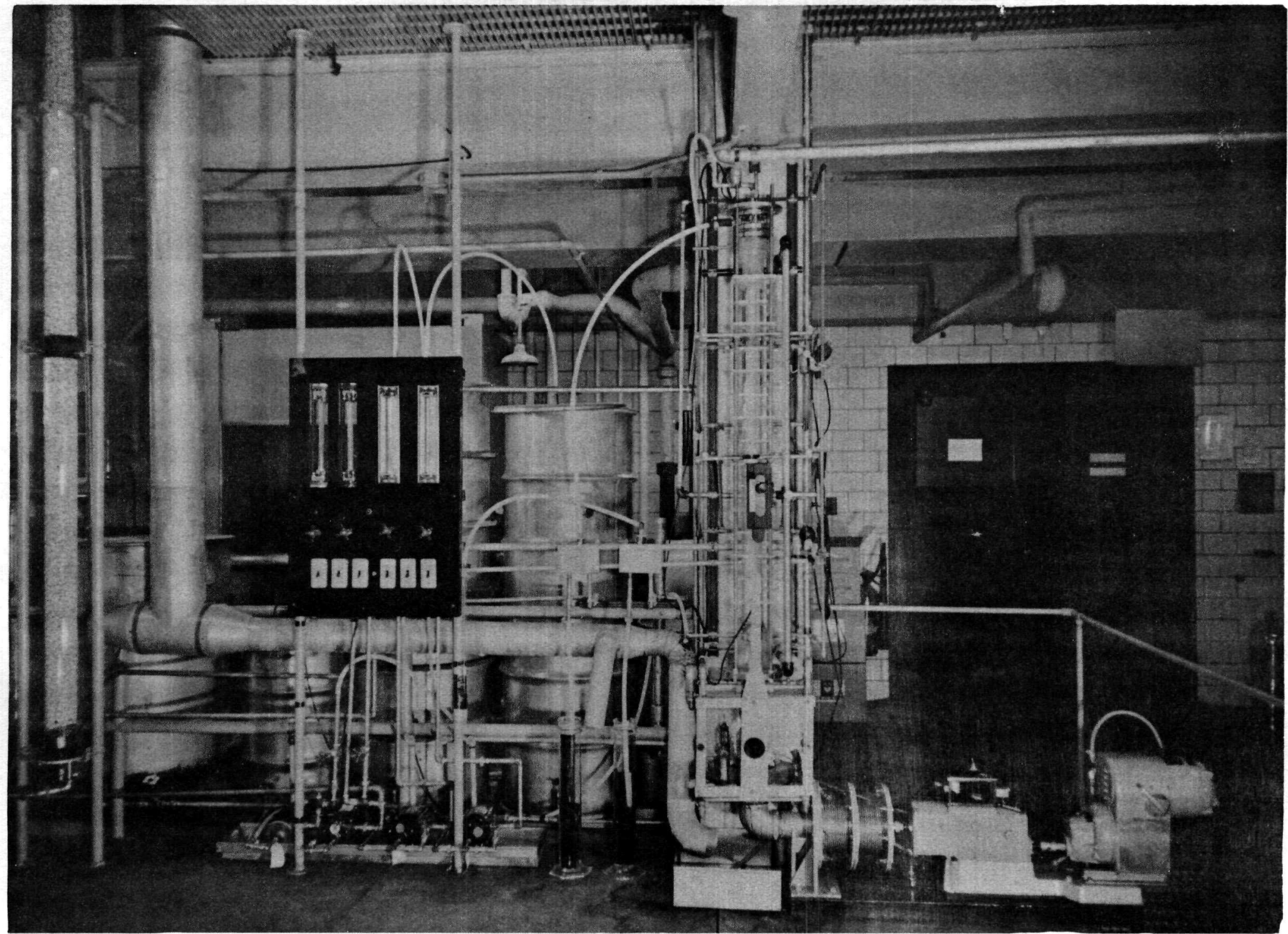

Figure 23. Photograph of the pulse column and associated equipment. 
simusoidal.

A packed tower was used as a stripping column to recover solute and solvent. The tower was ten feet high, four inches in diameter, and packed with $\frac{1}{4}$-in. berl saddles. No data were taken on the stripping column.

The arrangement used for measuring hold-up in the pulse column is shown in Figure 24. By stopping all flow instantaneously, its contents were "frozen" at the end of an upstroke or a dormstroke of the pulse generator. 'This was accomplished by installing a cock valve in each feed line and one betiveen the column and the pulse generator, then providing a control lever with which all three valves could be closed at the same time. A solenoid valve in the raffinate line was turned off at the same time the control lever was moved. Pressure relief valves were installed in the pulse line and in each feed line as a protective measure.

The control lever was operated at the end of an upstroke or a downstroke of the pulse generator, closing the three cock valves and shutting off all flow to the column. The holes in the perforated plates were so small that no liquid flowed between the stages when the column was shut down, so the two phases separated and formed a single interface in each stage. By means of a short-range telescope mounted on a vertical scale, the depth of the discontinuous phase layer could be measured.

Stage efficiencies were determined by direct measurement of the concentration of interstage flow streams. The technique used for obtaining samples of the interstage flow streans is illustrated in Figure 25. A curved needle made from $1 / 16$-in. stainless steel tubing was inserted through self-sealing rubber ampules in each stage of the column. The tip of the needle was machined so that it fit through one of the holes in the 


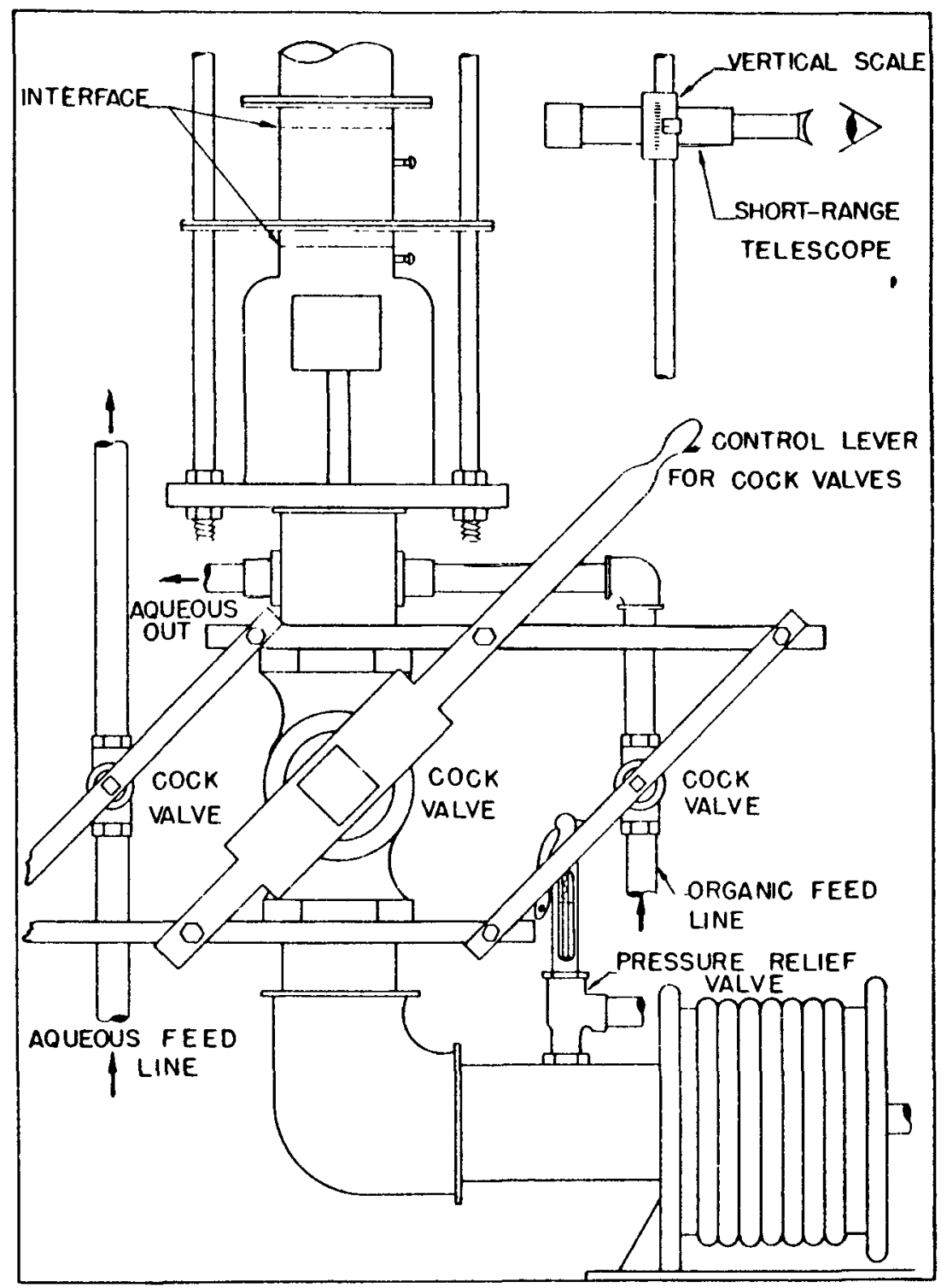

Figure 24. Technique for measuring hold-up. 


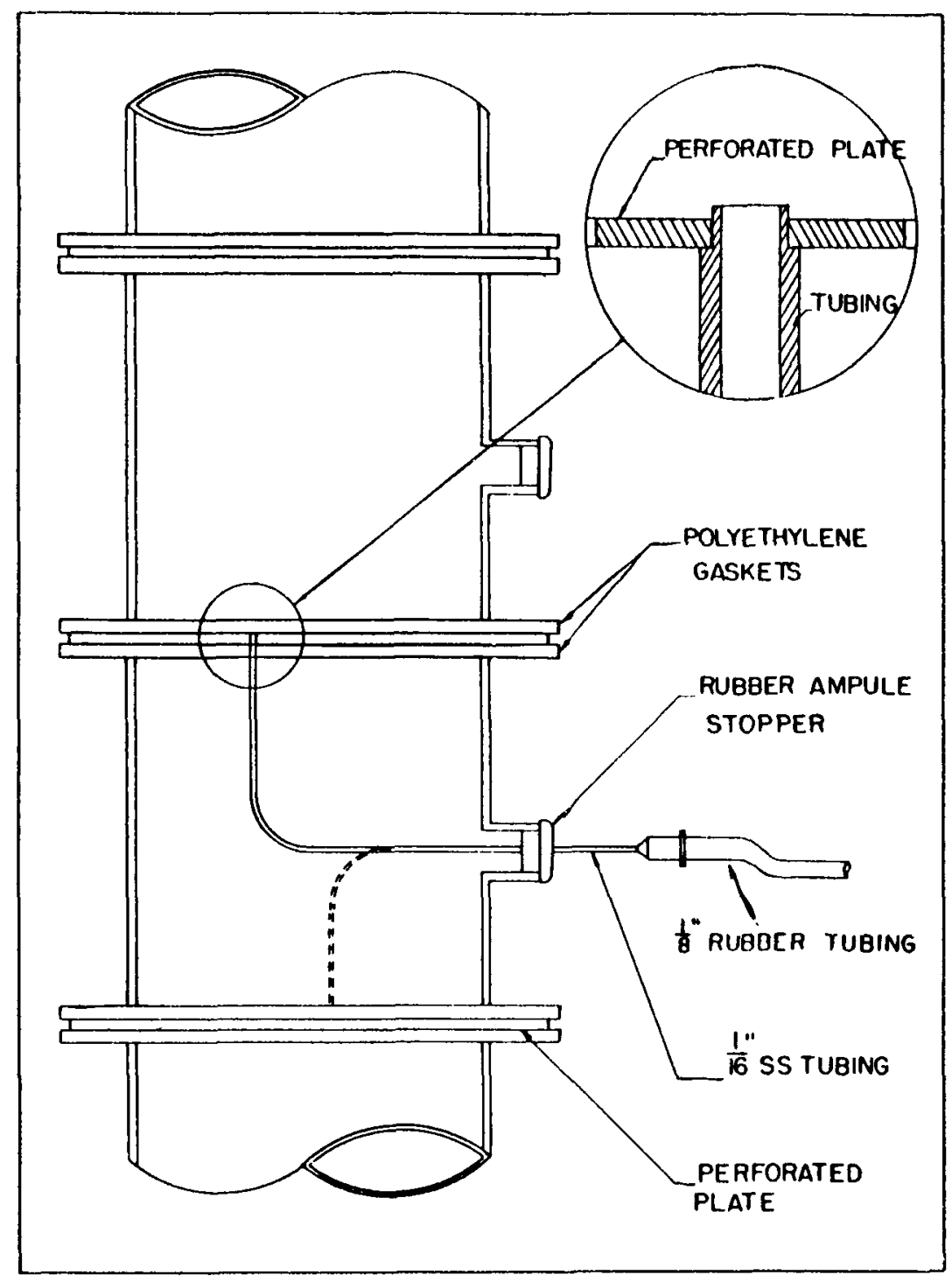

Figure 25. Method of obtaining samples of the interstage flow streams. 
perforated plate.

A modified solenoid valve was used to allow the sample to flow out at the proper time. The valve was controlled by two micro-switches located on the pulse generator. These micro-switches operated a latching relay which turned the valve on and off at the beginning and end of the desired half-cycle. The solenoid valve could also be hand-operated by disabling the micro-switches. A diagram of the modified solenoid valve and its control circuit is show in Figure 26. The resulting valve had a much smaller liquid hold-up. The sample was pulled under a slight vacuum created by the squeeze bulb attached to the collecting bottle. Using this technique, a sample of the interstage flow stream could be taken as it left one stage but before it had reached the next stage. Both upstroke and downstroke samples could be taken. A photograph of the samples is shown in Figure 27.

The recycled liquid consists entirely of the continuous phase as long as only one phase passes through the plate on one half-cycle. For example, with the light phase discontimuous the recycle on both halfcycles consists only of heavy phase so long as no light phase is pulled back through a plate on the downstroke of the pulse generator. However, In the emulsion region, a two-phase mixture passes through the plates on each half-cycle and the phase composition of the recycle is not known. In order to use the theory proposed for a pulse column operating in the emulsion region the phase composition of the recycled liquid must be known.

By using the sampler described above, a sample of the liquid entering a stage could be drawn off. If the column was operating in the emulsion 


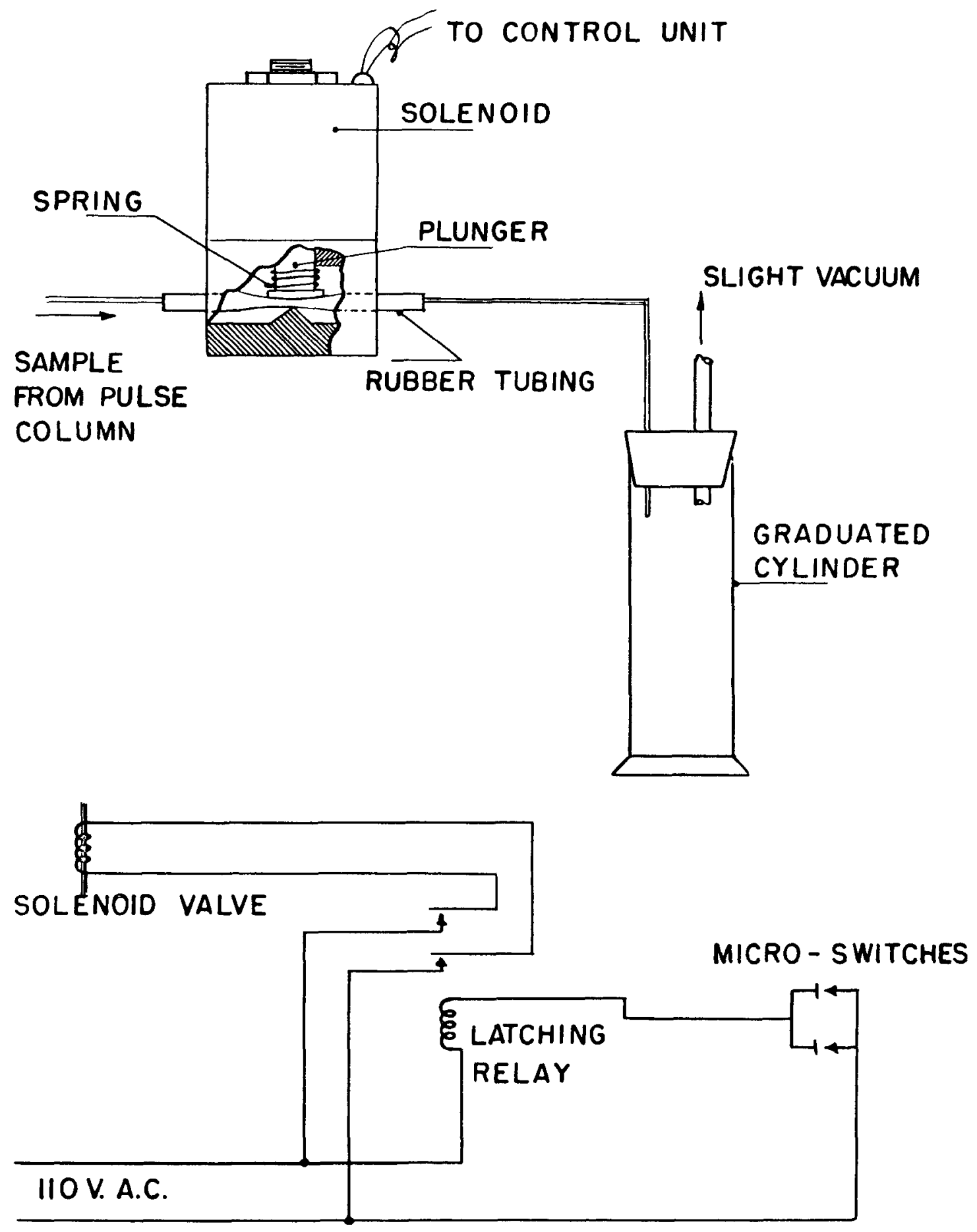

Figure 26. Diagram of modified solenoid valve and control circuit used in sampling interstage flow streams. 
region, this sample consisted of two phases. The ratio, $\xi$, of the two phases in the sample was used to find the phase composition of the entering fluid. For a downstroke of the pulse generator:

$$
\begin{gathered}
T=I+V_{R_{d}} \text { where } T=\text { total volume of liquid entering the } \\
\text { stage per half-cycle. }
\end{gathered}
$$

Since the recycled liquid consists of two-phases:

$$
V_{R}=A_{R_{d}}+O_{R_{d}}
$$

Now:

$$
T=L+A_{R_{d}}+O_{R_{d}}
$$

Rearranging,

$$
\frac{T}{0_{R_{d}}}=\left(\frac{I+A_{R_{d}}}{0_{R_{d}}}\right)+1
$$

but the first term on the right is $\xi$, the aqueous to organic ratio so:

$$
\mathrm{T}=o_{\mathrm{R}_{\mathrm{d}}}(1+\xi)
$$

and,

$$
O_{R_{d}}=\frac{T}{I+\xi}
$$

then,

$$
A_{R}=v_{R}-o_{R}=\frac{\xi v_{R}-L}{1+\xi} .
$$

The quantity $V_{R}$ was calculated from Edwards' equation, $L$ was known, and 
61
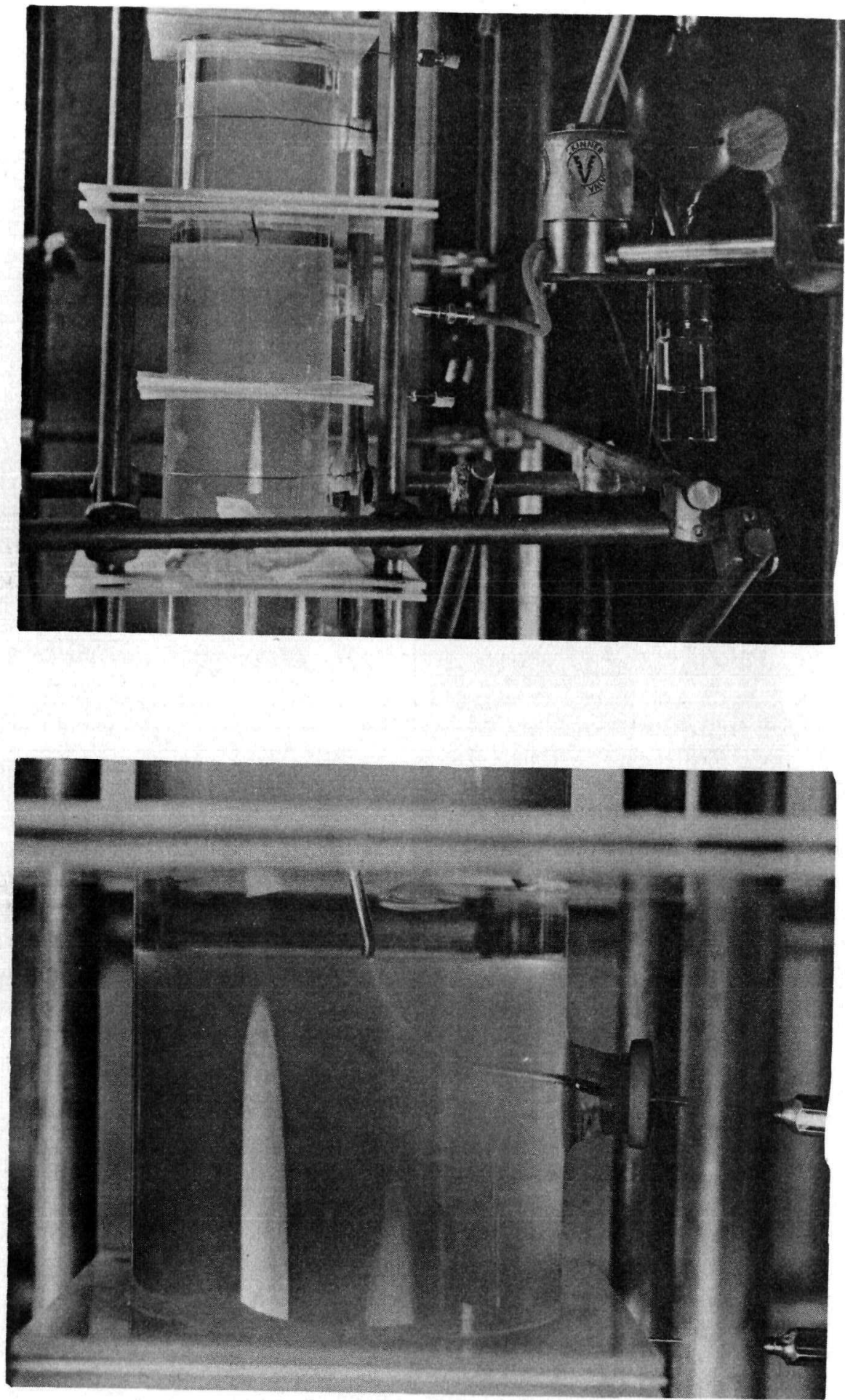

Figure 27. Photographs of automatic sampling equipment. 
$\zeta$ measured experimentally.

Packed needles were used to obtain individual phase samples from the emulsion. Needles for taking an aqueous phase sample were packed with 60-80 mesh aluminum powder until about the $\frac{1}{2}$ in. of the tip end of the needle had been filled. Since the water phase strongly wet the aluminum, only water flowed through the interstices of the packing. Needles for taking a solvent phase sample were prepared the same way except that they were dipped in a solution of polyethylene dissolved in hot xylene then baked under an infrared lamp to remove the solvent, leaving a thin plastic film over the needle and the packing. The polyethylene was preferentially wet by the organic phase and only organic phase flowed through the interstices of the polyethylene coated packing.

A single phase sample was taken through a packed needle and a two phase sample was taken through a hollow needle. With such samples the concentration of each phase in the column at the point of sampling may be found by a material balance. 
EXPERDMENTAI RESULTS

Hold-up Studies

Two systems, isoamyl alcohol-water and methyl isobutyl ketone-water, were used to study hold-up in the pulse column. The physical properties of these systems are given in Table 1.

Table 1. Physical properties of two-phase systems (mutually saturated) used in hold-up studies

\begin{tabular}{|c|c|c|c|}
\hline System & $\begin{array}{l}\text { Density } \\
\left(\mathrm{gm} / \mathrm{cm}_{0}{ }^{3}\right)\end{array}$ & $\begin{array}{c}\text { Viscosity } \\
\text { (centipoises) }\end{array}$ & $\begin{array}{l}\text { Interfacial } \\
\text { tension } \\
\text { (dymes/cm.) }\end{array}$ \\
\hline $\begin{array}{l}\text { Isoamyl alcohol } \\
\text { Water }\end{array}$ & $\begin{array}{l}0.814 \\
0.99\end{array}$ & $\begin{array}{l}3.9 \\
1.0\end{array}$ & 5.9 \\
\hline $\begin{array}{l}\text { Methyl isobutyl ketone } \\
\text { Water }\end{array}$ & $\begin{array}{l}0.802 \\
1.00\end{array}$ & $\begin{array}{l}0.59 \\
1.0\end{array}$ & 10.2 \\
\hline
\end{tabular}

The results of the hold-up studies showed that these systems exhibited very different behavior in the pulse column.

The isoamyl alcohol - water system

A series of runs was made near the lower flooding point to see if the hold-up of the discontinuous phase was numerically equal to the interstage flow rate, per cycle, of the discontinuous phase. A six-stage column was used with stainless steel plates perforated to $23 \%$ free area with $1 / 16-i n$. holes. Water was made the discontinuous phase because the 
water phase did not leak through the holes in the perforated plates when the column was shut off. Thus, the height of the water layer could be read with a traveling microscope after all flow to and from the column had been stopped. The results given in Table 2 show that in the irmediate vicinity of the lower flooding point, the hold-up per stage was equal to the interstage flow, per cycle, of the water phase. For these conditions, the pulse frequency at the lower flooding point was 16.06 cycles/min. so the above relationship held over the range $16.06 \mathrm{cpm}$. to approximately $25 \mathrm{cpm}$.

The hold-up per stage decreased with increasing pulse frequency above the lower flooding point. The hold-up was essentially constant from stage to stage up to a pulse frequency of about $35 \mathrm{cpm}$. Above $35 \mathrm{cpm}$. the hold-up increased with stage number down the column. At higher frequencies the maximan hold-up occurred consistently in stage number four. The total hold-up of discontinuous phase also exhibited a minimum point as the pulse frequency increased above the lower flooding limit. This is shown in Figure 28.

If the flow rate of the discontinuous phase is too high, then the hold-up per stage may not be equal to the interstage flow at the lower flooding point, as shorm in Table 3. In this run the flow rate of the discontinuous phase was increased from $780 \mathrm{ml} / \mathrm{min}$. to $1380 \mathrm{ml} . / \mathrm{min}$. All other conditions remained the same. The pulse frequency at the lower flooding point at the new flow rate is $25 \mathrm{cpm}$. and the run in Table 3 was made at a pulse frequency of $25.10 \mathrm{cpm}$. If the pulse frequency is too low, the discontinuous phase may flow through more than one plate per half cycle and the hold-up per stage may be less than the interstage flow. An 
Table 2. Hold-up measurements on a six-stage pulse column

System: Isoanyl alcohol-water

Discontimuous phase: Water

Pulse amplitude: $\frac{1}{2}$ in.
Water flow rate: $780 \mathrm{ml} . / \mathrm{min}$. Solvent flow rate: $730 \mathrm{ml} / \mathrm{min}$.

\begin{tabular}{|c|c|c|c|c|c|c|c|c|c|}
\hline $\begin{array}{c}\text { Pulse } \\
\text { frequency }\end{array}$ & 17.86 & 19.29 & 20.10 & 30.31 & 39.22 & 50.21 & 59.41 & 70.00 & 78.95 \\
\hline \multicolumn{10}{|l|}{ Stage number } \\
\hline 1 & 42.25 & 40.32 & 36.88 & 31.02 & 26.00 & 20.68 & 17.02 & 21.24 & 24.99 \\
\hline 2 & 42.87 & 40.36 & 34.88 & 29.68 & 25.72 & 26.70 & 28.95 & 31.33 & 32.78 \\
\hline 3 & 43.35 & 40.98 & 38.76 & 29.39 & 27.01 & 35.00 & 37.01 & 40.77 & 49.30 \\
\hline 4 & 42.37 & 40.30 & 37.89 & 31.50 & 30.97 & 40.83 & 45.04 & 48.84 & 55.31 \\
\hline 5 & 41.13 & 38.20 & 38.76 & 29.60 & 29.37 & 36.46 & 39.98 & 42.06 & 48.20 \\
\hline 6 & 41.68 & 38.12 & 35.60 & 29.71 & 31.90 & 39.72 & 42.54 & 46.62 & 53.20 \\
\hline Total & 253.65 & 238.28 & 222.77 & 180.90 & 170.97 & 199.39 & 210.54 & 230.36 & 263.58 \\
\hline $\begin{array}{l}\text { Theoretical } \\
\text { value }\left(I_{s} / f\right)\end{array}$ & 43.64 & 40.49 & 38.99 & 26.10 & 20.32 & 16.03 & 13.17 & 17.34 & 9.96 \\
\hline
\end{tabular}




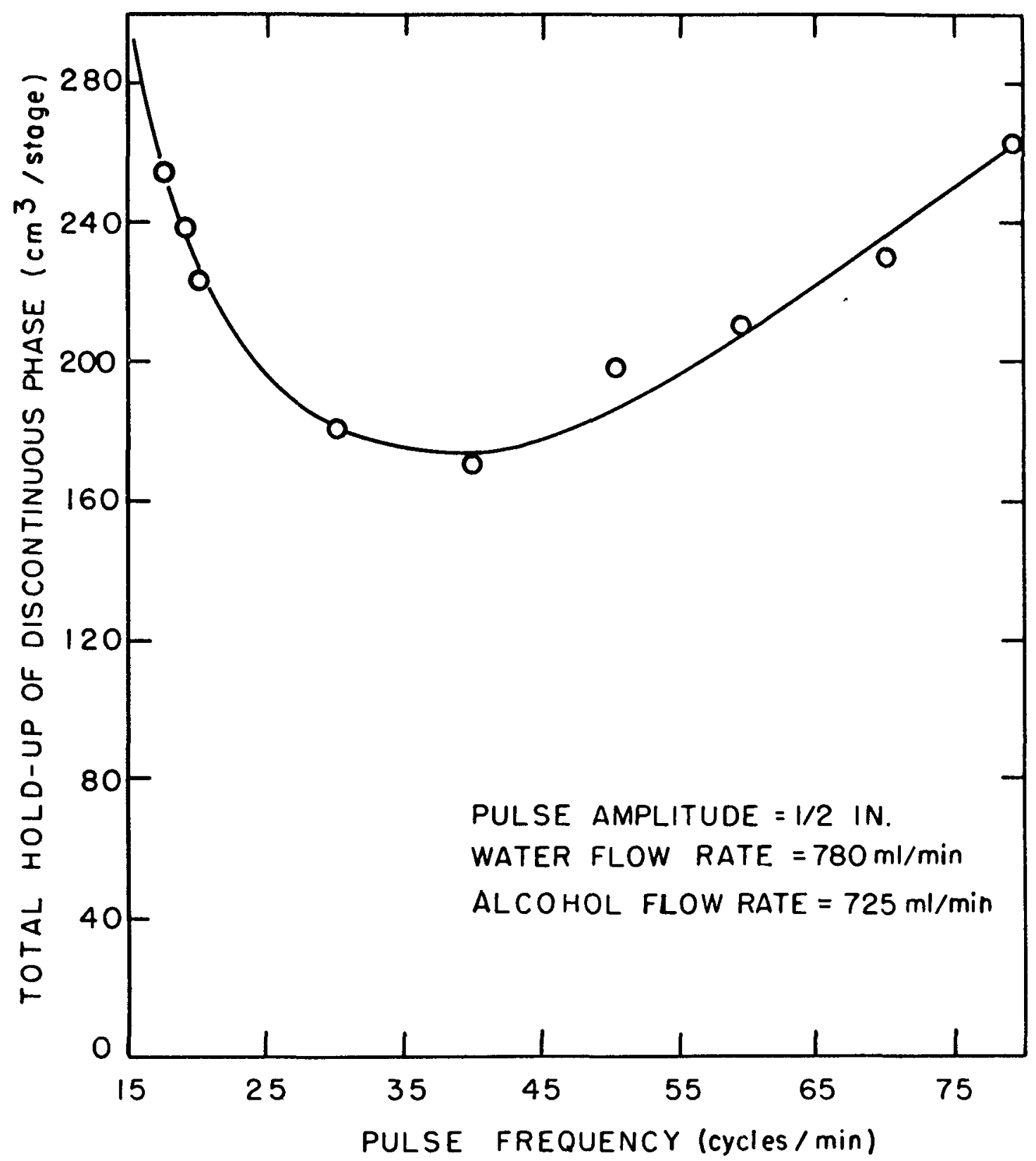

Figure 28. Total hold-up of discontimuous water phase for the isoamyl. alcohol-water system in a six-stage pulse column. 
Table 3. Hold-up measurement on a six-stage pulse column at a water flow rate of $1380 \mathrm{ml} . / \mathrm{min}$. and pulse frequency of 25.10 cycles/min.

\begin{tabular}{cc}
\hline Stage number & Hold-up $(\mathrm{cm} .3 /$ stage $)$ \\
\hline 1 & 57.74 \\
2 & 60.15 \\
3 & 60.93 \\
4 & 61.33 \\
5 & 61.54 \\
6 & 62.17 \\
Theoretical & 54.98 \\
value $\left(I_{s} / f\right)$ & \\
\hline
\end{tabular}

example of this will be shown later (Figure 34).

Since the solvent phase preferentially wets the plates, good dispersion of water into solvent was obtained but the dispersion of solvent into water on an upstroke of the pulse generator was very poor. In fact. no dispersion at all was obtained. The solvent phase passed through the water layer in rivulets and very little interfacial area between the two phases existed during the upstroke.

In order to produce good dispersion in both directions, the tops of the perforated plates were mechanically polished to a high luster. As originally purchased, these plates had a 2-B finish. The 2-B finish is a 
chenically etched surface which has been lightly rolled after etching to produce a satin appearance. It is the smoothest mill finish which can be obtained without mechanical polishing. Thus, the plates which had been mechanically polished on the top were essentially dual plates with a smooth, bright surface on top and an etched, satin surface on the bottom. When viewed under a three-dimensional microscope, the plates had strikingly different surfaces on top and bottom. The top of the plate was preferentially wet by the water phase and the bottom of the plate was preferentially wet by the solvent phase.

The polished plates produced good dispersion in both directions. It was also possible, using the plates, to make the solvent phase discontinuous and measure hold-up. The solvent phase did not leak through the holes in the plates after the colurn had been shut down. However, no hold-up data were recorded because the polished surfaces were not uniform from plate to plate. This effect could be avoided by having a uniform polished surface (No. 4 finish) put on one side of the sheet before it was perforated instead of trying to reproduce a polished surface on each plate by hand.

Plates with the original 2-B finish were again installed in the column and the number of stages increased to 14 to study the effect of column length on hold-up. A $\frac{1}{2}$-in. pulse amplitude was used again. The flow rates were one liter per minute for each phase. The water phase was discontinuous (interface at bottcm of column). Experimental data for this series are Iisted in the Appendix. These muns are plotted in Figures 29 and 30. The hold-up per stage decreased with increasing pulse frequency up to 30 cycles/min. then began to increase. At 37.5 cycles/min. a sharp 


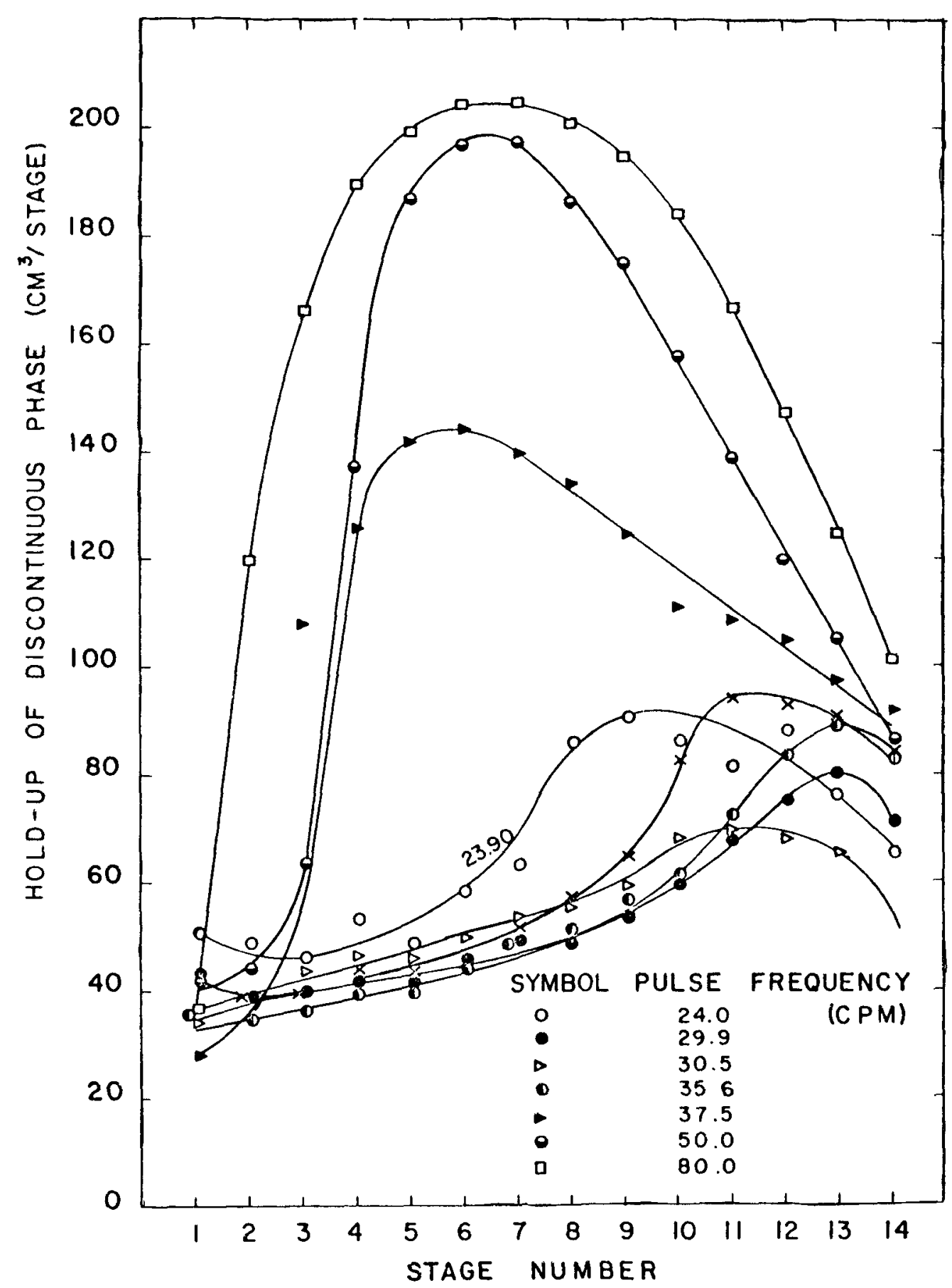

Figure 29. Hold-up of discontinuous water phase for the isoamyl alcohol-water system in a fourteen-stage pulse column. 


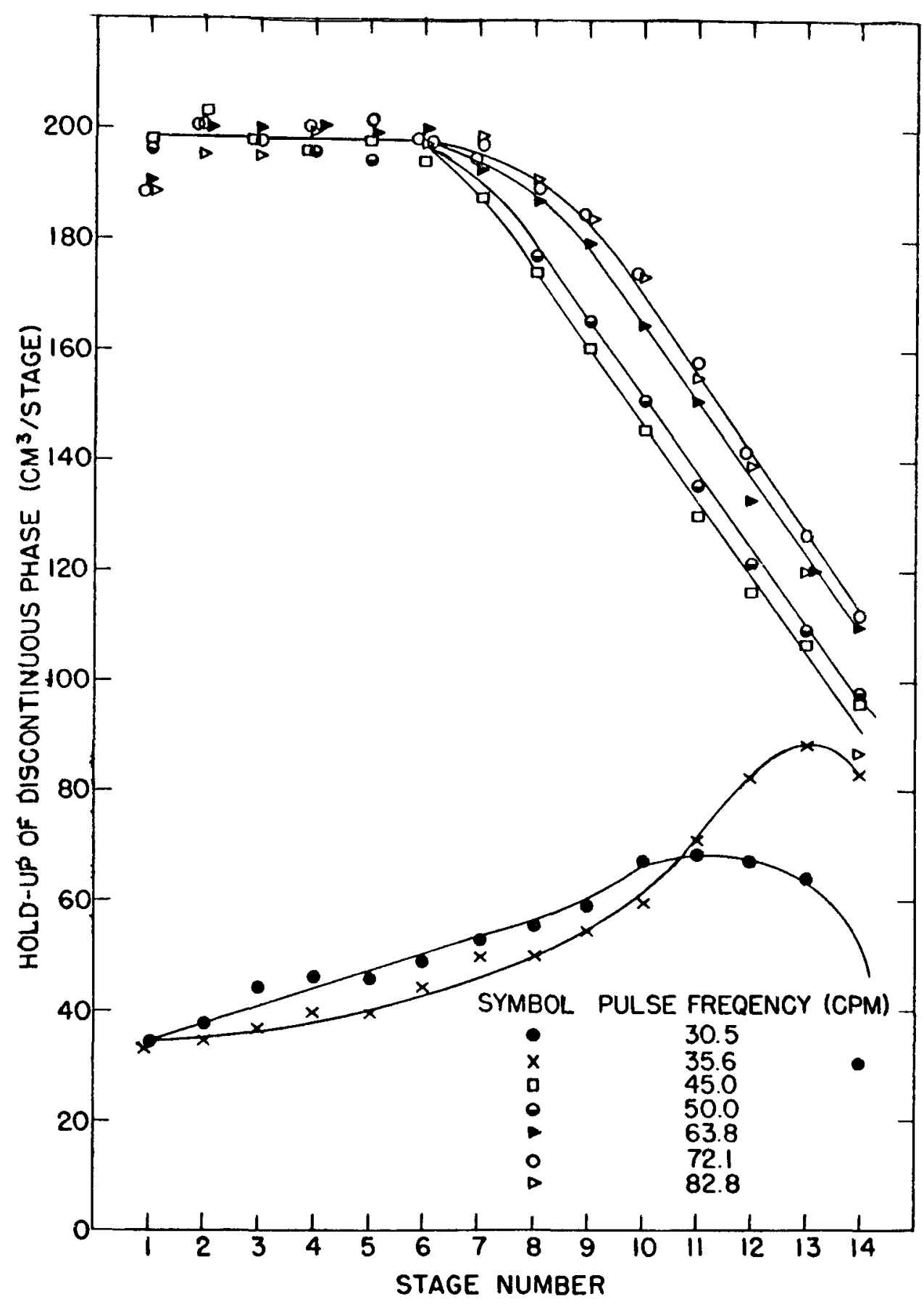

Figure 30. Hold-up of discontinuous water phase for the isoamyl alcohol-water system in a fourteen-stage pulse column. 
Increase in the hold-up occurred and beyond 40 cycles per minute two series of hold-up curres were obtained. In one series, shown in Figure 29, the hold-up rose very rapidly, reaching a maximum in the vicinity of stage six and then decreasing again toward the bottom of the column. The stage in which the sudden increase in hold-up occurred could be found easily by observing the column in operation. In this stage a "secondary" interface could be seen. The line was very sharply defined and was produced by the difference between the size of the droplets of dispersed phase and the number of droplets above and below this point. The emulsion below the secondary interface was composed of a high density of small droplets of approximately equal size. Above this "interface" there was a much lower density of droplets and the droplets were larger and irregular in size. The line could be seen moving up or down the column after start-up. For the runs shown in Figure 29 this secondary interface usually rose above its final resting place then settled back down very slowly.

If the secondary Interface rose up above the top plate in the column and remained there, a hold-up distribution of the type shown in Figure 30 resulted. The colum was run contimously for ten hours on three occasions In an attempt to determine which type of distribution was the more stable. During these long runs the hold-up would follow one type of curve for about two hours, then shift so that it followed the other type of curve for about two hours. The high hold-up distribution appeared to predominate, although there was not sufficient evidence to make a definite statement as to which type of distribution was the more stable.

The position of the secondary interface was extremely sensitive to 
the flow rate of the continuous solvent phase. A small variation of the solvent phase flow rate would cause the secondary interface to move up or down when the hold-up distribution curve was convex as in Figure 29. Another series of runs was made at a lower flow rate of the water phase. The stagewise hold-up data for these runs are presented in Figure 31. Again a sharp increase in the hold-up of the discontimuous phase was found. In this case the break occurred at a pulse frequency of about 68 cycles/min. The discontinuities in the hold-up curves are more obvious in Figure 32 where the total hold-up of water phase in the contacting section is plotted against pulse frequency for both sets of alcohol-water runs. The break in each curve occurs at approximately the same total holdup in the column.

The methyl isobutyl ketone - water system

A second system, the methyl isobutyl ketone-water system was also used to study hold-up in the pulse column. The pulse amplitude was kept at $\frac{1}{2}$ in. and the flow rates for each phase were again 1 liter/min. The organic phase was continuous. The stagewise data for this series of runs are presented in Figure 33. At a fixed frequency, the hold-up per stage was essentially constant down the column at low pulse frequencies. Above 50 cycles/min. the hold-up per stage increased in the lower stages of the column. The total hold-up of discontinuous phase in the contacting portion of the column is given in Table 4 for pulse frequencies from 25 cycles/min. to $90 \mathrm{cycles} / \mathrm{min}$. The total hold-up of the discontinuous water phase passed through a minimum at about 50 cycles/min.

The hold-up data from two extraction runs are given in Figure 34. 


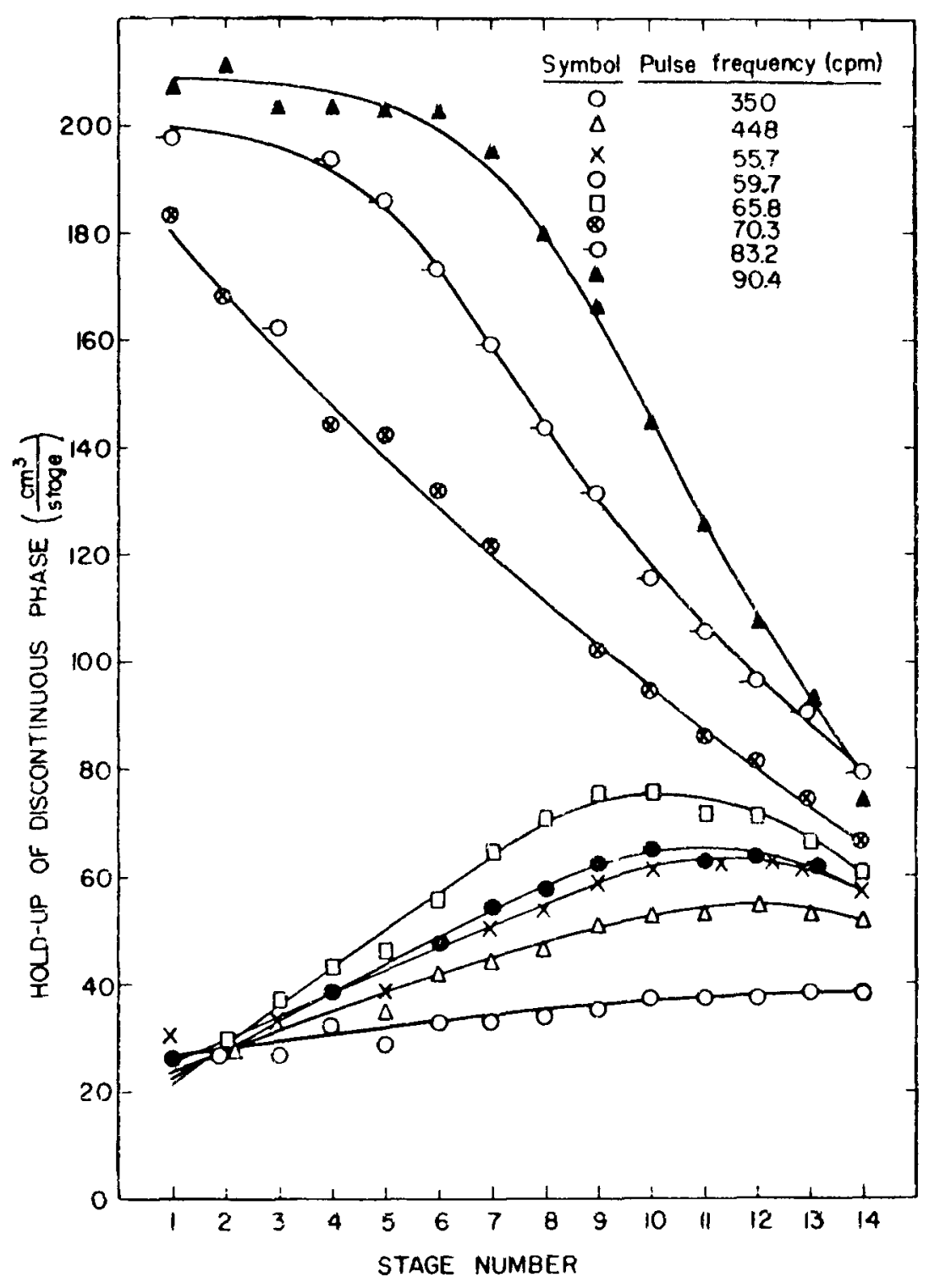

Figure 31. Hold-up of discontinuous water phase for the isoamyl alcohol-water system in a fourteen-stage pulse column using a water flow rate of 0.66 liter/min. 


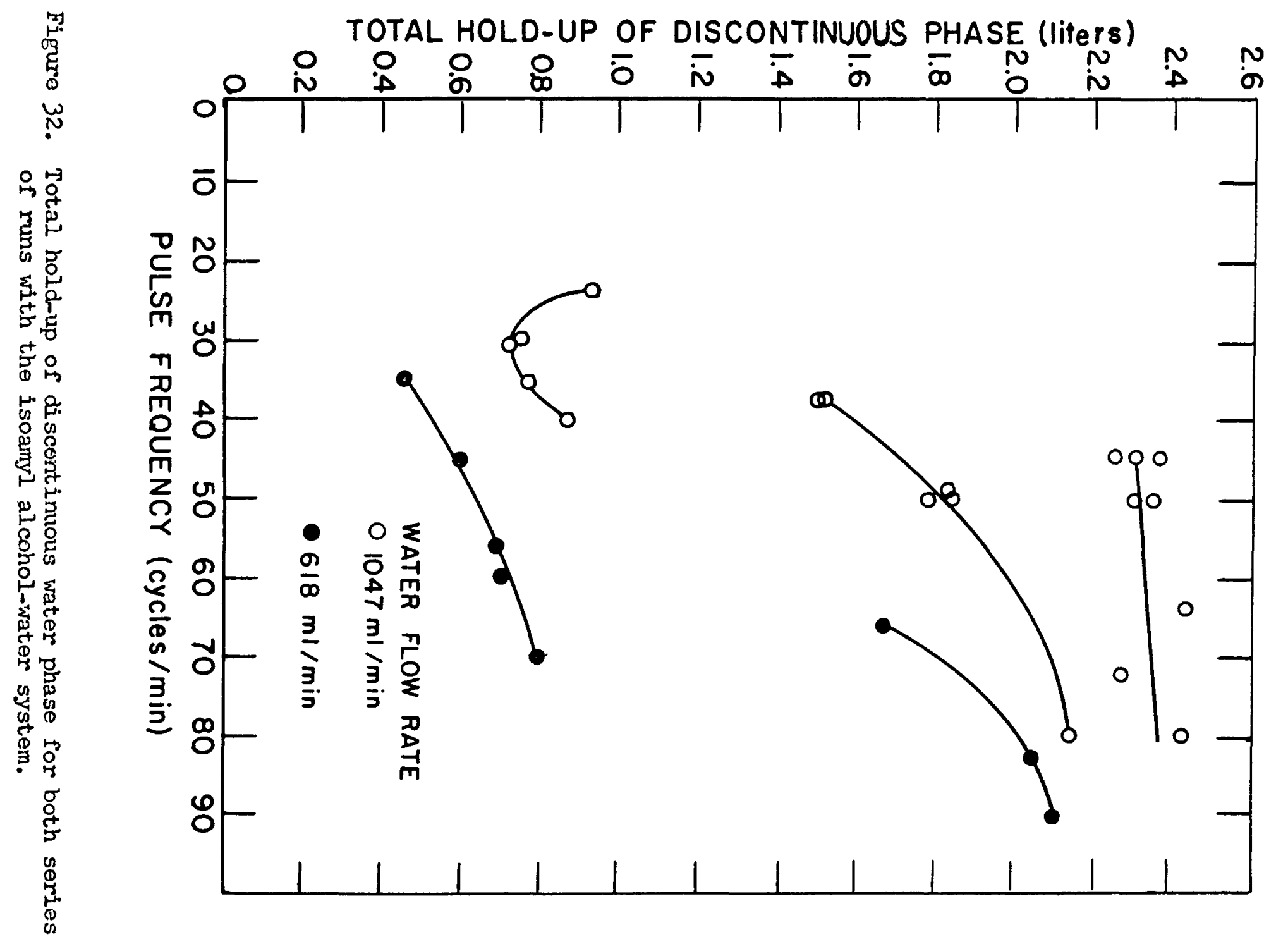




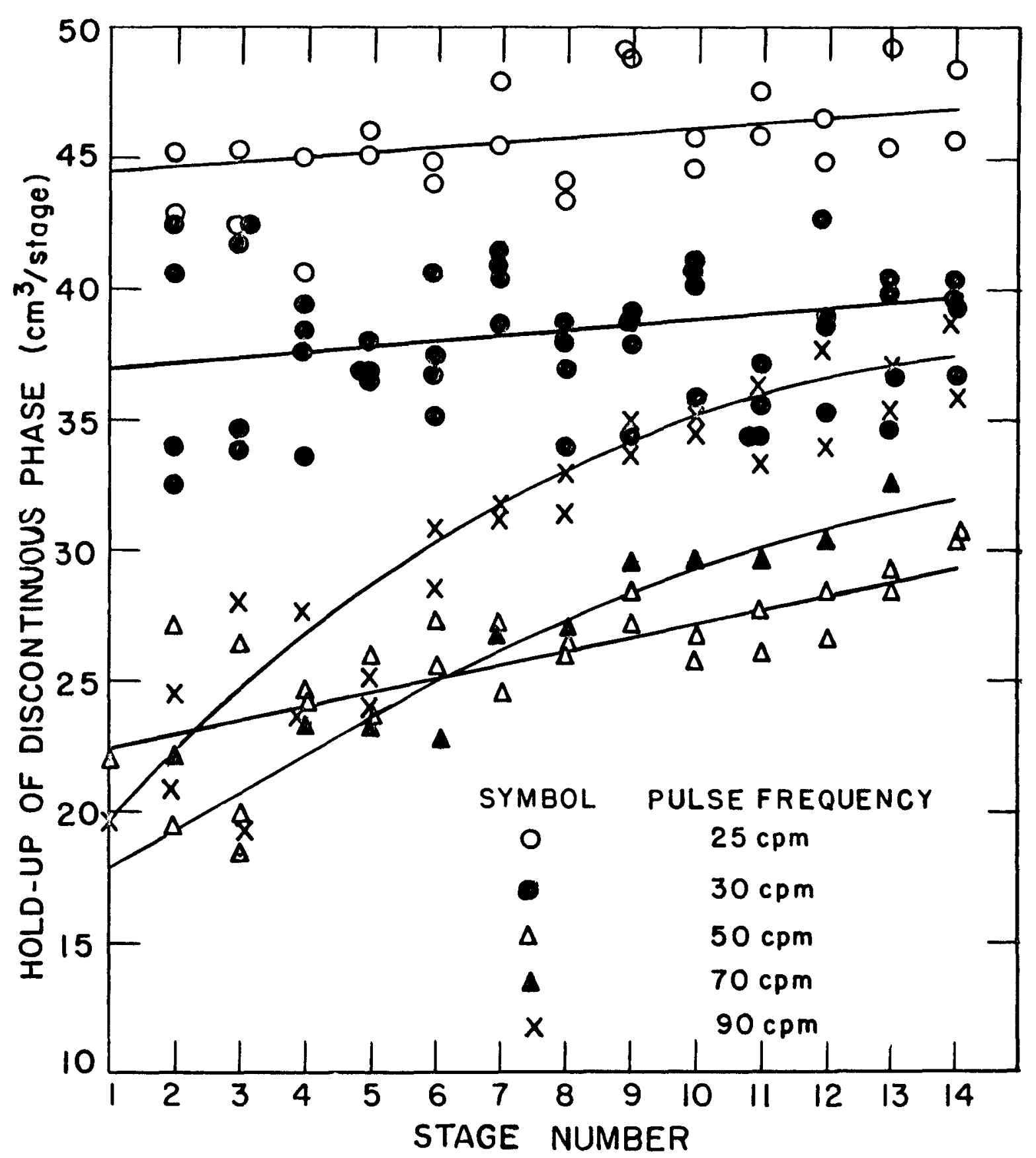

Figure 33. Hold-up of discontinuous water phase for the methyl isobutyl ketone-water systern in a fourteen-stage pulse column. 


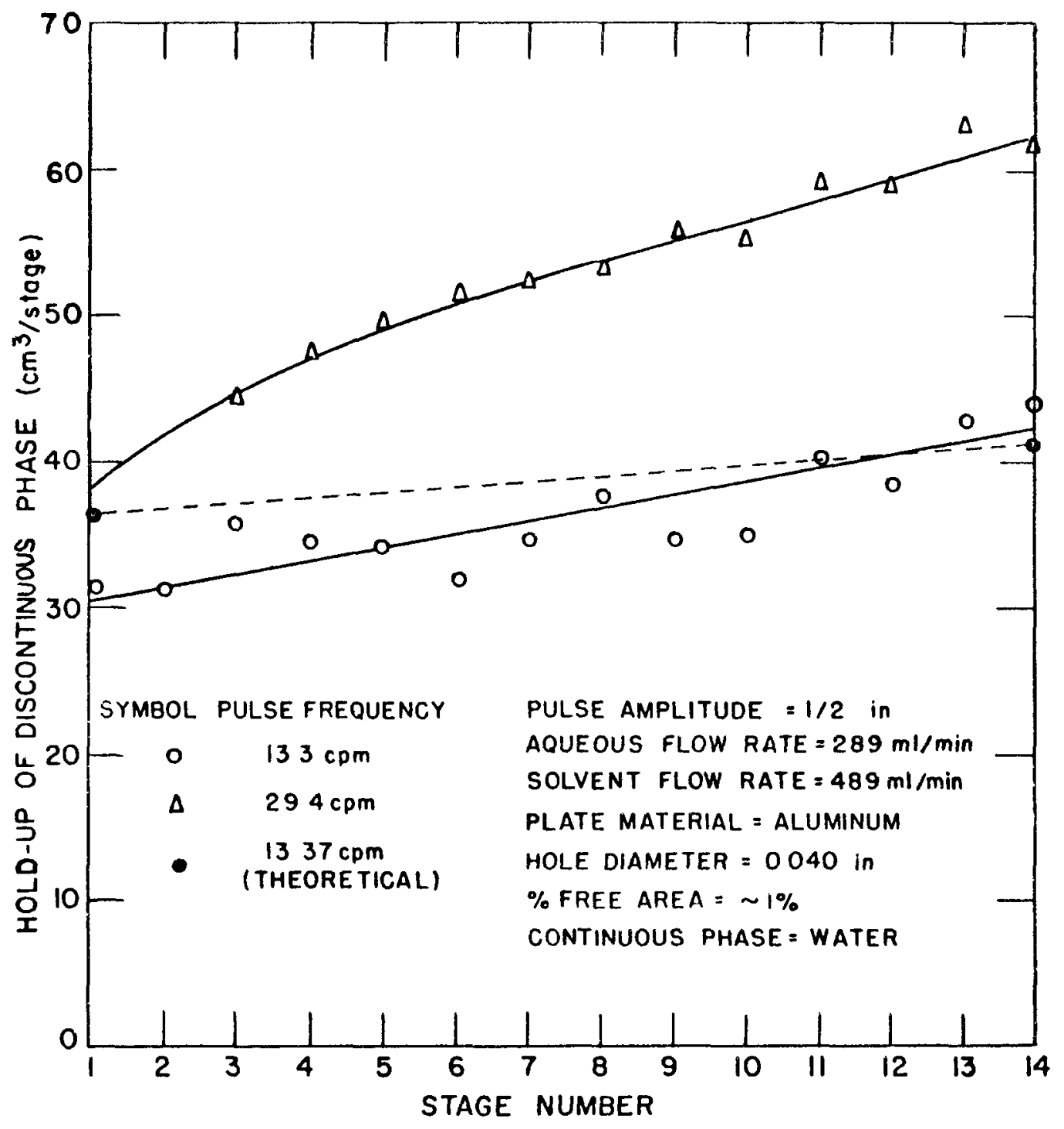

Figure 34. Hold-up of discontinuous organic phase for the methyl isobutyl ketone-acetic acid-water system showing a case where the hold-up is less than the interstage flow per cycle. 
Table 4. Total hold-up in contacting portion of the pulse column at various pulse frequencies

\begin{tabular}{cc}
$\begin{array}{c}\text { Pulse frequency } \\
\text { (cycles/min.) }\end{array}$ & $\begin{array}{c}\text { Total hold-up } \\
\left(\mathrm{cm} .{ }^{3}\right)\end{array}$ \\
\hline 25 & 640 \\
30 & 538 \\
50 & 362 \\
70 & 364 \\
90 & 434 \\
\hline
\end{tabular}

The organic phase was dispersed. At the low pulse frequency of 13.3 cycles/min. the hold-up per stage was lower than the interstage flow, per cycle, of the dispersed phase. This happens when the pulse frequency is low with respect to the free rise time of the droplets of dispersed phase or when the pulse amplitude is high enough to force the droplets to rise too rapidly in comparison with the time required for a half-cycle of the pulse generator. The droplets do not all coalesce under the plate at the top of the stage. Instead, some of them pass through this plate and on to the next stage. The run illustrates one limitation to the theory which has been presented and also explains why the assumption was made in the derivation that the fluid passes through only one stage per half-cycle of the pulse generator. 
Discussion of Hold-up Data

At most operating conditions studied, the hold-up in the column was very different for the two systems. The hold-up curves for the isoamyl alcohol-water system showed a sharp break which was not found with the methyl isobutyl ketone-water system. The hold-up was generally higher for the alcohol-water system. This higher hold-up was to be expected with the alcohol system because the interfacial tension was low and the viscosity of the continuous phase was relatively high for the types of organic solvents generally used in liquid extraction work.

The sudden increase in hold-up observed in the alcohol-water system appeared to be an elutriation effect. As the pulse frequency was increased, drop size decreased. The hold-up in the column began to increase and this increase in hold-up was more rapid in the lower stages of the column. At higher frequencies the region of high hold-up shifted up toward the center of the column. The size of many of the droplets became equal to or slightly less than the diameter of the holes in the perforated plates and less coalescence and redispersion of the drops occurred.

As the hold-up increased in the bottom portion of the column, hindered settling began to take place. Finally the over-all force tending to cause the smaller drops to fall became equal to the buoyant force on these drops. A secondary interface formed. The drops appeared to behave much the same as the resin particles in an ion exchange column when it is back-washed. The appearance of two sets of curves after the break in the first series of alcohol-water runs was probably caused by variations in the continuous phase flow rate. A small variation in this 
flow rate was inevitable since the continuous solvent phase line had some pulsation in it and the solvent was fed with a centrifugal pump. This flow rate was watched more closely in the second series of runs and only one line appeared after the break in the hold-up curve.

The maximum hold-up in any single stage in the alcohol-water runs was approximately $200 \mathrm{ml}$. After this hold-up had been reached, an increase in pulse frequency had little or no effect on the hold-up in the top few stages of the column. Instead, the hold-up began to increase in each of the lower stages. The value of $200 \mathrm{ml}$. per stage was very close to the volume necessary to cause phase inversion in the stage and some difficulty was experienced with phase inversion during the approach to steady-state for runs made at a high pulse frequency. The behavior exhibited by the alcohol water system might be expected for any system with a low interfacial tension and a high continuous phase viscosity. Dispersion was more difficult in the ketone-water system than in the alcohol-water system. Again this was to be expected from the higher interfacial tension between the liquids and from the low viscosity of the continuous ketone phase. The hold-up decreased with increasing pulse frequency over a greater range above the lower flooding point. Drop size did not appear to be materially affected by an increase in the pulse frequency. In fact, the drop size appeared to increase at first, then decrease slightly as the frequency was increased above the lower flooding limit.

As the pulse frequency decreased the difference in behavior of the two systems became less. Over a given range of flow rates the hold-up for both systems became equal to the interstage flow of the discontinuous 
phase for pulse frequencies at or near the lower flooding point. There are two Iimits to this hold-up relationship which has been shown to exist near the flooding point. First the amplitude-frequency combination must not be such that the discontinuous phase flows through more than one stage per half-cycle of the pulse generator. Second, the flow rates must not be so high that, due to dispersion, the hold-up at the lower flooding point builds up beyond a value equal to the volume of the interstage flow of the dispersed phase. Cases in which both of these limiting phenomena occur have been demonstrated experimentally.

\section{Extraction Studies}

Extraction muns were made in the pulse column to study the operation of the column in the light of the theory which has been proposed. Runs were made at different operating conditions to test the various sampling techniques and to determine upstroke and dowmstroke stage efficiencies. The results of these tests provided information which illustrated the application of the theory and which served to outline a pattern for future work. The system: methyl isobutyl ketone - acetic acid - water was used.

The first series of runs was made with the water phase dispersed since no perforated plates were available which would disperse the solvent phase properly and still permit hold-up to be measured after the column was shut dowm. The plates were coated with a polyethylene film formed by dipping the plates into a solution of polyethylene dissolved in hot xylene, then baking the plates under an infrared lamp. The solvent phase strongly wet these plates. The pulse amplitude was $\frac{1}{2}$ in. 
and the flow rates were $990 \mathrm{ml} . / \mathrm{min}$. for the solvent phase and 1046 ml./min. for the water phase. The concentration of acetic acid in the aqueous feed was $150 \mathrm{gm}$./ liter. The column was permitted to run until at least 5 change-overs of the-continuous phase had passed through the column.

The organic phase was continuous and the discontimous water phase settled to the bottom of each stage between strokes so that only organic phase passed through the plates during an upstroke of the pulse generator. Stagewise samples of the upstroke streams were taken automatically by placing needles through the perforated plates and operating the solenoid valves with the micro-switches on the pulse generator. These were the samples labled $y_{n}$. Samples of the discontinuous water phase were taken during a downstroke by inserting needjes from the bottom of the plates and operating the solenoid valve manually to prevent entrainment of the organic phase recycle into the needle. These were the samples labled $x_{n}^{\prime}$. Finally, stagerise samples of the water phase were taken at the end of an upstroke by placing sampling needles in position at three to five stages in the column, stopping all flow to the column at the end of an upstroke and operating all the solenoid valves simultaneously as soon as the column was shut off. The time required for this operation was less than five seconds. These were the samples labeled $x_{n}$.

After samples of the effluent streams were taken and flow rate measurements were made, the column was stopped by turning the control lever at the base of the colurn. Hold-up measurements were taken with the traveling microscope. The solvent was stripped to recover solvent and acid. Feed solution was prepared for the next run by using raffinate 
from the stripping column. This water contained the acid recovered by stripping the solvent from the test column and was also saturated with the organic phase.

The data were smoothed and upstroke and downstroke stage efficiencies calculated. The experimental data for one of these runs is shown in Figure 35. The hold-up curves are shown in Figure 36.

Stage efficiencies were calculated from the defining equations. The downstroke stage efficiency was defined as:

$$
\varepsilon_{a_{n}}=\frac{\bar{x}_{n}-x_{n+1}^{\prime}}{\bar{x}_{n}^{*}-x_{n+1}^{\prime}} .
$$

The value of $x_{n+1}^{\prime}$ was obtained from direct experimental measurements. By a material balance,

$$
\begin{aligned}
& I_{n} \bar{x}_{n}+(R-L)_{n} x_{n}^{\prime}=R x_{n} \\
& x_{n}=\left(\frac{R}{L}\right)_{n} x_{n}-\left(\frac{R-L}{I}\right)_{n} x_{n}^{\prime}
\end{aligned}
$$

The value of $\bar{x}_{n}{ }^{*}$ was determined from the equilibrium curve as the $x$ concentration in equilibrium with $y_{n}$, or $y_{n}=m_{x_{n}}^{*}$.

By definition, the upstroke stage efficiency was:

$$
\varepsilon_{u_{n}}=\frac{\bar{y}_{n}^{\prime}-y_{n-1}}{\bar{y}_{n}^{\prime *}-y_{n-1}}
$$

The concentration, $\mathrm{y}_{\mathrm{n}-1}$, was measured by direct sampling of the column. The value of $\bar{y}_{n}^{\prime}$ was read from the equilibrium curve since 
83

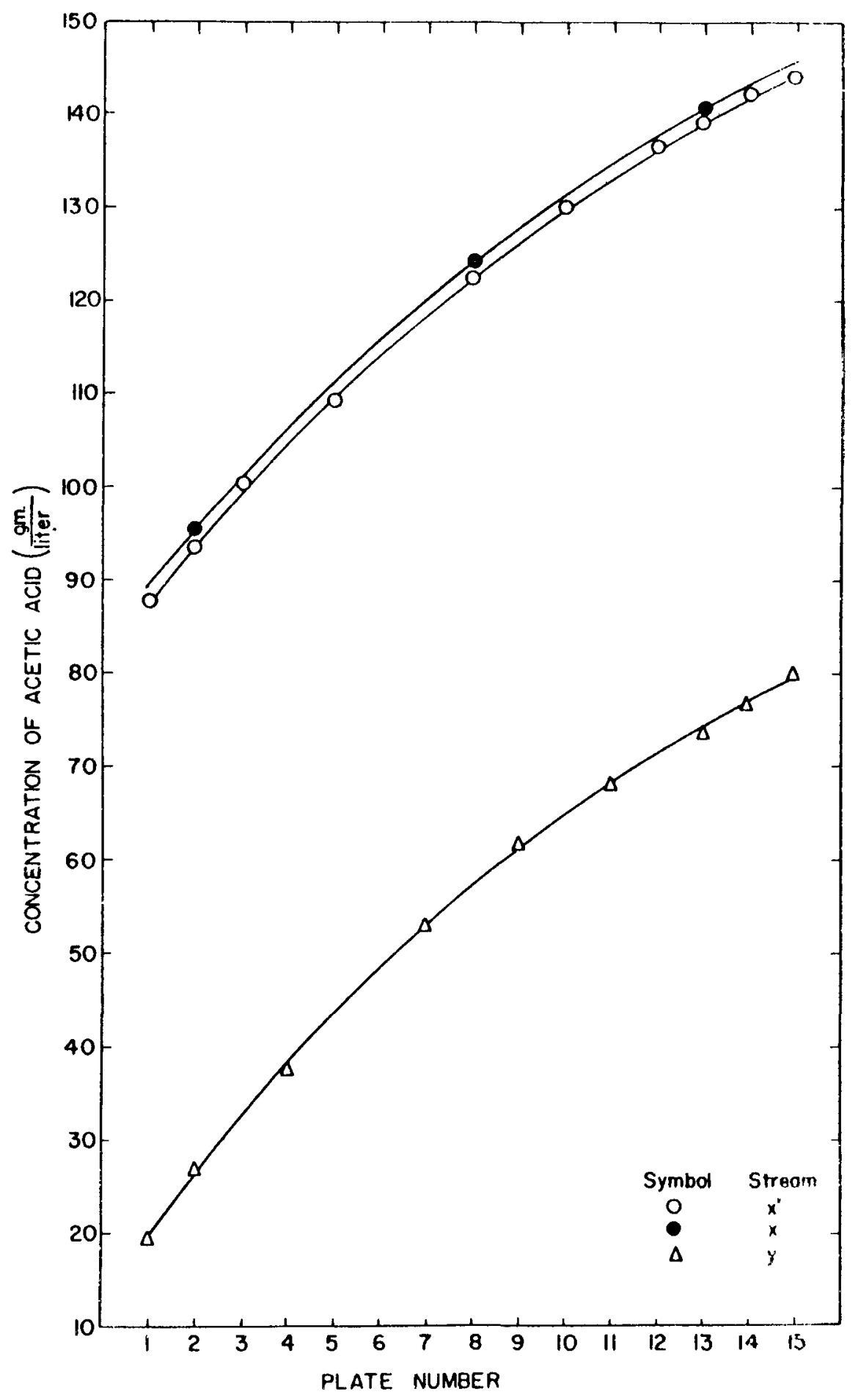

Figure 35. Plot of smooth curve drawn through experimentally determined stagewise concentration data. 


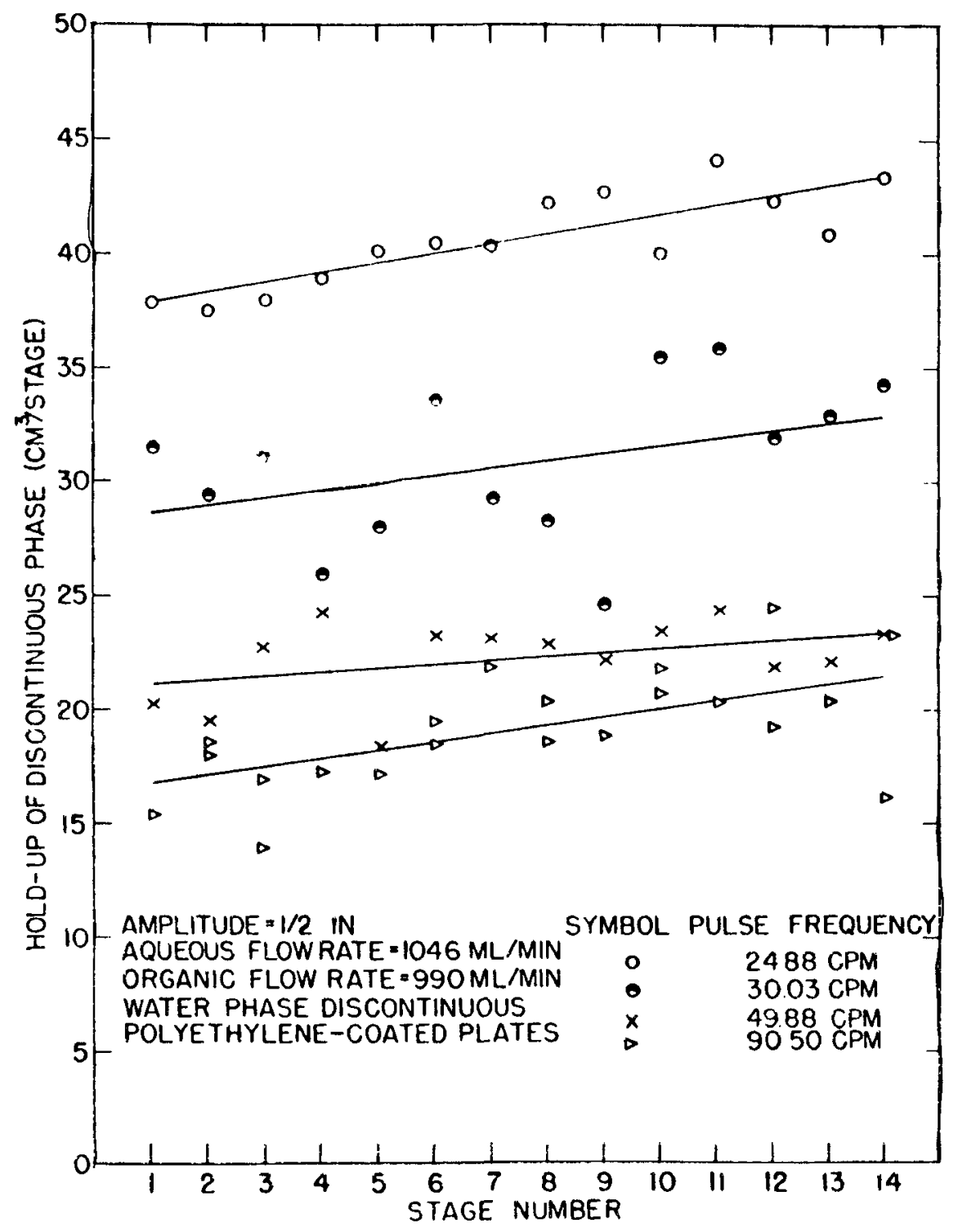

Figure 36. Holdup of discontinuous water phase for extraction runs using the methyl isobutyl ketone-acetic acidwater system. 
$\bar{y}_{n}^{\prime *}=m x_{n}^{\prime}$. By a material balance,

$$
\begin{gathered}
\left(G+O_{R_{u}}\right)_{n-1} y_{n-1}+R_{n} x_{n}=\left(G+O_{R_{u}}\right)_{n} \bar{y}_{n}^{\prime}+R_{n} x_{n} \\
\bar{y}_{n}^{\prime}=y_{n-1}+\left(\frac{R_{n}}{G+o_{R_{u}}}\right)\left(x_{n}-x_{n}^{\prime}\right) .
\end{gathered}
$$

The subscript was dropped from the term $\left(G+O_{\mathrm{R}_{\mathrm{u}}}\right)$ since no water phase was recycled on the upstroke of the pulse generator and,

$$
\left(G+O_{R_{u}}\right)_{n-1}=\left(G+O_{R_{u}}\right)_{n}=\left(G+o_{R_{u}}\right)_{n+1} \text {, etc. }
$$

Four runs were made at nominal pulse frecpencies of $25,30,50$, and 90 cycles/min. Only hold-up data could be obtained for the run at $90 \mathrm{cycles} / \mathrm{min}$. The layer of discontinuous water phase in each stage became so small that samples could not be taken without entraining organic phase in the needle. Stage efficiencies for the first three runs are presented in Table 5.

The variation in stage efficiency from stage to stage in Table 5 should not be considered as representing a trend to increase or decrease along the column because the key concentration measurement necessary in separating upstroke and downstroke stage efficiencies was not considered accurate enough to draw this conclusion. This key concentration was the value of $x_{n}$. Three concentrations, $y_{n}, x_{n}^{\prime}$, and $x_{n}$ were measured by direct sampling of the column. Sarples for determining $y_{n}$ and $x_{n}^{\prime}$ were taken from the column while it was at steady state. The sample from which the concentration $x_{n}$ was found was taken from the column immediately after it 
Table 5. Upstroke and downstroke stage efficiencies for a pulse column at various pulse frequencies

System: Methyl isobutyl ketone-acetic acid-water

Aqueous flow rate $=1047 \mathrm{ml} . / \mathrm{min}$.

Organic flow rate $=990 \mathrm{ml} . / \mathrm{min}$.

Pulse amplitude $=\frac{1}{2}$ in.

Discontinuous phase $=$ water

Plates $=$ polyethylene coated

Pulse frequency

(cycles/min.)

24.88

30.30

49.88

Stage number

$\varepsilon_{d_{n}} \quad \varepsilon_{u_{n}}$

$\varepsilon_{d_{n}}$

$\varepsilon_{u_{n}}$

$\varepsilon_{\alpha_{n}}$

$\mathcal{E}_{u_{n}}$

$\begin{array}{rrrrrrr}1 & 9.83 & 4.05 & 10.07 & 1.57 & 16.50 & 2.00 \\ 2 & 9.69 & 4.39 & 10.12 & 1.67 & 15.02 & 2.23 \\ 4 & 9.36 & 5.27 & 10.35 & 1.93 & 13.82 & 2.54 \\ 6 & 8.90 & 6.23 & 9.73 & 2.22 & 12.12 & 2.87 \\ 8 & 8.27 & 7.24 & 9.08 & 2.52 & 11.19 & 3.32 \\ 10 & 7.47 & 8.23 & 7.99 & 2.89 & 10.98 & 3.90 \\ 12 & 6.36 & 9.24 & 8.68 & 3.20 & 8.67 & 4.48 \\ 14 & 5.38 & 10.30 & 8.52 & 3.37 & 4.50 & 5.18\end{array}$

had been shut down. This may have introduced some error into the measurement and any small error was significant in this case because of the small difference between $x_{n}$ and $x_{n}^{\prime}$. The experimental results of these latter measurements are shown in Table 6. An average value of the concentration difference between $x_{n}$ and $x_{n}^{\prime}$ was used for each run and 
Table 6. Difference between experimental values of $x_{n}$ and $x_{n}^{\prime}$ in gm./Iiter.

\begin{tabular}{|c|c|c|c|}
\hline Pulse frequency (cpm) & 24.88 & 30.03 & 49.88 \\
\hline$\left(x_{1}-x_{1}^{\prime}\right)$ & & & 0.79 \\
\hline$\left(x_{2}-x_{2}^{\prime}\right)$ & 1.82 & 0.70 & \\
\hline$\left(x_{3}-x_{3}^{\prime}\right)$ & & & 1.55 \\
\hline$\left(x_{6}-x_{6}^{\prime}\right)$ & & & 0.76 \\
\hline$\left(x_{8}-x_{8}^{\prime}\right)$ & 1.65 & 0.62 & \\
\hline$\left(x_{11}-x_{11}^{\prime}\right)$ & & & 0.35 \\
\hline$\left(x_{13}-x_{13}^{\prime}\right)$ & 1.68 & 0.92 & 1.76 \\
\hline Average & 1.70 & 0.75 & 1.10 \\
\hline
\end{tabular}

this value was assumed to be constant from stage to stage. For this reason the results shown in Table 5 should be interpreted to give an order of magnitude for the stage efficiencies, and not a test of the variation of stage efficiency with the position of the stage in the column.

The three runs described above are plotted in Figures 37,38 , and 39. The double operating lines and double stage lines were not drawn since they would be only slightly separated because of the low stage efficiencies which were obtained.

The end effect at the bottom of the column was large. Part of the 


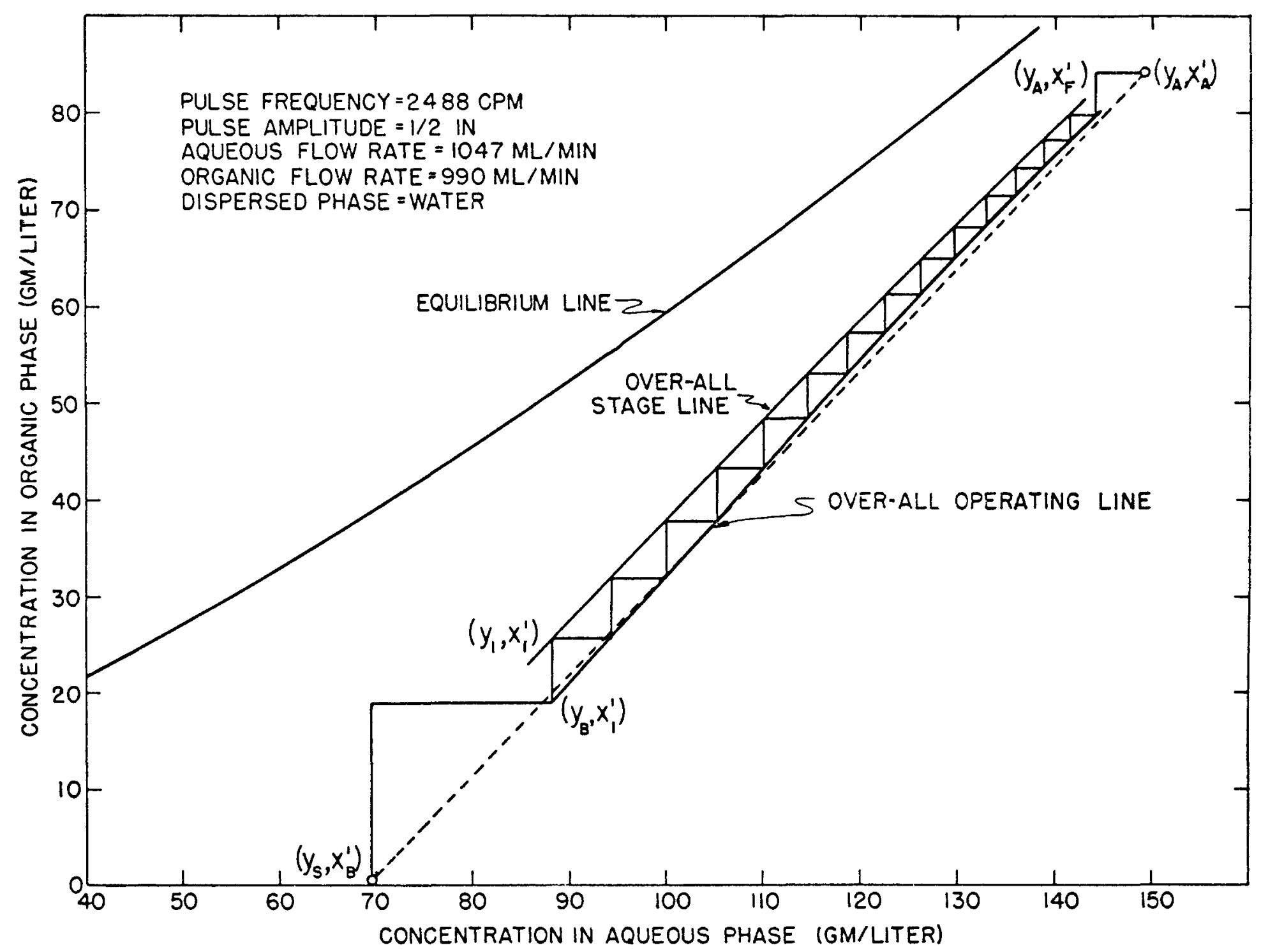

Figure 37. Diagram of extraction run at a pulse frequency of 24.88 cycles/min. 


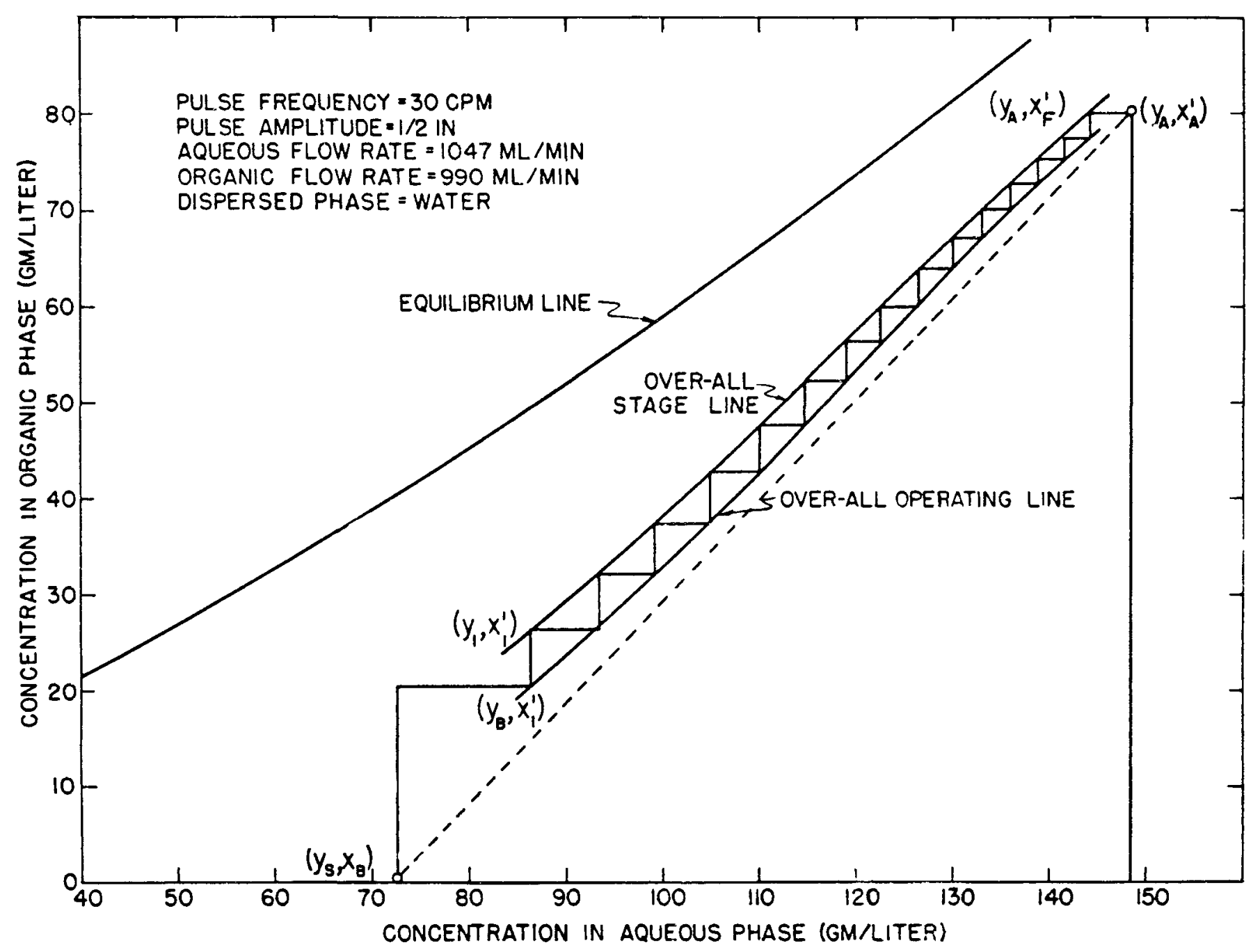

Fizure 38. Diagram of extraction run at a pulse frequency of $30 \mathrm{cycles} / \mathrm{min}$. 


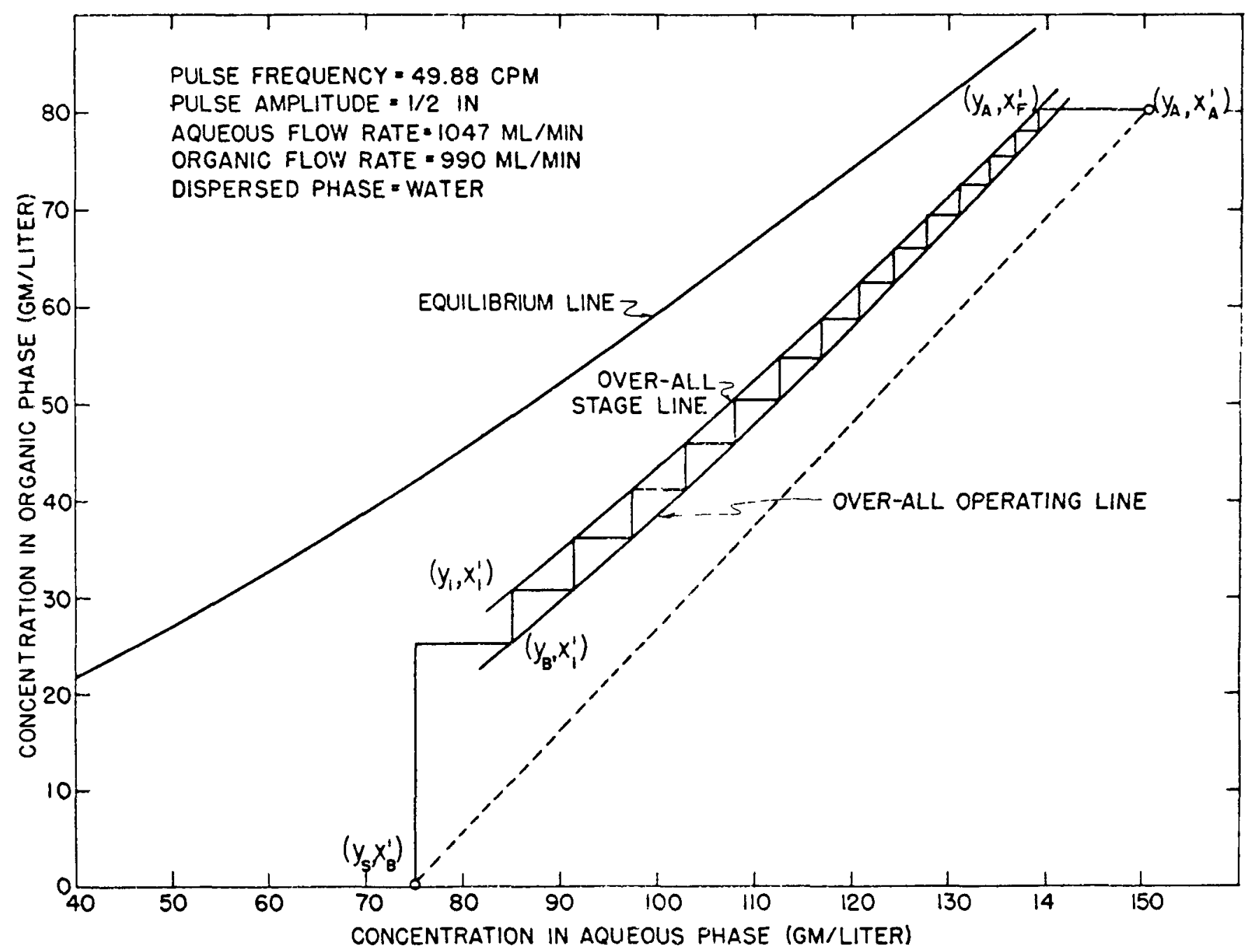

Figure 39. Diagram of extraction mun at a pulse frequency of 49.88 cycles $/ \mathrm{min}$. 
bottom end effect can be explained by the physical construction of the column. The column was originally designed to have the light phase dispersed and a perforated plate inlet distributor was placed at the bottom of the column. When the heavy phase was made the discontinuous phase, fresh solvent as continuous phase was sprayed into the bottom end section at a constant rate during both half-cycles.

The separation performed by the contacting section of the column renained approxinately constant for all three runs. However the separation, based on the compositions of the inlet and outlet streans, decreased with increasing pulsation. A dotted line has been drawn on Figures 37,38 , and 39 between the two points representing the end compositions of the column. This would be the approximate position of an operating line used for determining the number of theoretical stages by the McCabe-Thiele method. In the present case the over-all operating line moved upward from this dotted line as the pulse frequency was increased. Sufficient data were not taken to permit an analysis of the end sections but the change in position of the operating line was probably due to the unequal effect of recycle in the end section as compared with the recycle effect in the stages of the column. The feed stream to the top end-section was fixed and its concentration unaffected by the operating conditions of the column. Similarly the composition of the solvent stream into the bottom end-section was not affected by operating conditions set for the column.

The shift in the position of the operating line in relation to a line through the end product compositions can also be seen in the theoretical problems presented in Figures 10 and 14 . These results show the 
the need for a careful study of the end-sections of the column and future work should be planned so that the end effects may be investigated more thoroughly.

Karm and Scheibel (II) studied the methyl isobutyl ketone-acetic acid-water system in a Scheibel column. They reported that the mass transfer coefficients for the case of ketone dispersed-ketone extractant were about three times as high as for the case water dispersed-ketone extractant. Low stage efficiencies were obtained in the first three runs described above. Methyl isobutyl ketone was made the discontinuous phase for the next run in order to obtain higher stage efficiencies. Since the polyethylene coated plates would not disperse the solvent phase, new plates were used. The new plates were cut from the same perforated stainless steel sheet used for the polyethylene plates. The new plates were cleaned with trichloroethylene, soaked overnight in a hot trisodium phosphate solution, and thoroughly washed with distilled water. The cleaned plates were then passivated by placing them in a $50 \%$ solution of warm nitric acid.

It was known from previous plate-wetting studies that these plates would disperse the solvent phase satisfactorily. It was also known that the discontinuous solvent phase would leak through the holes in these plates after the column was stopped so that no hold-up measurements could be made. On the basis of results derived from the hold-up studies, a set of operating conditions was estimated that would produce a stagewise hold-up equal to the interstage flow per cycle and this theoretical hold-up distribution was used in calculating the stage efficiencies. Since volume changes occurred for this system, the change in hold-up per 
stage was assumed to be proportional to the concentration change of the discontimuous phase. Pulse amplitude was $\frac{1}{2}$ in. Pulse frequency was 16.8 cycles/min. Feed and solvent flow rates were $540 \mathrm{ml} . / \mathrm{min}$. and $912 \mathrm{ml} . / \mathrm{min}$., respectively. Calculated stage efficiencies are given in Table 7. The column was operating at a point just above the lower flooding limit. This run is plotted in Figure 40 where the double stage lines and double operating lines are shown. Again the variation in stage efficiency from one stage to the next may not indicate an actual trend because the samples from which a value for $y_{n}^{\prime}$ was calculated were taken after the column had been shut down, and the data were somewhat erratic. The downstroke stage efficiency was lower than the upstroke stage efficiency. This was consistent with the results of the three runs where water was the dispersed phase and where the upstroke stage efficiency was lower than the downstroke stage efficiency. The stage efficiency, then, is lower when the wetting fluid passes through the plates than when the non-wetting fluid passes through the plates or, as a general corollary, the stage efficiency is lower on that half-cycle of the pulse generator in which the continuous phase goes through the plates.

Another set of plates was made to obtain still higher stage efficiencies. The plates were made of alumimur so that they would be preferentialIy wet by the water phase. Sixty-one holes $0.040 \mathrm{in}$. in diameter were drilled in each plate. The free area of a plate was $1.33 \%$. The flowrates were $289 \mathrm{ml} . / \mathrm{min}$. and $489 \mathrm{ml} . / \mathrm{min}$., respectively for the feed and the solvent. Pulse amplitude was 0.39 in. Because of the small free area of the plates, the velocity of the dispersed solvent phase was so high that no interstage samples of the dispersed phase could be taken. 
Table 7. Upstroke and downstroke stage efficiencies for an extraction run with the solvent dispersed

Stage number

$\varepsilon_{u_{n}}$

$\varepsilon_{d_{n}}$

\begin{tabular}{lll}
\hline 2 & 27.10 & 6.46 \\
4 & 23.53 & 6.67 \\
6 & 20.10 & 6.68 \\
8 & 19.65 & 6.91 \\
10 & 20.38 & 6.95 \\
12 & 23.40 & 7.31 \\
14 & 25.92 & 7.60 \\
\hline
\end{tabular}

When the pulse frequency was low enough to obtain a solvent layer thick enough to sample, the column flooded. Increasing the pulse frequency caused excessive dispersion of the discontinuous phase and it did not settle out between strokes of the pulse generator.

A second run was made using the alumimum plates. The column was operated in the emulsion region at a pulse frequency of $29.4 \mathrm{cycles} / \mathrm{min}$. Interstage samples could not be taken because the packed neodles which were used for sampling did not function properly. Only one phase was drawn from the two-phase mixture. However, this phase reached equilibrium with the surrounding liquid. The concentration value obtained using a packed needle, then, was an equilibrium concentration and did not repre- 


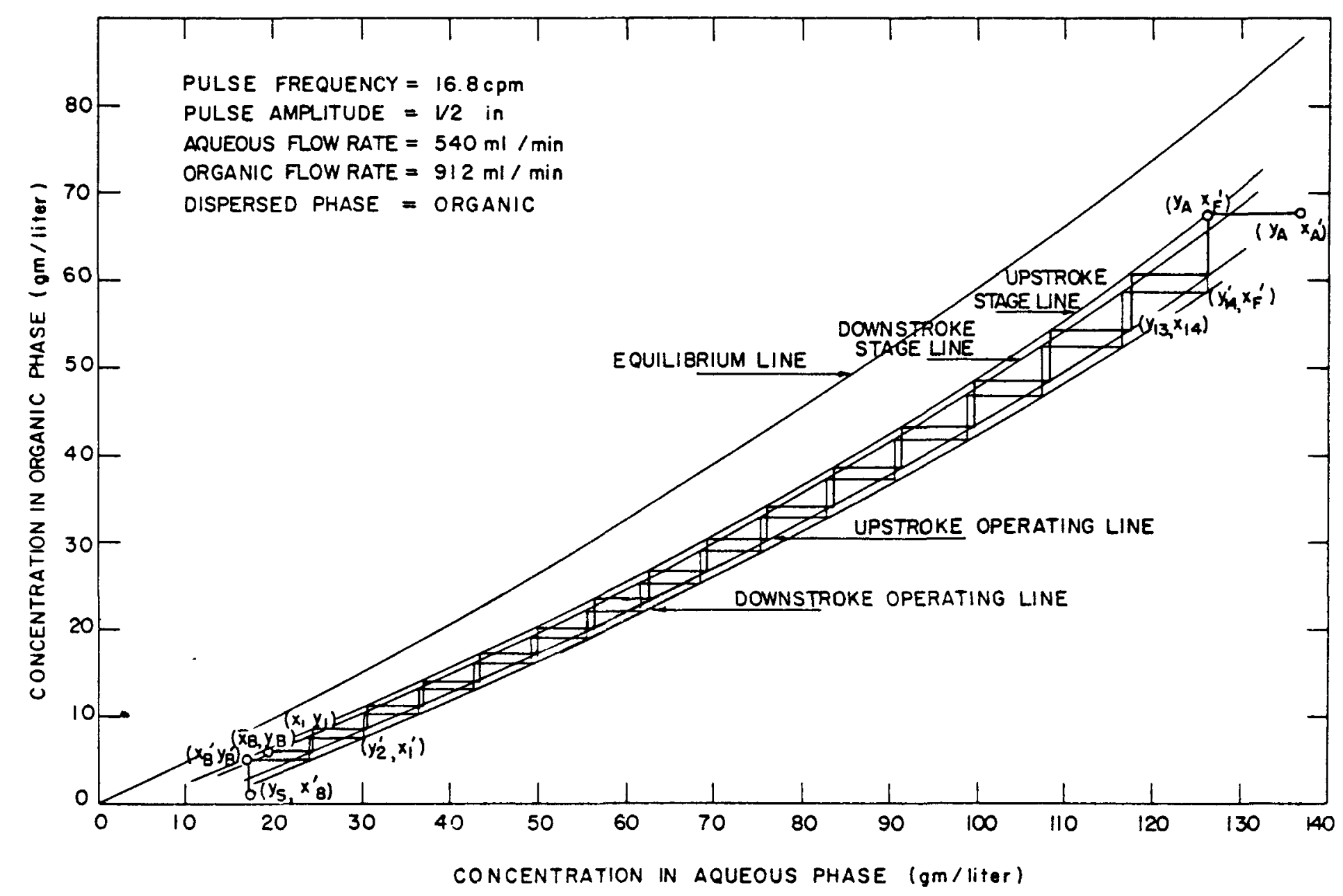

i̊

Figure 40. Diagram of extraction mun showing upstroke and downstroke stage lines and operating lines. 
sent the true concentration of that phase in the column at the point from which it was taken. The liquid was pulled through the needle so slowly that it reached equilibrium with the other phase before it entered the packing of the needle. The ratio of phases in the interstage flow streams, as determined from the two-phase samples taken through hollow needles, was also found to be in error. These last two runs yielded less information than had been anticipated. However, the information obtained will be useful in planning future work. The composition of the inlet and outlet streams is presented in Table 8.

Table 8. End compositions in gm./Liter for runs with aluminum plated having small diameter holes

Pulse frequency $(\mathrm{cpm})$ Feed Solvent Extract Raffinate

$\begin{array}{rrrrr}13.3 & 137.52 & 0.67 & 69.43 & 9.08 \\ 29.4 & 137.86 & 2.59 & 67.96 & 19.69\end{array}$

The hold-up measurement for the run at $13.3 \mathrm{cycles} / \mathrm{min}$. was used in Figure 34 as an example of a case in which the dispersed phase passed through more than one plate per half-cycle of the pulse generator.

The experimentally measured composition of the interstage flow leaving a stage $n$ on the upstroke of the pulse generator is shown in Table 9. Two phase samples were taken with a hollow needle and the 
Table 9. Experimental measurements of the phase composition of the liquid leaving a stage on the upstroke of the pulse generator

\begin{tabular}{ccc} 
Stage number & $\%$ water & $\%$ solvent \\
\hline 2 & 74.60 & 25.40 \\
4 & 68.28 & 31.80 \\
6 & 65.50 & 34.50 \\
8 & 64.25 & 35.75 \\
10 & 63.00 & 37.00 \\
12 & 61.80 & 38.20 \\
14 & 60.60 & 39.40
\end{tabular}

volume of each phase was measured. For the conditions under which the column was operating, at least $41.67 \%$ of the liquid leaving the top of stage one must have been organic phase or the column would have flooded. At the top of the column, the minimum amount of solvent phase in the interstage flow stream must have been slightly greater than $41.6 \%$ to account for a small increase in volume as the solvent passed through the column. These figures are minimum numbers calculated from the net flow of solvent which must have been maintained through the column. Since operation was in the emulsion region where solvent was also recycled on the downstroke, the per cent of solvent phase in the upstroke interstage flow could have been greater than the minimum value of $41.67 \%$. 
Although the measurements shown in Table 9 are incorrect, the data are not erratic. The points form a smooth curve and this suggests the very definite possibility that a correction factor could be determined to account for the preferential wetting of the sample needle by the water phase.

\section{Discussion of Extraction Studies}

\section{Sampling techniques}

The key concentration measurement necessary to determine a separate stage efficiency for the upstroke and the downstroke in a column where the heavy phase is discontimuous and the two phases separate between pulses is the concentration $x_{n}$. The concentration, $x_{n}$, of the discontinuous phase at the end of a downstroke half-cycle must be measured by internal sampling of a stage as contrasted with a sample taken to measure $x_{n}^{\prime}$. A sample for measuring $x_{n}^{\prime}$ can be taken as the stream of concentration passes through a plate and down into the next stage during a downstroke of the pulse generator. However, very little time is available during each cycle when an $x_{n}$ sample can be taken. The sample must be drawn at the end of a downstroke after the liquid has settled to the bottom of the stage but before light phase is dispersed into it when the upstroke halfcycle begins.

In order to take an $x_{n}$ sample while the column is operating at steadystage the sampling needle must be inserted through the bottom of the plate and a small amount of liquid drawn off at the end of each downstroke until a sample of sufficient size for analysis has been accumulated. If the layer of discontinuous heavy phase is too thin, the solvent phase just 
above the interface is entrained in the needle and two phases are obtained. There are four methods of attack for obtaining the desired sample:

(1) Stop the column at the end of a downstroke of the pulse generator and take samples of the discontinuous phase immediately.

(2) Adjust the flow rate of the discontinuous phase so that a sufficiently deep layer is obtained in the stage to prevent entrainment of the continuous phase.

(3) Take the sample with a packed needle so that only one phase will pass through the packing into needle.

(4) Deliberately pull a series of samples containing both phases in different volume ratios, analyze the concentration of the discontinuous phase in each sample, and extrapolate back to zero volume of the unwanted contimuous phase.

The first method has been tried and found to yield somewhat erratic results, although part of the difficulty was due to the small differences between the concentration of the discontinuous phase at the end of an upstroke and the end of a domstroke for the cases studied. The second method may be used over a limited range of operating conditions for the pulse column. As the discontinuous phase flow rate is increased to obtain a heavier layer in each stage, the pulse frequency must be increased correspondingly to prevent the column from flooding. If the frequency is increased too far the dispersed phase will no longer coalesce between strokes. 
The frequency at which coalescence between strokes begins to decrease will be dependent upon the system under study, the wetting characteristics of the plates, the diameter of the holes in the plates, the per cent free area of the plates, and the plate spacing. The plate spacing affects coalescence because the rise or fall time of the discontinuous phase as it passes through the stage sets the pulse frequency, or the time between strokes, necessary for the liquid to reach the far end of the stage so it can coalesce. The plate variables are closely interrelated and play an important part not only in determining the hold-up behavior in the column but also the mass transfer rates. The physical dimensions of the column components are more critical at low frequencies than at high frequencies.

The third method may be used regardless of the size of the layer of the discontinuous phase if a satisfactory porous packing can be found to place in the end of the sample needle. The operation of the packed needle can be show by a force balance over the tip of the sampling needle (17). If the size of the capillaries in the packing is small, the liquid which preferentially wets the packing will flow through but the interfacial film separating the two liquids will block the capillaries and prevent flow of the non-wetting liquid. If the pressure against the needle is too large, then this film will be broken and both phases will flow through the packing. At equilibrium, a balance of forces exists. If the entrance to one of the capillaries is circular with diameter do. the resisting interfacial force is $\pi \cdot d_{0} \cdot \sigma$, where $\sigma$ is the interfacial tension between the two liquids. The force tending to break this film is the product of the cross-sectional area of the capillary and the 
pressure, or $\frac{1}{4} \cdot \pi \cdot \alpha_{0} \cdot p$. Therefore, at equilibrium,

$$
\begin{gathered}
\pi d_{0} \sigma=\frac{\pi d_{0}^{2} p}{4} \\
p=\frac{4 \sigma}{d_{0}} .
\end{gathered}
$$

Only one phase will flow through the packing if this pressure, $p$, is not exceeded.

The packed needles used in this work were packed with 60-80 mesh aluminum powder. The shape of the packing was irregular. Although needles were made which drew only one phase from a two phase mixture, the sample had to be drawn very slowly. Porous plugs have been used successfully in sampling extraction columns where the sample can be drawn contimuously (7). Sampling is more difficult in the pulse column. The liquid must be drawn off at a certain point with respect to time. The concentration at the point at which the sample must be taken undergoes a cyclic variation with time. Hence, liquid can flow through the sampling needle only part of the time when a sample is collected at a given point during the cycle. During the rest of the cycle a stagnant film of the wetting phase is held over the end of the sampling needle and is exposed to a concentration gradient which will cause mass transfer. The error caused by this exposed film on the end of the needle becomes greater as the amount of liquid pulled through the needle on each halfcycle decreases.

The pressure drop which can be maintained to cause flow through the needle is limited, as show above. A packing material of more uniform 
porosity would provide a larger nunioer of the proper size capillaries and would thus provide a faster rate of flow through the needle.

The fourth method of sampling is the surest, although more work is required to obtain a given concentration in the column. This technique could be applied while other methods are being developed and operating conditions for the column can be selected so that at least two different techniques may be employed as a cross-check during the development of an adequate sampling technique.

The needle which was used for measuring the volume of each phase in the interstage flow stream during emulsion operation was preferentially wet by the water phase. This caused an abnormally high volume of water to enter the sampling needle and produced incorrect measurements. This error may be corrected by calibrating the needle to account for the preferential wetting. Calibration measurements could be carried out in a beaker in which known volumes of each phase have been mixed to produce a uniform emulsion.

Another way of calibrating the needle would be to take samples from a pulse column operating in the transition region between mixer-settler and emulsion type operation. As the pulse frequency is increased beyond the lower flooding point, the two phases do not settle out between pulses. If the light phase is discontimous, two phases will pass through the plates on the upstroke and one phase will pass through the plates on a downstroke of the pulse generator. As long as the pulse frequency is kept low enough that only one phase passes through the plates on a downstroke, the phase composition of the total interstage flow on the upstroke half-cycle must be equal to the interstage flow rate of the light phase 
plus the heavy phase recycle. This interstage flow stream may be sampled and the wetting correction determined by comparison of the measured phase ratio with the cal.culated flow ratio. The phase ratio may be changed by changing the pulse frequency.

Stage efficiencies and recjele

In general, the stage efficiency for that half-cycle during which the non-wetting phase passed through the plates was the higher of the two. The stage efficiencies for the other half-cycle were considerably lower. If plates were available which would disperse both phases, the performance of the column could be improved. Here, then, is some justification for the use of dual plates as described by Sege and Woodfield (15). An obvious selection for the two materials would be metal and plastic. These could be two sheets of material placed back to back and oriented so that each plate faces its wetting liquid. They could be metal plates coated on one side with a plastic film similar to the polyethylene film used in this work, or they could be metal plates with different surfaces on each side, like the polished stainless steel plates described earlier.

This problem of phase composition of the interstage flow streams during emulsion operation may possibly be solved in the future without resort to difficult sampling techniques. The phase composition can already be determined at pulse frequencies from the lower flooding point up to the point where two phases pass through the plates on both halfcycles. When the pulse column is operating at steady-state in the emulsion region a stoichiometric relationship must still exist over a complete cycle of the pulse generator. Further study of the theory of 
the pulse column may show that, at high pulse frequencies, a saturation effect occurs and the phase ratio of the two liquids which flow through the plates on each half-cycle tends to become constant and independent of the pulse frequency or that some predictable relationship exists at froquencies near the upper flooding limit.

A careful distinction must be made between the stage efficiencies defined in this work for the pulse column and the more cormon Murphree stage efficiency. A higher Murphree stage efficiency gives an indication that a greater degree of separation can be effected. However, using the two stage efficiencies defined for the pulse column, a higher stage efficiency does not in itself indicate that greater separation can be effected. The composition of the products from the pulse column is affected by both the stage efficiencies and the recycle rate. For two given pulse frequencies, the separation obtained at the lower frequency may be greater than the separation obtained at the higher frequency, even though the stage efficiencies may be higher at the higher frequency. This phenomenon may well explain the data obtained by the zuthors in this work and in previous work (3) and also by Chantry, et al. (4). In all three cases the degree of separation obtained with the methyl isobutyl ketone - acetic acid - water system decreased with increasing pulse frequency. The data reported in the literature on most other systems showed that the over-all effectiveness of the column first increased with increasing pulse frequency, went through a maximum, and then decreased as the pulse frequency was raised still higher. In particular, this latter effect was obtained by Cohen and Beyer (5) for the system isoamyl alcohol - boric acid - water. 
105

The results of the holdup studies with the isoanyl alcohol - water system and the methyl isobutyl ketone - water system showed that holdup increased quite rapidly with increasing pulse frequency. This would provide better stage efficiencies. The holdup decreased with increasing frequency for the ketone - water system then went through a minimum and increased slowly. Hence the increase in stage efficiencies with increasing pulse frequency was rapid enough to overcome the recycle effect in the isoamyl alcohol - boric acid - water runs reported by Cohen and Beyer, but the increase in stage efficiencies with increasing pulse frequency was not sufficient to overcome the recycle effect for the methyl isobutyl ketone - acetic acid - water system. 


\section{CONCLUSIONS AND RECOMMENDATIONS}

(1) By assuming the operation of a pulse column to be a stagewise process a theory was developed which explained some of the data which have been reported for the pulse column and which predicted other phenomena which had not yet been observed and reported. From this theory a design method was derived and illustrated by problems and by experimental data. This represents the first over-all theory of the pulse column which has been reported. Froln this theory a design method was proposed which utilized double operating lines and double stage lines across which stages could be stepped off as in a McCabe - Thiele diagran.

(2) For the two systerns studied and for any system in general, the hold-up per stage of the discontinuous phase is numerically equal to the interstage flow, per cycle, of the discontinuous phase at the lower flooding point, this relationship being subject to two limitations. First, the discontinuous pnase must not pass through more than one stage per cycle of the pulse generator. Second, the flow rates must not be so high that excessive dispersion causes the hold-up to increase to a point beyond the theoretical value. This relation was first predicted by the theory and then proven from experimental data.

(3) As the pulse frequency was increased above the lower flooding point, the hold-up per stage in the column was shown to decrease then increase. This decrease in hold-up was also first predicted by the theory and shown from experimental data. 
(4) A stage efficiency was defined for each half-cycle of the pulse generator. These stage efficiencies were defined independent of the effect of recycle so that the two effects could be separated. It was possible for the stage efficiencies to increase with increasing pulse frequency even though the over-all separation performed by the column decreased because of the effects of the recycle.

(5) Stage efficiencies were shown to be lower during that half-cycle in which the wetting fluid passed through the plates. The operation of the column could probably have been improved by using dual plates with each material facing the phase which preferentially wets it.

(6) Sampling techniques were devised by which interstage samples could be withdrawn from the column when it was operating in the mixersettler region. Hollow needles were forced through rubber ampule covers in the side of the column and inserted into one of the holes in a perforated plate. The time during which liquid flowod through the needle was controlled by micro-switches on the pulse generator. These micro-switches operated a specially constructed solenoid valve in the sampling line. 
NOMENCLATURE

$A=$ cross-section area of column, $\mathrm{cm}$. (with no subscript): heavy (aqueous) phase recycle per cycle, liters (with subscript)

$E=$ light (organic) phase hold-up per stage, liters.

$G=$ light (organic) phase interstage flow rate, liters/cycle.

$L=$ heavy (aqueous) phase interstage flow rate, liters/cycle.

$\mathrm{N}=$ top stage in column of unspecified number of stages.

$0=$ light (organic) phase recycle per cycle, liters.

$R=$ heavy (aqueous) phase hold-up per stage, liters.

$\mathrm{T}=$ total interstage flow during one half-cycle, liters.

$\mathrm{V}=$ total volume of recycle liquid, liters.

$a=$ pulse amplitude (displacement from one extreme position to the other), cm.

$f=$ pulse frequency, cycles/min.

$m=$ distribution coefficient (slope of the equilibrium line), no units.

$x=$ concentration of solute in light (organic) phase, gm./liter.

$y=$ concentration of solute in heavy (aqueous) phase, gm./Iiter.

$\mathcal{E}=$ stage efficiency, per cent.

$\xi=$ ratio of heavy (aqueous) phase to light (organic) phase in interstage flow strean, no units.

Subscripts:

$A=$ flow stream at top of column (extract or feed)

$B=$ bottom end-section of column

$F=$ top end-section of column

$\mathrm{R}=$ recycle

$S=$ superficial flow rate (when used with $I$ or $G$ ); solvent stream (when used with $y$ ). 
$\mathrm{N}=$ top stage in column of unspecified number of stages

$\mathrm{d}=$ downstroke

$\mathrm{n}=$ typical stage in column

$u=$ upstroke

$1,2, \ldots$ = stage numbered from bottom of column.

Superscripts:

$(')=$ prime, refers to conditions at the end of an upstroke but before the beginning of an upstroke of the pulse generator.

$(\quad)=$ no prime, refers to conditions at the end of a downstroke but before the beginning of an upstroke of the pulse generator.

$(-)=$ transient composition (see page 16).

(*) = equilibrium concentration. 


\section{LTTERATURE CITED}

1. Allerton, J. B., Strom, B. O., and Treybal, R. E. Liquid extraction in perforated-plate and packed towers. Transactions of the American Institute of Chemical Engineers 39:361-382. 1943.

2. Belaga, M. W. and Bigelow, J. E. Effect of pulse column operating variables on H.T.U. U. S. Atomic Energy Commission Report KT-133 (Massachusetts Institute of Technology, Engineering Practice School, Oak Ridge, Tenn.). (Washington 25, D. C., Office of Technical Services, Department of Commerce). Jan. $11,1952$.

3. Burkhart, L. E. and Fahien, R. W. Extraction efficiency of a pulse column of varied geometry. U. S. Atomic Energy Commission Report ISC-860 (Iowa State College, Ames, Iowa). (Washington 25. D. C., Office of Technical Services, Department of Commerce). June 1956.

4. Chantry, W. A., Von Berg, R. I., and Wiegandt, H. F. Application of pulsation to liquid-liquid extraction. Industrial and Engineering Chemistry 47: 1753-1159. 1955.

5. Cohen, R. M. and Beyer, G. H. Performance of a pulse extraction column. Chemical Engineering Progress 49: 279-286. 1953.

6. Edwards, R. B. and Beyer, G. H. Flooding characteristics of a pulse column. A. I. Ch. E. Journal (American Institute of Chemical Engineers) 2: 148-152. 1956.

7. Eugenio, M. R. The effect of pulsation on liquid-liquid masstransfer resistances. U. S. Atomic Energy Commission Report ANL-5874 (Argonne National Laboratory). (Washington 25, D. C., Office of Technical Services, Department of Commerce). July 1958.

8. Feick, G. and Anderson, H. M. Performance of a packed liquid-liquld extraction column under controlled agitation. Industrial and Engineering Chemistry 44: 404-409. 1952.

9. Coundry, P. C. and Romero, Y. M. Effect of agitation on liquidIiquid extraction in a packed column. Umpublished Senior Project Report (typewritten). Ithaca, New York. Cornell University, Department of Chemical Engineering. Feb. 1950.

10. Griffith, W. L., Jasny, G. R., and Tupper, H. J. The extraction of cobalt from nickel in a pulse column. U. S. Atomic Energy Commission Report AECD-31440 (Technical Information Service, Oak Ridge, Tenn.). (Washington 25, D. C., Office of Technical Services, Department of Commerce). Aug. 22, 1952. 
11. Karr, A. E. and Scheibel, E. G. Mass transfer between immiscible liquids in continuous flow in an agitated chamber. In Antwerpen, F. J., ed. Chemical Engineering Progress Symposium Series, 50, No. 10: 73-92. 1950.

12. Li, W. H. and Newton, W. M. Liquid-liquid extraction in a pulsed perforated-plate column. A. I. Ch. E. Joumal (American Institute of Chemical Engineers) 3: 56-62. 1957.

13. Pike, F. P., Plank, C. A., and Arnold, D. S. The performance of contactors for liquid-liquid extraction. Raleigh, N. C., North Carolina State College, Department of Engineering Research. March 1952.

14. Row, S, B., Koffolt, J. H., and Withrow, J. R. Characteristics and performance of a nine-Inch liquid-liquid extraction column. Transactions of the American Institute of Chemical Engineers 37: 559-594. 1941.

15. Sege, G. and Woodfield, F. W. Pulse column variables. Chemical Engineering Progress 50: 396-402. 1954.

16. Thornton, J. D. Pulsed plate liquid-liquid extraction columns. British Chemical Engineering 3: 247-251. 1958.

17. Treybal, R. E. Liquid-liquid extraction. New York. McGraw-Hill Book Co., Ine. 1951.

18. and Dumoulin, F. E. Iiquid-liquid extraction in a perforated-plate tower. Industrial and Engineering Chemistry 34: 709-713. 1942.

19. Van Dijck, W. J. D. Extraction apparatus. U. S. Patent No. $2,011,186$.

20. Weigandt, H. F. and Von Berg, R. L. Key to better extraction. Chemical Engineering 61, No. 7: 183-188. 1954. 


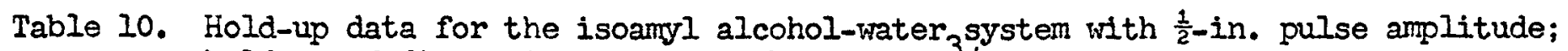
hold-up of discontinuous water phase in $\mathrm{cm}^{3} / \mathrm{stage}$

Water flow rate $=1$ liter/min.

\begin{tabular}{|c|c|c|c|c|c|c|c|c|c|c|c|}
\hline $\begin{array}{l}\text { Pulse } \\
\text { frequency } \\
\text { (cpm) }\end{array}$ & 23.90 & 29.90 & 30.50 & 35.63 & 37.50 & 37.50 & 39.89 & 49.96 & 50.29 & 50.38 & 79.79 \\
\hline \multicolumn{12}{|l|}{$\begin{array}{l}\text { Stage } \\
\text { number }\end{array}$} \\
\hline $\begin{array}{r}1 \\
2 \\
3 \\
4 \\
5 \\
6 \\
7 \\
8 \\
9 \\
10 \\
11 \\
12 \\
13 \\
14\end{array}$ & $\begin{array}{l}50.7 \\
48.6 \\
45.8 \\
52.6 \\
47.8 \\
57.9 \\
62.7 \\
85.3 \\
89.8 \\
85.6 \\
80.9 \\
87.5 \\
75.3 \\
64.7\end{array}$ & $\begin{array}{l}43.1 \\
38.8 \\
39.6 \\
41.2 \\
41.5 \\
45.5 \\
48.3 \\
48.9 \\
53.5 \\
59.4 \\
67.6 \\
74.8 \\
79.4 \\
70.4\end{array}$ & $\begin{array}{l}34.5 \\
37.4 \\
44.2 \\
46.1 \\
45.4 \\
49.7 \\
53.0 \\
55.7 \\
59.2 \\
67.3 \\
68.3 \\
67.1 \\
64.3 \\
30.1\end{array}$ & $\begin{array}{c}34.0 \\
34.3 \\
36.4 \\
39.8 \\
39.8 \\
44.8 \\
48.1 \\
50.3 \\
56.0 \\
59.2 \\
71.5 \\
82.5 \\
88.4 \\
-\end{array}$ & $\begin{array}{r}28.9 \\
39.5 \\
107.6 \\
125.0 \\
141.5 \\
143.0 \\
139.3 \\
133.0 \\
124.9 \\
115.6 \\
108.5 \\
104.5 \\
96.9 \\
90.4\end{array}$ & $\begin{array}{r}28.0 \\
44.6 \\
121.6 \\
130.7 \\
145.1 \\
144.6 \\
141.6 \\
133.0 \\
126.1 \\
116.4 \\
107.5 \\
101.7 \\
96.3 \\
85.5\end{array}$ & $\begin{array}{l}36.0 \\
37.8 \\
39.5 \\
44.0 \\
43.1 \\
48.3 \\
52.4 \\
57.0 \\
64.7 \\
82.1 \\
93.2 \\
92.7 \\
90.6 \\
83.7\end{array}$ & $\begin{array}{r}40.0 \\
43.3 \\
51.9 \\
57.5 \\
106.0 \\
170.4 \\
193.5 \\
195.8 \\
195.1 \\
188.1 \\
173.2 \\
157.5 \\
142.7 \\
127.9\end{array}$ & $\begin{array}{r}42.2 \\
43.8 \\
63.4 \\
137.4 \\
186.4 \\
196.3 \\
197.2 \\
185.4 \\
174.0 \\
157.0 \\
138.4 \\
119.6 \\
104.3 \\
85.3\end{array}$ & $\begin{array}{r}40.8 \\
45.2 \\
54.2 \\
70.1 \\
150.0 \\
183.3 \\
194.9 \\
192.0 \\
182.5 \\
167.7 \\
150.9 \\
132.6 \\
116.1 \\
92.6\end{array}$ & $\begin{array}{r}36.6 \\
119.3 \\
166.0 \\
189.7 \\
199.0 \\
203.0 \\
206.8 \\
200.3 \\
194.1 \\
183.1 \\
166.0 \\
146.3 \\
124.2 \\
100.4\end{array}$ \\
\hline Total & 936 & 753 & 723 & 769 & 1499 & 1523 & 866 & 1843 & 1831 & 1773 & 2135 \\
\hline
\end{tabular}


Table 10. (Continued)

\begin{tabular}{|c|c|c|c|c|c|c|c|c|}
\hline $\begin{array}{c}\text { Pulse } \\
\text { frequency } \\
\text { (cpm) }\end{array}$ & 44.71 & 44.71 & 44.94 & 49.42 & 50.93 & 63.83 & 72.12 & 82.76 \\
\hline \multicolumn{9}{|l|}{$\begin{array}{l}\text { Stage } \\
\text { number }\end{array}$} \\
\hline $\begin{array}{l}1 \\
2 \\
3 \\
4 \\
5 \\
6 \\
7 \\
8 \\
9 \\
10 \\
11 \\
12 \\
13 \\
14\end{array}$ & $\begin{array}{l}190.1 \\
200.0 \\
198.5 \\
200.6 \\
200.9 \\
199.0 \\
193.7 \\
180.0 \\
167.1 \\
153.0 \\
137.0 \\
124.6 \\
115.0 \\
107.0\end{array}$ & $\begin{array}{l}193.0 \\
201.0 \\
193.5 \\
194.7 \\
198.0 \\
192.1 \\
186.6 \\
171.5 \\
157.8 \\
141.9 \\
125.8 \\
110.6 \\
99.4 \\
85.7\end{array}$ & $\begin{array}{r}210.0 \\
210.0 \\
195.1 \\
193.6 \\
195.4 \\
191.8 \\
184.9 \\
170.5 \\
157.3 \\
143.1 \\
129.5 \\
116.5 \\
107.4 \\
97.2\end{array}$ & $\begin{array}{r}197.6 \\
203.4 \\
205.2 \\
203.8 \\
203.4 \\
200.5 \\
196.5 \\
181.4 \\
168.6 \\
151.6 \\
133.5 \\
117.2 \\
100.1 \\
85.0\end{array}$ & $\begin{array}{l}195.5 \\
199.2 \\
185.4 \\
184.8 \\
190.6 \\
187.5 \\
182.6 \\
173.0 \\
162.3 \\
150.0 \\
136.8 \\
125.5 \\
119.1 \\
110.8\end{array}$ & $\begin{array}{l}190.7 \\
200.8 \\
200.5 \\
200.3 \\
199.4 \\
199.3 \\
193.2 \\
187.7 \\
179.1 \\
164.9 \\
151.4 \\
133.8 \\
119.7 \\
110.0\end{array}$ & $\begin{array}{l}189.1 \\
200.9 \\
198.2 \\
200.4 \\
201.6 \\
197.8 \\
197.3 \\
189.3 \\
185.9 \\
174.6 \\
158.3 \\
142.0 \\
127.4 \\
112.1\end{array}$ & $\begin{array}{r}188.9 \\
195.4 \\
195.4 \\
200.1 \\
199.4 \\
197.6 \\
199.0 \\
190.8 \\
185.0 \\
174.5 \\
155.5 \\
140.2 \\
120.1 \\
87.4\end{array}$ \\
\hline Total & 2366 & 2251 & 2305 & 2348 & 2303 & 2431 & 2263 & 2429 \\
\hline
\end{tabular}


Table 17. Hold-up data for the isoamyl alcohol - watȩr system with $\frac{1}{2}$-in. pulse amplitude; hold-up of discontinuous water phase in $\mathrm{cm}^{3} /$ stage.

Water flow rate $=0.66$ liter $/$ min .

\begin{tabular}{ccccccccc}
\hline $\begin{array}{c}\text { Pulse } \\
\text { frequency } \\
(\mathrm{cpm})\end{array}$ & 35.05 & 44.81 & 55.60 & 59.70 & 65.76 & 70.26 & 83.16 & 90.43 \\
\hline $\begin{array}{c}\text { Stage } \\
\text { number }\end{array}$ & & & & & & & & \\
1 & 27.0 & 25.0 & 30.4 & 26.1 & 183.7 & 25.0 & 198.2 & 207.0 \\
2 & 27.7 & 27.9 & 31.0 & 28.4 & 168.8 & 29.4 & 197.0 & 210.9 \\
3 & 26.6 & 32.2 & 32.9 & 35.9 & 158.0 & 37.0 & 162.1 & 203.2 \\
4 & 32.4 & 37.6 & 38.7 & 38.7 & 144.6 & 43.3 & 194.0 & 203.7 \\
5 & 28.8 & 34.7 & 39.3 & 40.9 & 142.1 & 46.2 & 186.1 & 202.8 \\
6 & 32.9 & 41.2 & 45.8 & 47.9 & 132.9 & 55.5 & 173.4 & 202.8 \\
7 & 32.9 & 43.8 & 50.7 & 54.1 & 122.0 & 64.8 & 159.3 & 194.9 \\
8 & 33.8 & 45.8 & 53.6 & 57.8 & 110.0 & 70.8 & 143.8 & 179.4 \\
9 & 35.2 & 50.1 & 59.5 & 62.6 & 102.6 & 75.2 & 131.4 & 166.2 \\
10 & 37.1 & 52.2 & 62.0 & 64.9 & 94.6 & 75.3 & 115.9 & 144.2 \\
11 & 37.4 & 53.0 & 61.3 & 63.0 & 86.7 & 71.9 & 106.0 & 125.2 \\
12 & 37.7 & 54.3 & 62.0 & 63.4 & 81.2 & 71.1 & 96.9 & 106.8 \\
13 & 38.2 & 52.3 & 61.2 & 61.4 & 74.7 & 66.4 & 91.9 & 91.0 \\
14 & 38.2 & 51.1 & 57.8 & 58.0 & 66.2 & 60.1 & 89.5 & 73.6 \\
& & & & & & & & \\
Total & 466 & 601 & 686 & 703 & 1668 & 792 & 2046 & 2105 \\
& & & & & & & & \\
\hline
\end{tabular}


Table 12. Hold-up data for the methrl isobutyl ketong - water system with $\frac{1}{2}$-in. pulse amplitude; hold-up of discontinuous water phase in cm/stage

Water flow $=1$ liter/min.

\begin{tabular}{|c|c|c|c|c|c|c|c|c|c|c|c|}
\hline $\begin{array}{l}\text { Pulse } \\
\text { frequency } \\
\text { (cpm) }\end{array}$ & 24.98 & 24.98 & 29.73 & 29.73 & 29.97 & 29.97 & 49.83 & 50.00 & 70.30 & 89.55 & 90.57 \\
\hline \multicolumn{12}{|l|}{$\begin{array}{l}\text { Stage } \\
\text { number }\end{array}$} \\
\hline $\begin{array}{l}1 \\
2 \\
3 \\
4 \\
5 \\
6 \\
7 \\
8 \\
9 \\
10 \\
11 \\
12 \\
13 \\
14\end{array}$ & $\begin{array}{l}45.18 \\
42.45 \\
40.61 \\
46.07 \\
44.80 \\
45.45 \\
43.43 \\
49.03 \\
45.84 \\
47.80 \\
44.94 \\
49.23 \\
45.92\end{array}$ & $\begin{array}{l}- \\
43.05 \\
45.32 \\
45.17 \\
45.03 \\
43.90 \\
47.91 \\
44.19 \\
49.33 \\
44.52 \\
45.91 \\
46.68 \\
45.31 \\
45.72\end{array}$ & $\begin{array}{c}- \\
34.02 \\
42.09 \\
33.71 \\
36.85 \\
35.16 \\
41.52 \\
38.09 \\
37.85 \\
35.89 \\
35.47 \\
38.77 \\
34.62 \\
40.49\end{array}$ & $\begin{array}{c}- \\
32.53 \\
42.60 \\
39.64 \\
36.87 \\
40.63 \\
40.53 \\
38.76 \\
39.08 \\
40.06 \\
34.28 \\
42.79 \\
36.86 \\
39.32\end{array}$ & $\begin{array}{l}- \\
40.62 \\
34.65 \\
38.45 \\
36.42 \\
37.14 \\
40.83 \\
33.84 \\
38.93 \\
40.83 \\
34.41 \\
38.98 \\
40.32 \\
36.68\end{array}$ & $\begin{array}{c}- \\
42.74 \\
33.90 \\
37.63 \\
38.08 \\
37.35 \\
38.74 \\
36.92 \\
34.36 \\
41.18 \\
37.18 \\
35.22 \\
39.82 \\
39.20\end{array}$ & $\begin{array}{l}22.00 \\
19.47 \\
26.66 \\
24.47 \\
25.83 \\
27.23 \\
24.64 \\
26.04 \\
28.85 \\
26.65 \\
25.85 \\
26.59 \\
29.21 \\
30.74\end{array}$ & $\begin{array}{l}27.12 \\
19.92 \\
24.50 \\
23.57 \\
25.37 \\
27.14 \\
26.57 \\
27.02 \\
25.86 \\
25.81 \\
28.33 \\
28.44 \\
30.24\end{array}$ & $\begin{array}{c}- \\
22.17 \\
18.58 \\
23.38 \\
23.17 \\
22.78 \\
26.81 \\
26.78 \\
29.43 \\
29.55 \\
29.52 \\
30.33 \\
32.52 \\
27.61\end{array}$ & $\begin{array}{l}19.77 \\
20.87 \\
20.82 \\
28.07 \\
23.90 \\
28.51 \\
31.28 \\
33.00 \\
33.71 \\
34.444 \\
33.27 \\
34.56 \\
35.30 \\
35.74\end{array}$ & $\begin{array}{l}- \\
24.64 \\
19.41 \\
27.75 \\
25.20 \\
30.88 \\
31.96 \\
31.30 \\
34.98 \\
35.19 \\
36.26 \\
37.71 \\
37.13 \\
38.87\end{array}$ \\
\hline
\end{tabular}


Table 13. Hold-up data for the methyl isobutyl ketone - acetic acid - water system; hold-up of discontinuous water phase in $\mathrm{cm}^{3} /$ stage

\begin{tabular}{|c|c|c|c|}
\hline $\begin{array}{c}\text { Pulse } \\
\text { frequency } \\
\text { (cpm) }\end{array}$ & 24.88 & 30.00 & 49.88 \\
\hline \multicolumn{4}{|l|}{$\begin{array}{l}\text { Stage } \\
\text { mumber }\end{array}$} \\
\hline 1 & 37.88 & 31.49 & 20.36 \\
\hline 2 & 37.41 & 29.54 & 19.50 \\
\hline 3 & 37.87 & 31.27 & 22.73 \\
\hline 4 & 38.89 & 25.91 & 24.39 \\
\hline 5 & 40.01 & 27.97 & 18.29 \\
\hline 6 & 40.47 & 33.56 & 23.18 \\
\hline 7 & 40.27 & 29.19 & 23.08 \\
\hline 8 & 42.25 & 28.38 & 22.99 \\
\hline 9 & 42.71 & 24.69 & 22.30 \\
\hline 10 & 40.01 & 35.45 & 23.46 \\
\hline 11 & 44.13 & 35.72 & 24.42 \\
\hline 12 & 42.34 & 31.84 & 21.87 \\
\hline 13 & 40.86 & 32.86 & 22.86 \\
\hline 14 & 43.31 & 34.26 & 23.26 \\
\hline
\end{tabular}


Table 14. Experimental data from extraction runs with the methyl isobutyl ketone - acetic acid water system with water phase dispersed; concentration in gm./liter

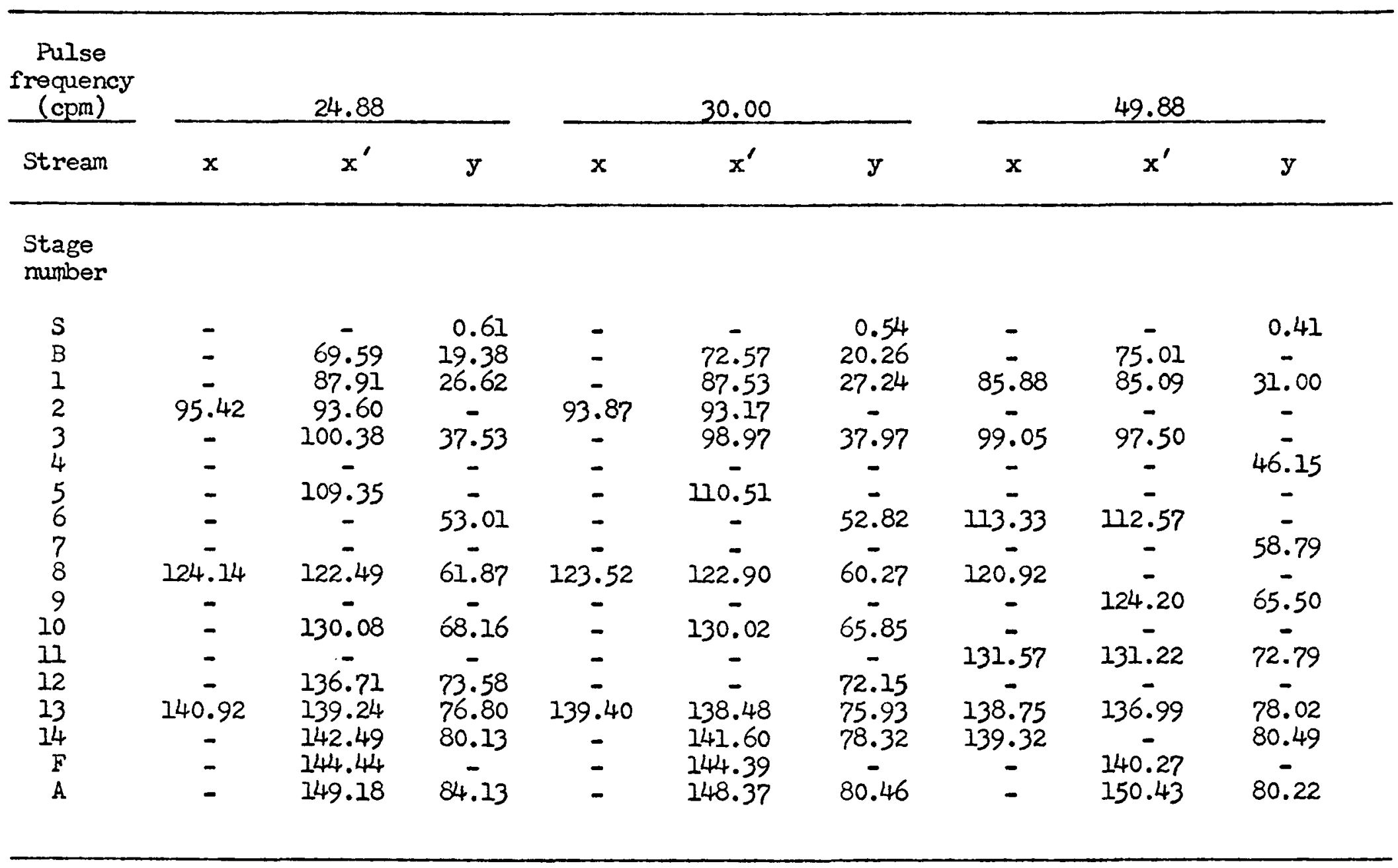


Table 15. Experimental data from extraction mun using the methyl isobutyl ketone - acetic acid - water system with organic phase dispersed; concentrations in

\begin{tabular}{|c|c|c|c|}
\hline Stream & $x$ & $y$ & $y^{\prime}$ \\
\hline \multicolumn{4}{|l|}{$\begin{array}{l}\text { Stage } \\
\text { number }\end{array}$} \\
\hline$S$ & - & 0.50 & - \\
\hline$B$ & 15.34 & 5.76 & - \\
\hline 1 & 24.08 & - & 8.34 \\
\hline 2 & - & 11.78 & - \\
\hline 3 & 36.20 & - & - \\
\hline 4 & - & $17 \cdot 31$ & - \\
\hline 5 & 49.05 & - & - \\
\hline 6 & - & - & - \\
\hline 7 & 62.20 & 27.54 & 25.03 \\
\hline 8 & - & - & - \\
\hline 9 & 74.92 & 33.68 & - \\
\hline 10 & - & 37.82 & 25.72 \\
\hline 17 & 90.43 & - & - \\
\hline 12 & - & 48.07 & 47.75 \\
\hline 13 & 107.02 & - & - \\
\hline 14 & - & 62.41 & - \\
\hline$F$ & 126.12 & - & - \\
\hline A & 136.42 & 66.22 & - \\
\hline
\end{tabular}

